MARCELA DE MELO ANICÉZIO

\title{
Atenuação de Vibrações em Pás de Helicópteros utilizando Circuito Piezelétrico Semi-Passivo
}





\section{Atenuação de Vibrações em Pás de Helicópteros utilizando Circuito Piezelétrico Semi-Passivo}

Dissertação apresentada à Escola de Engenharia de São Carlos, Universidade de São Paulo, para obtenção do título de Mestre em Ciências.

Programa: Engenharia Mecânica Área de concentração: Aeronaves

Orientador: Prof. Dr. Carlos De Marqui Junior

$$
\begin{gathered}
\text { ESTE EXEMPLAR TRATA-SE DA } \\
\text { VERSÃO CORRIGIDA. } \\
\text { A VERSÄO ORIGINAL. ENCONTRA-SE } \\
\text { DISPONIVEL JUNTO AO } \\
\text { DEPARTAMENTO DE ENGENHARIA } \\
\text { MECÂNICA DA EESC-USP. }
\end{gathered}
$$

São Carlos-SP 
AUTORIZO A REPRODUÇÃO TOTAL OU PARCIAL DESTE TRABALHO, POR QUALQUER MEIO CONVENCIONAL OU ELETRÔNICO, PARA FINS DE ESTUDO E PESQUISA, DESDE QUE CITADA A FONTE.

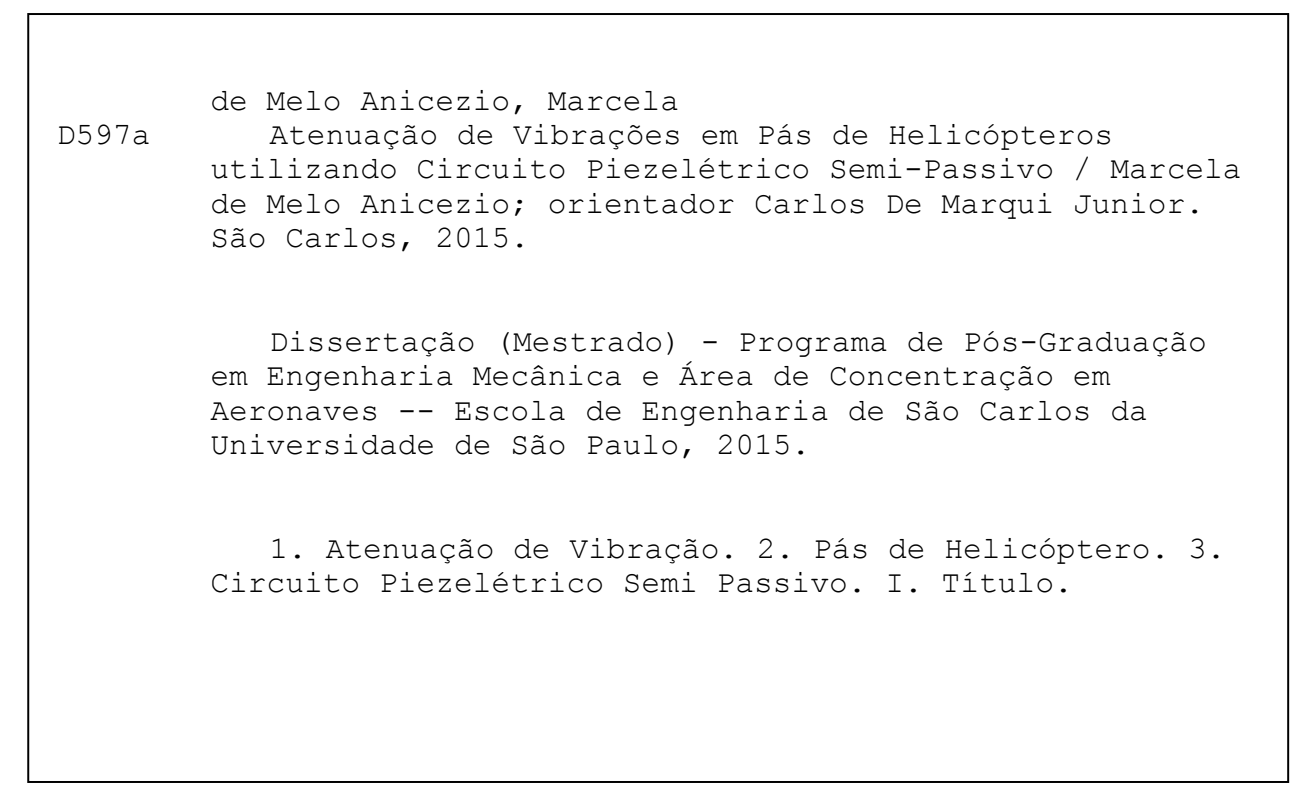




\section{FOLHA DE JULGAMENTO}

Candidata: Engenheira MARCELA DE MELO ANICÉZIO.

Título da dissertação: "Atenuação de vibrações em pás de helicópteros utilizando circuitos piezelétrico semi-passivo ".

Data da defesa: 02/03/2015

Comissão Julgadora:

Resultado:

Prof. Dr. Carlos De Marqui Junior

(Orientador)

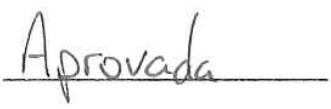

(Escola de Engenharia de São Carlos/EESC)

Prof. Dr. Rui Marcos Grombone de Vasconcellos

(Universidade Estadual Paulista "Júlio de Mesquita Filho"/UNESP - São João da Boa Vista)

Prof. Dr. Ricardo Afonso Angélico

APROUADO

(Instituto Federal de São Paulo/IFSP - Campus São Carlos)

Coordenador do Programa de Pós-Graduação em Engenheira Mecânica:

Prof. Associado Marcelo Areias Trindade

Presidente da Comissão de Pós-Graduação:

Prof. Associado Paulo César Lima Segantine 


\section{Agradecimentos}

$\mathrm{O}$

período que compreendeu o meu mestrado foi a época em que mais aprendi sobre

o verdadeiro valor das pessoas e o quanto essa relação interpessoal interfere na produtividade e nos resultados finais do trabalho. Por isso, tenho que agradecer e muito a várias pessoas que me ajudaram durante esse período.

Agradeço primeiramente ao meu orientador, Carlos De Marqui Jr., pela paciência, bom humor e sabedoria em me orientar, sempre a disposição para me mostrar o melhor caminho a seguir na pesquisa. Muito obrigada pelas reuniões, discussões, conselhos e pelo apoio e compreensão nos momentos mais difíceis desta caminhada. Sem o senhor, certamente esse trabalho não seria concluído.

Agradeço a Fundação de Amparo e Pesquisa do Estado de São Paulo (FAPESP) pela concessão da bolsa de mestrado e pelo apoio financeiro para a pesquisa desenvolvida.

Agradeço ao Conselho Nacional de Desenvolvimento Científico e Tecnológico (CNPq) pela concessão da bolsa de mestrado durante os primeiros meses dessa caminhada.

Agradeço ao Departamento de Engenharia Aeronáutica por ser minha segunda casa. O apoio durante esse período foi essencial para o desenvolvimento da pesquisa, não somente pelo espaço físico, mas também pelas amizades feitas e consolidadas. Gi, Tiltis (Mazé), Claudinho e João, muito obrigada por sempre se preocuparem comigo, pelas caronas infinitas e por todas as conversas durante os nossos lanches. Vocês tornaram os meus dias bem mais divertidos $=)$. Professores Catalano e Belo, muito obrigada pelo apoio em continuar com a pesquisa e, principalmente, no ramo aeronáutico. Professor Flávio, obrigada pelo apoio e pelos conselhos durante a qualificação, eles foram essenciais para o término desse trabalho. Professor Volnei, obrigada por ter se disponibilizado para me aplicar a prova de admissão ao Mestrado do Programa de Pós Graduação da Engenharia Mecânica durante a minha estadia na França, sem a tua ajuda, eu não estaria concluindo mais essa etapa. João Paulo, obrigada pela ajuda com a parte técnica computacional, facilitou e muito o meu trabalho.

Agradeço aos "meninos"da pós graduação pelas conversas, piadas, risadas e compa- 
nhias durante os nossos almoços. Em especial, Douglas, Marcel, Cid, Homer, Vagner, Paganni e Wander, obrigada pelas discussões e ajudas, tanto na parte técnica quanto na experimental. Vocês foram também essenciais para a finalização desse trabalho.

Agradeço às meninas da secretaria da pós graduação, Ana Paula e Iara, pela ajuda com a parte burocrática. Vocês sempre facilitam nossas vidas.

Agradeço a minha família. Mãe, muito obrigada por ter me apoiado e me ensinado a sonhar e lutar pelo o que eu acredito. Pai, muito obrigada por ter me inspirado na escolha da minha carreira e ter me apoiado sempre nas minhas decisões. Agradeço a meus irmãos, Gustavo e Rafael, pela paciência durante esses anos. Agradeço a meu namorado, Gustavo Pessin, pela paciência durante todo esse tempo e pelo apoio em continuar firme e forte nessa caminhada. Agradeço a minha família de coração, Iara, Walter e Cinthia, pelo apoio e carinho durante todo esse tempo. Desculpem-me pela ausência.

Agradeço a todos os meus amigos pela compreensão e apoio, em especial, Lianna e Bárbara. Obrigada pelas conversas e por tornarem minhas semanas menos massacrantes e mais interessantes.

E por último, não menos importante, agradeço imensamente a Deus, por ter me guiado pelo caminho certo. Tenho certeza que não foram os caminhos mais fáceis, mas tenho certeza que foram os que me trariam maior aprendizado. Obrigada meu Deus por ter me mostrado as situações que errei e por ter me aberto os olhos e o coração quanto ao verdadeiro valor das pessoas. 
Um barco navega para o leste e outro para o oeste, levados pelo mesmo vento. É a posição das velas e não a ventania que determina o caminho que eles seguem. Como os ventos no mar, assim é o destino; à medida que navegamos ao longo da vida, é a posição da alma que decide seu rumo, não a calmaria ou o conflito.

Ella Wheeler Wilcox 


\section{Resumo}

ANICEZIO, M. M. Atenuação de Vibrações em Pás de Helicópteros utilizando Circuito Piezelétrico Semi-Passivo. 2014. 57f. Dissertação (Mestrado) - Escola de Engenharia de São Carlos, Universidade de São Paulo, São Carlos-SP, Brasil, 2015.

O uso de materiais inteligentes em problemas de controle de vibração tem sido investigado em diversas pesquisas ao longo dos últimos anos. Apesar de que diferentes materiais inteligentes estão disponíveis, o piezelétrico tem recebido grande atenção devido à facilidade de uso como sensores, atuadores, ou ambos simultaneamente. As principais técnicas de controle usando materiais piezoelétricos são os ativos e passivos. Circuitos piezelétricos passivos são ajustados para uma frequência específica e, portanto, a largura de banda efetiva é pequena. Embora os sistemas ativos possam apresentar um bom desempenho no controle de vibração, a quantidade de energia externa e hardware adicionado são questões importantes. As técnicas SSD (Synchronized Switch Damping) foram desenvolvidas como uma alternativa aos controladores passivos e controladores ativos de vibração. Elas podem ser técnicas semi-ativas ou semi-passivas que introduzem um tratamento não linear na tensão elétrica proveniente do material piezelétrico e induz um aumento na conversão de energia mecânica para energia elétrica e, consequentemente, um aumento no efeito de amortecimento. Neste trabalho, o controle piezoelétrico semi-passivo de uma pá piezelétrica engastada é apresentado e comparado com outros controladores. O modelo não linear electromecânico de uma pá com piezocerâmicas incorporados é determinado com base no método variacional-assintótico (VAM). O sistema rotativo acoplado não linear é resolvido no domínio do tempo, utilizando um método de integração alfa-generalizado a fim de garantir a estabilidade numérica. As simulações são realizadas para uma vasta gama de velocidades de rotação. Em primeiro lugar, um conjunto de resistências (variando desde a condição de curto-circuito para a condição de circuito aberto) é considerada. O efeito da resistência ótima (que resulta em máximo amortecimento) sobre o comportamento do sistema é investigado para o aumento da velocidade de rotação. Mais tarde, a técnica SSDS é utilizada para amortecer as oscilações da pá com o aumento da velocidade de rotação. Os resultados mostram que a técnica SSDS pode ser um método útil para o controle de vibrações de vigas rotativas não lineares, tais como pás de helicóptero.

Palavras-chave: Atenuação de vibração. Pás de Helicóptero. Circuito Piezelétrico SemiPassivo. 


\section{Abstract}

ANICEZIO, M. M. Vibration Attenuation in Helicopter Blades using SemiPassive Piezoelectric Circuit. 2014. 57f. Dissertation (Marter's Degree) - Sao Carlos School of Engineering, University of Sao Paulo, Sao Carlos-SP, Brazil, 2015.

The use of smart materials in vibration control problems has been investigated in several researches over the last years. Although different smart materials are available, the piezoelectric one has received great attention due to ease of use as sensors, actuators, or both. The main control techniques using piezoelectric materials are the active and passive ones. Passive piezoelectric networks are adjusted for specific target frequencies and, therefore, the effective bandwidth of such systems is small. Although active systems can achieve good vibration control performance, the amount of external power and added hardware are important issues. The synchronized switch damping (SSD) technique was developed in order to address the issues of passive damping methodologies as well as the issues of active control systems. The SSD can be classified as semi-passive technique or semi-active technique that introduce the nonlinear treatment of the piezoelectric element voltage output and induce an increase in mechanical to electrical energy conversion and, consequently, the shunt damping effect. In this work, the semi-passive piezoelectric control of a rotating cantilever beam response is presented and compared with other controllers. The nonlinear electromechanical model of a rotating beam with embedded piezoceramics is derived based on the variational-asymptotic method (VAM). The coupled non-linear rotary system is solved in the time-domain by using a generalized-alpha integration method in order to guarantee numerical stability. The simulations are performed for a wide range of rotating speeds. First, a set of load resistances (ranging from short circuit condition to open circuit condition) is considered. The effect of optimum load resistance (for maximum damping) on the elastic behavior of the beam is investigated for increasing rotating speed. Later, the synchronized switch damping on short (SSDS) technique is employed to damp the nonlinear oscillations of the rotating beam with increasing rotating speed. Results show that the SSDS technique can be a useful method of control for nonlinear rotating beams such as helicopter blades.

Keywords: Attenuation of vibration. Helicopter blades. Semi-Passive Piezoelectric Circuit. 


$$
\text { . }
$$




\section{Lista de Figuras}

Figura - 1 Frequência de ressonância do tronco de uma pessoal e frequência transferida do rotor para fuselagem.

Figura - 2 Relação entre: a) tensão mecânica e deformação; b) tensão e deslocamento elétrico; c) campo elétrico aplicado e deslocamento elétrico; e d) deformação e campo elétrico. (Leo (2007)). .................. 30

Figura - 3 Cubo de piezoelétrico indicando as coordenadas axiais da análise tri-

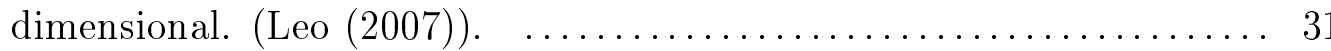

Figura - 4 Relação entre tensão mecânica e deformação de um material elástico em função da condição de contorno elétrica. (Leo (2007)).

Figura -5 Diferentes técnicas de controle passivo: a) resistivo puro; b) indutivo puro; c) resistivo-indutivo em série; d) resistivo-indutivo em paralelo; e e) resistivo-capacitivo em série. Modificado de D'Assunção (2013). . . 33

Figura -6 Principais tipos de controladores semipassivos: a) SS; b) SSDS; e c) SSDI. (D’Assunção (2013)). ......................... 36

Figura - 7 Comparação das tensões elétricas: a) circuito aberto; b) SSDS; e c) SSDI. (Richard et al. (2000)). ...................... 37

Figura $-8 \quad$ a) circuito básico BSDS; e b) Formas das ondas do controlador BSDS. (Lallart et al. (2009)). .................................... 38

Figura - 9 Circuito elétrico SSDV. (Lefeuvre et al. (2006)). .............. 39

Figura - 10 Resumo de técnicas de controle ativo em helicópteros. (Patt et al.

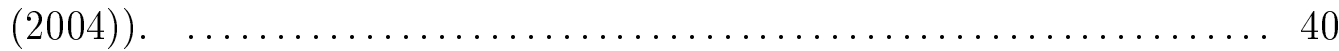

Figura - 11 Representação do princípio da smart spring. (Fred Nitzsche). ..... 41

Figura - 12 Atenuação da frequência 2/rev usando o APL. (Fred Nitzsche). .... 42 
Figura - 13 Associação de um controlador do tipo ACT, outro ACF e um APL representando o controle híbrido. (Fred Nitzsche). ............ 42

Figura - 14 Sistemas de referência de uma viga rotativa (Cheng (2002)). ...... 44

Figura - 15 Fluxograma do processo de solução para a análise estrutural da pá

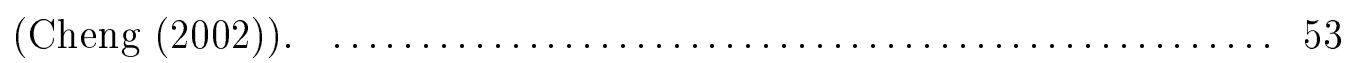

Figura - $16 \quad$ Fluxograma do método de solução Newton-Raphson (Cheng (2002)). 54

Figura -17 Modelo da pá piezelétrica. $\ldots \ldots \ldots \ldots \ldots \ldots \ldots \ldots \ldots \ldots \ldots \ldots \ldots \ldots \ldots \ldots \ldots \ldots \ldots \ldots$

Figura - 18 Comparação entre: a) deslocamento da ponta da viga do modelo numérico; b) deslocamento da ponta da viga apresentada por Cheng; c) ângulo da ponta da viga do modelo numérico; d) ângulo da ponta da viga apresentada por Cheng; e e)tensão elétrica do modelo numérico. (Cheng (2002)).

Figura - 19 FRF (deslocamento da ponta / Força de excitação) de uma pá piezelétrica engastada na condição de circuito aberto $\left(R=10^{6} \Omega\right)$. ..... 58

Figura - 20 FRF (deslocamento da ponta / Força de excitação) de uma pá piezelétrica engastada na condição de circuito aberto $\left(R=10^{6} \Omega\right)$ em 0 rpm.

Figura - 21 FRF (deslocamento da ponta / Força de excitação) de uma pá piezelétrica engastada na condição de circuito aberto $\left(R=10^{6} \Omega\right)$ em 200 rpm.

Figura - 22 FRF (deslocamento da ponta / Força de excitação) de uma pá piezelétrica engastada na condição de circuito aberto $\left(R=10^{6} \Omega\right)$ em 400 rpm.

Figura - 23 Tensão elétrica de uma pá piezelétrica engastada em 0 rpm - controlador SSDS.

Figura - 24 Representação da pá piezelétrica e do circuito chaveador.

Figura - 25 Deslocamento da ponta da pá piezelétrica em 0 rpm - controlador SSDS. 
Figura - 26 Ângulos na ponta da pá piezelétrica em 0 rpm - controlador SSDS $\quad . \quad 62$

Figura - 27 Tensão elétrica de uma pá piezelétrica em 200 rpm - controlador SSDS. 63

Figura - 28 Deslocamento da ponta da pá piezelétrica em 200 rpm - controlador SSDS.

Figura - 29 Ângulos na ponta da pá piezelétrica em 200 rpm - controlador SSDS. 63

Figura - 30 Tensão elétrica de uma pá piezelétrica em 400 rpm - controlador SSDS. 64

Figura - 31 Deslocamento da ponta da pá piezelétrica em 400 rpm - controlador SSDS.

Figura - 32 Ângulos na ponta da pá piezelétrica em 400 rpm - controlador SSDS. 65

Figura - 33 Tensão elétrica de uma pá piezelétrica em 0 rpm - controlador BSDS. 65

Figura - 34 Deslocamento da ponta da pá piezelétrica em 0 rpm - controlador BSDS.

Figura - 35 Ângulos na ponta da pá piezelétrica em 0 rpm - controlador BSDS. . 66

Figura - 36 Tensão elétrica de uma pá piezelétrica em 200 rpm - controlador BSDS. 66

Figura - 37 Deslocamento da ponta da pá piezelétrica em 200 rpm - controlador BSDS.

Figura - 38 Ângulos na ponta da pá piezelétrica em 200 rpm - controlador BSDS. 67

Figura - 39 Tensão elétrica de uma pá piezelétrica em 400 rpm - controlador BSDS. 67

Figura - 40 Deslocamento da ponta da pá piezelétrica em 400 rpm - controlador

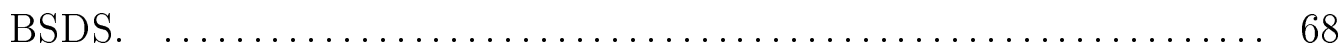

Figura - 41 Ângulos na ponta da pá piezelétrica em 400 rpm - controlador BSDS. 68

Figura - 42 Comparação entre a tensão elétrica de uma pá piezelétrica em 0 rpm - controladores SSDS e BSDS.

Figura - 43 Comparação entre os deslocamentos da ponta de uma pá piezelétrica em 0 rpm - controlador SSDS e BSDS.

Figura - 44 Comparação entre os ângulos da ponta de uma pá piezelétrica em 0 
rpm - controlador SSDS e BSDS.

Figura - 45 Analogia entre a) sistema mecânico de translação e b) sistema elétrico. (Medeiros ((Acessado em 17/06/2014))).

Figura - 46 Circuito chaveador autônomo.

Figura - 47 Comparação entre o sinal de tensão gerado pelo filtro e o sinal de tensão gerado pelo piezelétrico.

Figura - 48 Fluxograma da modelagem da viga piezelétrica no MATLAB/SIMULINK.

Figura - 49 Comparação entre FRF de tensão elétrica apresentada em Erturk e Inman (2009) e a FRF obtida pela modelagem numérica deste trabalho.

Figura - 50 FRF de uma viga piezelétrica engastada na condição de curto circuito $\left(R=10^{2} \Omega\right)$ e circuito aberto $\left(R=10^{6} \Omega\right)$.

Figura - 51 Resposta de flexão de uma viga piezelétrica engastada em função do tempo na condição de curto circuito $\left(R=10^{2} \Omega\right)$ e circuito aberto $\left(R=10^{6} \Omega\right)$.

Figura - 52 Tensão elétrica de uma viga piezelétrica engastada em função do tempo no circuito controlador SSDS.

Figura - 53 Deslocamento da ponta da viga piezelétrica engastada em função do tempo no circuito controlador SSDS.

Figura - 54 Tensão elétrica de uma viga piezelétrica engastada em função do tempo no circuito controlador SSDI.

Figura - 55 Deslocamento da ponta da viga piezelétrica engastada em função do tempo no circuito controlador SSDI.

Figura - 56 Tensão elétrica de uma viga piezelétrica engastada em função do tempo no circuito controlador SSDV.

Figura - 57 Deslocamento da ponta da viga piezelétrica engastada em função do tempo no circuito controlador SSDV.

Figura - 58 Comparação entre a tensão elétrica de circuito aberto e curto circuito experimental.

Figura - 59 Tensão elétrica do controlador SSDS experimental. 
Figura - 60 Tensão elétrica do controlador SSDI experimental. $\ldots \ldots \ldots \ldots \ldots \ldots$ 


\section{Lista de Tabelas}

Tabela - 1 Propriedades do material apresentadas em Cheng (2002) ........ 56

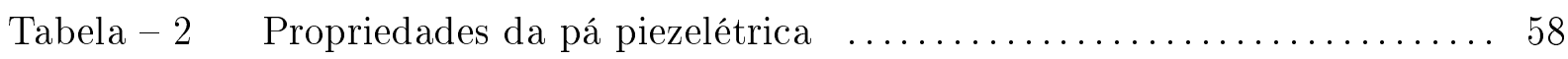

Tabela - 3 Analogia força-tensão entre os sistemas mecânico de translação e elé-

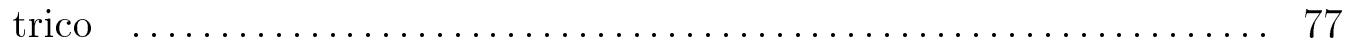

Tabela $-4 \quad$ Dados da viga bimorph apresentada em Erturk e Inman (2009) $\ldots . .90$ 


\section{Lista de Siglas}

SSD Synchronized Switch Damping, p. 27

SHM Structural Health Monitoring, p. 28

cc $\quad$ curto circuito, p. 32

ca circuito aberto, p. 32

SS State Switching, p. 36

SSDS Synchronized Switch Damping on Short, p. 36

SSDI Synchronized Switch Damping on Inductor, p. 36

BSDS Blind Switch Damping on Short Circuit, p. 38

BSDV Blind Switch Damping on Voltage Source, p. 38

SSDV Synchronized Switch Damping on Voltage, p. 39

ACSR Active Control of Structural Response, p. 40

HHC Higher Harmonic Control, p. 40

IBC Individual Blade Control, p. 40

ACF Active Controlled Flap, p. 41

ATR Active Twist Rotor, p. 41

ACT Active Controlled Tip, p. 41

APL Active Pitch Link, p. 41

BVI Blade Vortex Interaction, p. 42

VAM Variational-Asymptotic Method, p. 43

VABS Variational Asymptotic Beam Section, p. 43

HWP Hamilton Weak Principle, p. 44

VAM Variational-Asymptotic Method, p. 70

VABS Variational Asymptotic Beam Section, p. 70 
FRF Função de Resposta em Frequência, p. 89 


\section{Lista de Símbolos}

Tensão mecânica $\left[\mathrm{N} / \mathrm{m}^{2}\right]$, p. 29

Deformação mecânica $[\mathrm{m} / \mathrm{m}]$, p. 29

Flexibilidade $\left[m^{2} / \mathrm{N}\right]$, p. 29

Módulo de elasticidade ou módulo de Young [N/m²], p. 30

Coeficiente de tensão piezelétrico ou constante piezelétrica $[\mathrm{C} / \mathrm{N}]$, p. 30

Deslocamento elétrico $\left[\mathrm{C} / \mathrm{m}^{2}\right]$, p. 30

Campo elétrico $[\mathrm{V} / \mathrm{m}]$, p. 30

Permissividade dielétrica $[\mathrm{F} / \mathrm{m}]$, p. 30

Coeficiente de acoplamento piezelétrico, p. 32

Frequência de chaveamento BSDS [Hz], p. 38

Número de vezes que $f_{s}$ é maior que $f_{0}$, p. 38

Frequência de ressonância do sistema [Hz], p. 38

Sistema de referência inercial, p. 43

Sistema de referência associado com o centro de rotação do rotor, p. 43

Sistema de coordenadas fixado na viga não deformada, p. 44

Sistema de coordenadas fixado na viga deformada, p. 44

Tempo arbitrário [s], p. 44

Tempo arbitrário [s], p. 44

Energia Interna Virtual, p. 44

Trabalho Virtual, p. 44

Medida Virtual, p. 44 


\begin{tabular}{|c|c|}
\hline$F^{*}$ & Vetor de forças e momentos, p. 44 \\
\hline$\delta \gamma^{*}$ & Vetor de deformação e curvatura virtual generalizado, p. 44 \\
\hline$M^{*}$ & Vetor de momentos angular e linear, p. 44 \\
\hline$\delta V^{*}$ & Vetor de velocidades angular e linear, p. 44 \\
\hline$K$ & Energia Cinética, p. 44 \\
\hline$U$ & Energia Potencial, p. 44 \\
\hline$\gamma$ & Vetor coluna de deformações, p. 44 \\
\hline$\kappa$ & Vetor coluna de curvaturas, p. 44 \\
\hline$V_{B}$ & Vetor coluna de velocidade linear, p. 44 \\
\hline$\Omega_{B}$ & Vetor coluna de velocidade angular, p. 44 \\
\hline$F_{B}$ & $\begin{array}{l}\text { Vetor coluna de força interna medido no sistema de referên- } \\
\text { cia B, p. } 44\end{array}$ \\
\hline$M_{B}$ & $\begin{array}{l}\text { Vetor coluna de momento interno medido no sistema de re- } \\
\text { ferência B, p. } 44\end{array}$ \\
\hline$P_{B}$ & $\begin{array}{l}\text { Vetor coluna de momento linear medido no sistema de refe- } \\
\text { rência B, p. } 44\end{array}$ \\
\hline$H_{B}$ & $\begin{array}{l}\text { Vetor coluna de momento angular medido no sistema de re- } \\
\text { ferência B, p. } 44\end{array}$ \\
\hline$F$ & Vetor de forças, p. 45 \\
\hline$M$ & Vetor de momentos, p. 45 \\
\hline$A$ & Matriz de rigidez no plano de rotação, p. 45 \\
\hline$B$ & $\begin{array}{l}\text { Matriz de rigidez de acoplamento no plano de rotação e fora } \\
\text { do plano de rotação, p. } 45\end{array}$ \\
\hline$D$ & Matriz de rigidez fora do plano de rotação, p. 45 \\
\hline$P$ & Vetor de momento linear, p. 45 \\
\hline$H$ & Vetor de momento angular, p. 45 \\
\hline$m$ & Matriz de massa, p. 45 \\
\hline$S$ & Primeiro momento de massa, p. 45 \\
\hline
\end{tabular}


Matriz de inércia, p. 45

$u_{a}$

$\omega_{a}$

$\theta$

$\nu_{a}$

$e_{1}$

$C^{B a}$

$C^{b a}$

$\delta q^{T}$

$\hat{F}$

$\delta \Psi^{T}$

$\hat{M}$

$u$

$F^{T}$

$\delta M^{T}$

$\hat{\theta}$

$F_{S}$

$F_{L}$

X

$n$

$Q$

$\delta V_{p}$

$k_{1}$

$k_{2}$

$C_{p}$
Vetor de velocidade linear, p. 45

Vetor de velocidade angular, p. 45

Deslocamento, p. 45

Velocidade angular, p. 45

Ângulo de orientação, p. 45

Velocidade linear, p. 45

Vetor unitário, p. 45

Matriz de rotação do sistema de referência $a$ para $B$, p. 45

Matriz de rotação do sistema de referência $a$ para $b$, p. 46

Vetor de deslocamento virtual, p. 46

Vetor força, p. 46

Vetor rotação finita virtual, p. 46

Vetor momento, p. 46

Vetor deslocamento, p. 46

Vetor força virtual, p. 46

Vetor momento virtual, p. 46

Vetor de ângulos de orientação, p. 46

Operador estrutural, p. 48

Operador de carga, p. 48

Vetor de variáveis de carga, p. 48

Passo de tempo, p. 50

Carga elétrica, p. 50

Potencial elétrico, p. 50

Acoplamento eletromecânico linear, p. 51

Acoplamento eletromecânico de flexão, p. 51

Capacitância piezelétrica, p. 51 


\begin{tabular}{|c|c|}
\hline $\mathrm{M}$ & Massa, p. 78 \\
\hline $\mathrm{B}$ & Amortecimento, p. 78 \\
\hline $\mathrm{K}$ & Rigidez, p. 78 \\
\hline$\chi(t)$ & Deslocamento, p. 78 \\
\hline$f(t)$ & Força aplicada, p. 78 \\
\hline $\mathrm{L}$ & Indutância, p. 78 \\
\hline $\mathrm{R}$ & Resistência, p. 78 \\
\hline $\mathrm{C}$ & Capacitância, p. 78 \\
\hline$V(t)$ & Fonte de tensão em função do tempo, p. 78 \\
\hline $\mathrm{i}(\mathrm{t})$ & Corrente elétrica, p. 78 \\
\hline$q(t)$ & Carga elétrica, p. 78 \\
\hline$T^{*}$ & Energia cinétical total, p. 81 \\
\hline$U$ & Energia potencial, p. 82 \\
\hline$W_{e}$ & Energia elétrica, p. 82 \\
\hline$u$ & deslocamento mecânico [m], p. 82 \\
\hline$V_{s}$ ou $V_{p}$ & Volume da estrutura ou da piezocerâmica $\left[\mathrm{m}^{3}\right]$, p. 82 \\
\hline$\delta W$ & Trabalho, p. 82 \\
\hline$f$ & Força mecânica, p. 82 \\
\hline$q$ & Carga elétrica, p. 82 \\
\hline$\varphi$ & Potencial elétrico, p. 82 \\
\hline$\phi$ & Modos, p. 83 \\
\hline$r(t)$ & Coordenada temporal do deslocamento u, p. 83 \\
\hline$\psi$ & Potencial elétrico, p. 83 \\
\hline$t_{p}$ & espessura do material piezelétrico, p. 83 \\
\hline$v_{p}$ & Tensão elétrica gerada pela piezocerâmica, p. 83 \\
\hline$M$ & Massa, p. 83 \\
\hline$C$ & Amortecimento, p. 83 \\
\hline
\end{tabular}




\begin{tabular}{|c|c|}
\hline$K$ & Rigidez, p. 83 \\
\hline$\theta$ & Acoplamento eletromecânico, p. 83 \\
\hline$M^{*}$ & Vetor de força efetiva da aceleração de base, p. 83 \\
\hline$\ddot{u}_{g}$ & Aceleração de base, p. 83 \\
\hline$C_{p}$ & Capacitância da piezocerâmica, p. 83 \\
\hline$\dot{Q}(t)$ & Corrente elétrica, p. 83 \\
\hline $\mathrm{L}$ & Comprimento da viga, p. 83 \\
\hline $\bar{m}$ & Massa da viga por unidade de comprimento, p. 83 \\
\hline$\alpha e \beta$ & Constante de proporcionalidade, p. 83 \\
\hline$R$ & Resistência elétrica, p. 85 \\
\hline$\beta_{n}$ & Constante da função de modos, p. 85 \\
\hline$\sigma_{n}$ & Constante da função de modos, p. 85 \\
\hline$A$ & Matriz de estado, p. 85 \\
\hline$B$ & Matriz de entrada, p. 85 \\
\hline$C$ & Matriz de saída, p. 85 \\
\hline$D$ & Matriz de transmissáo direta, p. 85 \\
\hline$y$ & Vetor de saída, p. 85 \\
\hline$u$ & Vetor de entrada, p. 85 \\
\hline$x$ & Vetor de estados, p. 85 \\
\hline$R 1$ e $R 6$ & Resistência do filtro passa-baixa, p. 86 \\
\hline$D 1$ e $D 6$ & Diodo do filtro passa-baixa, p. 86 \\
\hline$C 1$ e $C 2$ & Capacitância do filtro passa-baixa, p. 86 \\
\hline$R 2, R 3, R 4$ e $R 5$ & Resistência do comparador, p. 86 \\
\hline$D 2, D 5, D 9$ & Diodos do comparador, p. 86 \\
\hline$D 10, D 11, D 12$ & Diodos do comparador, p. 86 \\
\hline$T 1$ e $T 4$ & Transistor do comparador, p. 86 \\
\hline$D 3, D 4, D 7$ e $D 8$ & Diodos da chave, p. 87 \\
\hline
\end{tabular}


$T 2$ e $T 3$

$\omega_{n_{\text {circuito }}}$

$\Delta t_{i}$

$Q_{i}$

$R_{i}$

$\gamma$

$v_{\text {antes }}$

$v_{\text {depois }}$
Transistor da chave, p. 87

frequência natural do circuito elétrico, p. 88

tempo de inversão, p. 88

Fator de qualidade elétrica, p. 88

Resistência interna do circuito chaveador, p. 88

Coeficiente de inversão, p. 88

Sinal de tensão no final de chaveamento, p. 88

Sinal de tensão no início do chaveamento, p. 88 
1 Introdução e Justificativa $\quad 26$

2 Revisão da Literatura $\quad 29$

2.1 Materiais Inteligentes e Materiais Piezelétricos . . . . . . . . . . . . 29

2.2 Estratégias de Controle de Vibrações utilizando Materiais Piezelétricos . . . 33

2.2 .1 Controle Passivo . . . . . . . . . . . . . . . 33

2.2 .2 Controle Ativo . . . . . . . . . . . . . . . 34

2.2.3 Controles semipassivos e semiativos . . . . . . . . . . . . 35

2.2.3.1 Controle Semipassivo . . . . . . . . . . . . 36

2.2.3.2 Controle Semiativo . . . . . . . . . . . . 39

2.3 Utilização de Materiais Inteligentes em Asas Rotativas . . . . . . . . . . 40

3 Modelagem Eletromecânica de uma Pá Piezelétrica Engastada 43

3.1 Modelagem de uma Viga Elástica Rotativa . . . . . . . . . . . . . . 43

3.2 Modelagem de uma Viga Elástica Rotativa Piezelétrica (Pá + Piezo) . . . 50

3.3 Fluxograma de Solução . . . . . . . . . . . . . . . . . 52

4 Resultados Numéricos de uma Pá Piezelétrica Engastada 55

4.1 Verificação do Método Numérico . . . . . . . . . . . . . . 55

4.2 Controlador Passivo Resistivo Puro . . . . . . . . . . . . 57

4.3 Controlador Semipassivo SSDS ....................... 61

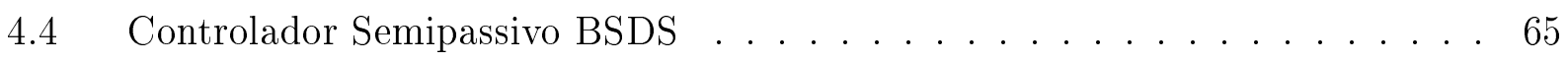

4.5 Comparação entre os controladores Semipassivos SSDS e BSDS . . . . . . 67 
Apêndice A - Analogia entre Sistema Mecânico de Translação e Sistema Elétrico

A.1 - Influência do Circuito Elétrico em um Sistema Piezelétrico Eletromecanicamente Acoplado . . . . . . . . . . . . . . . . . . . . . 78

Apêndice B - Modelagem de uma Viga Piezelétrica Fixa

B.1 - Modelagem da Viga Piezelétrica Engastada . . . . . . . . . . . . . . . 81

B.2 - Desenvolvimento dos Circuitos Elétricos e do Circuito Chaveador . . . . . . 86

B.3 - Verificação do Método Numérico . . . . . . . . . . . . . . . . . 89

B.4 - Controlador Passivo Resistivo Puro . . . . . . . . . . . . . . . . 91

B.5 - Controlador Semi-passivo SSDS . . . . . . . . . . . . . . . 92

B.6 - Controlador Semi-passivo SSDI . . . . . . . . . . . . . . . . 93

B.7 - Controlador Semi-ativo SSDV . . . . . . . . . . . . . . . 94

B.8 - Resultados Experimentais da Viga Piezelétrica Engastada . . . . . . . . . 95

$\begin{array}{ll}\text { Apêndice C - Método Alfa-Generalizado } & 98\end{array}$

Apêndice D - Dificuldades Encontradas nas Simulações Numéricas $\quad 100$ 


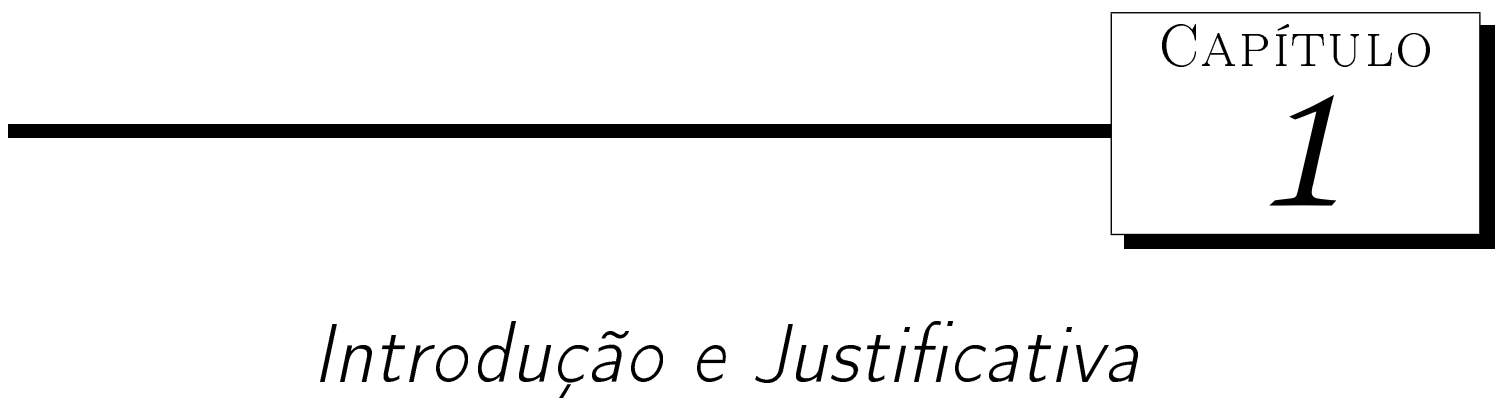

$\mathrm{H}$

elicópteros são inerentemente associados com a ocorrência de vibrações devido a diversos fatores, como por exemplo, folgas ou envelhecimento de componentes, desbalanceamento e efeitos aerodinâmicos indesejados. As pás que estão avançando podem entrar em regime transônico devido a alta velocidade relativa do escoamento do ar (velocidade do helicóptero somada com a velocidade da pá) e ocorrer o surgimento de ondas de choque, além disso, as pás no retorno (velocidade do helicóptero subtraída da velocidade da pá) podem apresentar estol dinâmico. Esse fenômeno induz vibrações que são transferidas para a fuselagem, causando desconforto aos passageiros e pilotos (Vallejo et al. (1999)). A freqüência de vibração transferida para a fuselagem depende do número de pás do rotor e resulta em uma faixa geralmente entre $2 \mathrm{~Hz}$ e $8 \mathrm{~Hz}$ (ou seja, na faixa entre $1 /$ rev e $\mathrm{N} /$ rev, onde $\mathrm{N}$ é o número de pás do rotor) e a frequência de ressonância da região do tronco de uma pessoa está em torno de $5 \mathrm{~Hz}$.

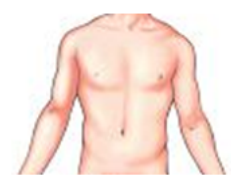

$\sim 5 \mathrm{~Hz}$

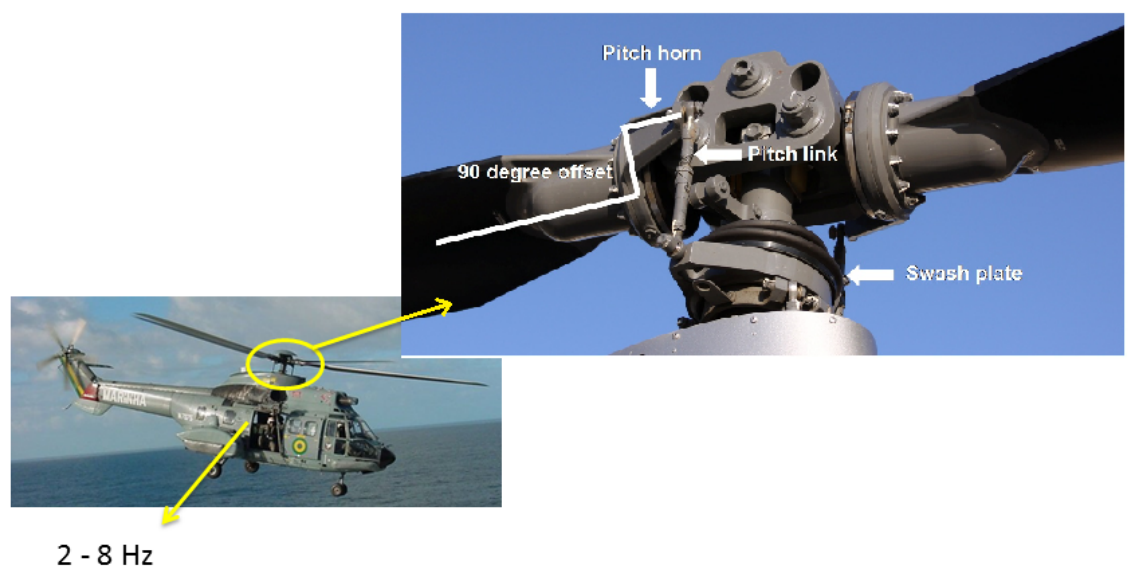

Figura 1 - Frequência de ressonância do tronco de uma pessoal e frequência transferida do rotor para fuselagem.

A velocidade máxima em voo de cruzeiro de um helicóptero também é limitada pelo 
surgimento de vibrações (provenientes do rotor) no sistema de comando, transmitidas através do pitch link (Feszty e Nitzsche (2011)). O pitch link é responsável pela transmissão de movimento da swash plate (bandeja giratória) para o pitch horn (vinculado ao bordo de fuga da pá na região da raiz), que por sua vez, altera o ângulo de passo da pá (Fig. 1).

Com o intuito de minimizar problemas como os anteriormente citados, o desenvolvimento de sistemas de controle de vibrações para helicópteros tem recebido grande atenção da comunidade científica nas últimas décadas. O controle de vibrações em helicópteros pode trazer benefícios para piloto e passageiros, para o desempenho da aeronave e também de evitar fadiga em componentes. Alguns autores apresentam sistemas mecânicos passivos (Feszty e Nitzsche (2011)), enquanto outros investigam sistemas que utilizam materiais inteligentes, como atuadores ou como sensores (Barrett (1990), Fabunmi (1991), Cesnik e Shin (2001), Nitzsche et al. (2005), Wall et al. (2008)).

Os materiais piezelétricos têm a capacidade de converter energia elétrica em energia mecânica e vice-versa. O efeito piezelétrico direto é definido como a conversão de energia mecânica em energia elétrica. Já a conversão de energia elétrica em energia mecânica define o efeito piezelétrico inverso. Uma característica interessante desses materiais é a possibilidade de uso simultâneo como sensores (efeito direto) e atuadores (efeito inverso), permitindo por exemplo o estudo de controladores semi-ativos (Zhao (2010)).

Dentre as diferentes possibilidades de controladores piezelétricos apresentados na literatura para atenuação de vibração (ativos, passivos e híbridos), Richard et al. (1999) apresentaram a alternativa do tratamento não linear da saída elétrica de materiais piezelétricos através das técnicas SSD (Synchronized Switch Damping) para controle de vibrações. O princípio básico de funcionamento do SSD consiste no chaveamento do sinal elétrico proveniente do material piezelétrico, conectando-o e desconectando-o a um circuito externo de forma sincronizada com as oscilações mecânicas. As diversas técnicas SSD serão posteriormente discutidas. Entretanto, de forma geral, elas não dependem de uma fonte externa de energia para seu funcionamento ou requerem baixa energia para o processo de chaveamento (dependendo da técnica utilizada), condições que podem resultar em controladores autoalimentados (ou autônomos) quando, por exemplo, associadas a sistemas de coleta piezelétrica de energia.

Um sistema de controle autoalimentado (ou autônomo energeticamente) em helicópteros evitaria a necessidade de transferência de energia elétrica da fuselagem para a parte rotativa. Além disso, sistemas de coleta piezelétrica de energia no referencial rotativo 
também possibilitariam a alimentação de outros sistemas de baixo consumo, como sistemas de verificação de integridade estrutural (SHM - Structural Health Monitoring, da sigla em inglês).

A presente dissertação apresenta um modelo eletroelástico de uma viga elástica rotativa (pá de helicóptero) com piezocerâmicas embutidas (região da raiz da pá) para a atenuação de vibrações utilizando circuitos semi-passivos. A verificação do método numérico será apresentada e os controladores passivo resistivo puro, semipassivo SSDS e semipassivo BSDS serão investigados. A presente investigação não prevê o desenvolvimento de sistemas de controle autoalimentados e também considera o circuito chaveador como um circuito ideal (sem resistências internas). Entretanto, o desenvolvimento deste projeto é um primeiro passo em tal direção. 


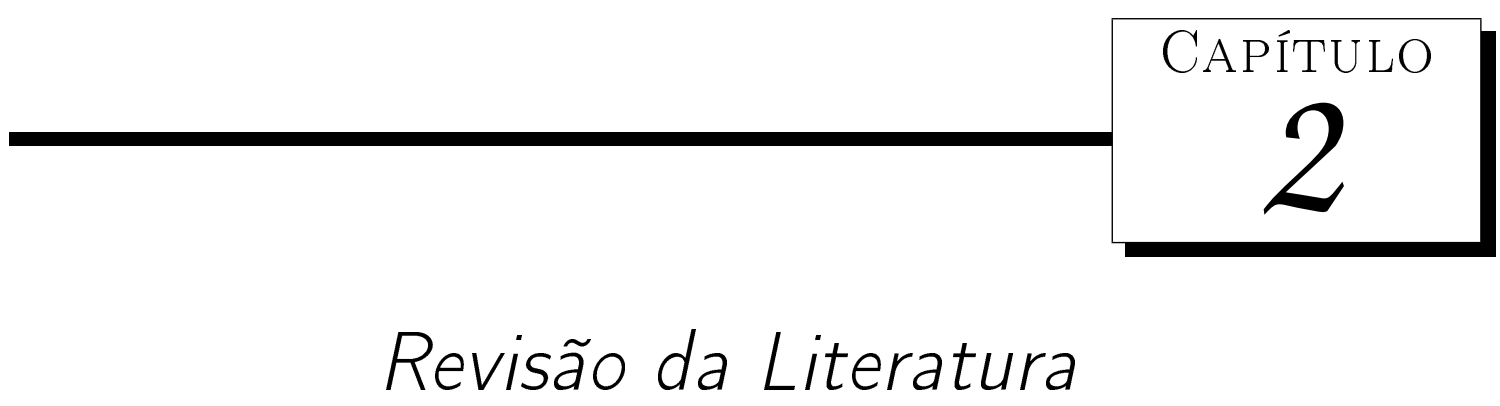

\subsection{Materiais Inteligentes e Materiais Piezelétricos}

Os materiais inteligentes são definidos como aqueles que exibem acoplamento entre múltiplos domínios físicos (mecânico, elétrico, térmico, magnético, químico e outros). Há acoplamento quando uma mudança na variável de estado de um domínio físico causa mudança em uma outra variável de estado de um outro domínio físico. Por exemplo, material piezelétrico é aquele que possui acoplamento entre os domínios mecânico e elétrico (acoplamento eletromecânico).

Quando o material piezelétrico é submetido a um deslocamento mecânico, surge um campo elétrico entre os eletrodos, que por sua vez produz atração entre a carga aplicada e os dipolos elétricos do material, rotacionando esses dipolos e uma saída elétrica é gerada (IEEE (1987)). Esse efeito é chamado de efeito piezelétrico direto e foi demonstrado pela primeira vez pelos irmãos Curie em 1880. Se o mesmo material for submetido a uma diferença de potencial entre seus eletrodos, ele se deformará mecanicamente, apresentando o efeito piezelétrico inverso que foi deduzido matematicamente por Gabriel Lippmann em 1881, logo após a descoberta do efeito piezelétrico direto.

A grande expansão do conceito de materiais inteligentes veio com a utilização de materiais ferroelétricos, como por exemplo o Titanato Zirconato de Chumbo (cerâmica PZT), com a grande vantagem de que a eficiência de conversão eletromecânica é bem maior se comparada com o Quartzo.

A relação entre tensão mecânica aplicada ao material piezelétrico $T\left[\mathrm{~N} / \mathrm{m}^{2}\right]$ e deformação mecânica $S[\mathrm{~m} / \mathrm{m}]$ é chamada de flexibilidade $s\left[\mathrm{~m}^{2} / \mathrm{N}\right]$,

$$
S=\frac{1}{Y} T=s T
$$


onde $Y\left[\mathrm{~N} / m^{2}\right]$ é o módulo de elasticidade do material ou módulo de Young na direção de deformação e tensão. O módulo de elasticidade possui um comportamento elástico seguido de uma não linearidade do material (Fig. 2(a)).
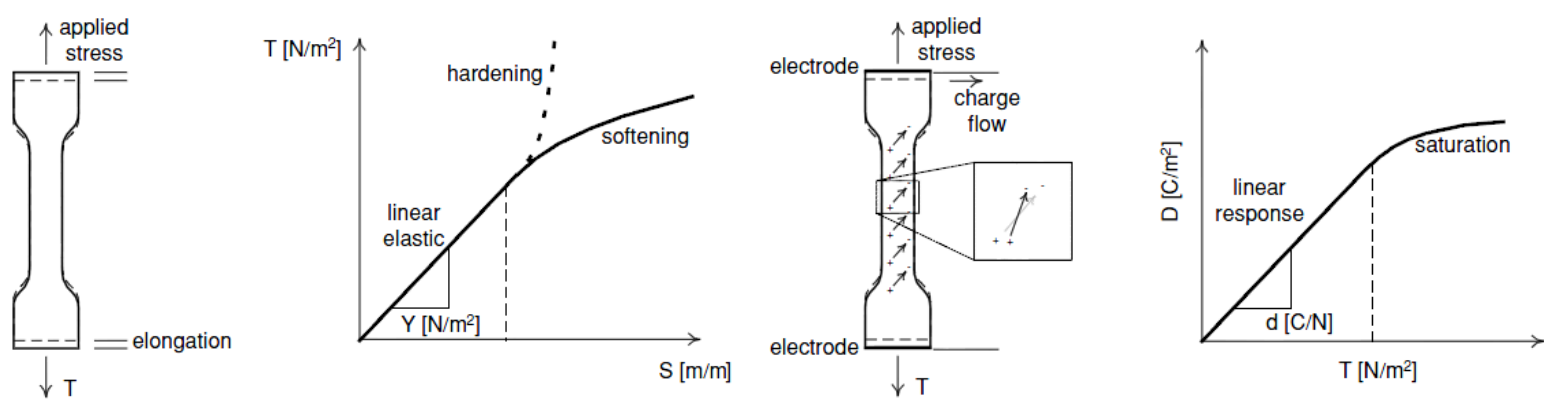

(a)

(b)

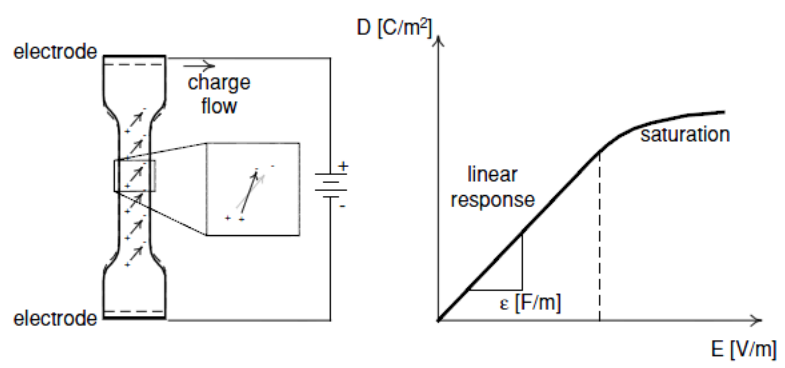

(c)

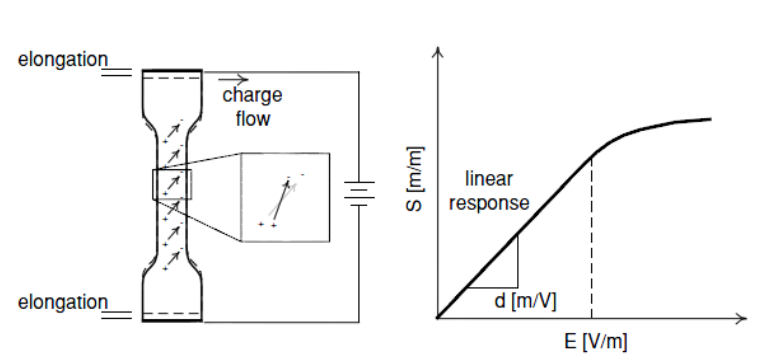

(d)

Figura 2 - Relação entre: a) tensão mecânica e deformação; b) tensão e deslocamento elétrico; c) campo elétrico aplicado e deslocamento elétrico; e d) deformação e campo elétrico. (Leo (2007)).

O coeficiente de tensão piezelétrico ou constante piezelétrica $d[\mathrm{C} / \mathrm{N}]$ é a relação entre o deslocamento elétrico $D\left[\mathrm{C} / \mathrm{m}^{2}\right]$ (carga elétrica/área) e a tensão mecânica $T\left[\mathrm{~N} / \mathrm{m}^{2}\right]$, ou seja,

$$
D=d T
$$

Observa-se saturação do sistema logo após o comportamento linear, como mostra a Fig. 2(b).

Quando uma tensão elétrica é aplicada no material piezelétrico e este responde com um deslocamento mecânico, dizemos que há acoplamento elétrico-mecânico, denominado de efeito piezelétrico inverso. A relação entre o deslocamento elétrico $D\left[C / \mathrm{m}^{2}\right]$ e o campo elétrico $E[\mathrm{~V} / \mathrm{m}]$ (Eq. 2.3) é chamada de permissividade dielétrica $\epsilon[\mathrm{F} / \mathrm{m}]$,

$$
D=\epsilon E
$$

como mostra a Fig. 2(c).

A relação entre a deformação mecânica aplicada $S[\mathrm{~m} / \mathrm{m}]$ e o campo elétrico $E[\mathrm{~V} / \mathrm{m}]$ 
é o coeficiente de tensão piezelétrico $d[\mathrm{C} / \mathrm{N}]$,

$$
S=d E
$$

Essa relação é demonstrada pela Fig. 2(d), onde é possível perceber um comportamento linear até certo ponto do gráfico, que pode variar dependendo do material.

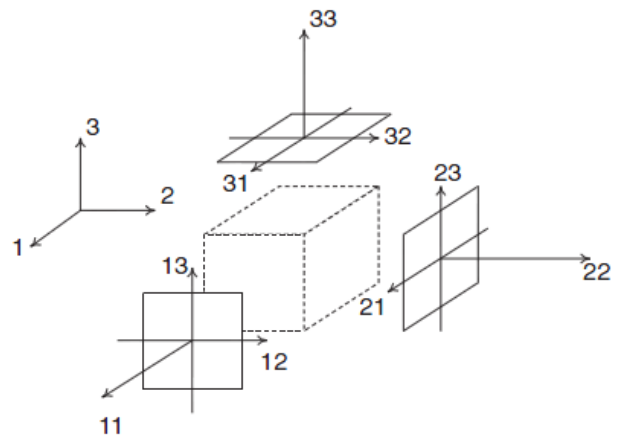

Figura 3 - Cubo de piezoelétrico indicando as coordenadas axiais da análise tridimensional. (Leo (2007)).

Em um volume elementar do material piezoelétrico, diferentes saídas são obtidas dependendo da direção em que a entrada é aplicada (Fig. 3). Por isso, é necessário estabelecer uma identificação para cada uma dessas direções (IEEE (1987)). Há três direções nas quais um campo elétrico e um deslocamento elétrico podem ser aplicados, representados como vetores $E_{n}$ e $D_{m}$, onde $\mathrm{n}, \mathrm{m}=1,2,3$ são as direções. Assim, as equações constitutivas do material piezelétrico linear são representadas como

$$
\begin{aligned}
& S_{i j}=s_{i j k l}^{E} T_{k l}+d_{i j n} E_{n} \\
& D_{m}=d_{m k l} T_{k l}+\epsilon_{m n}^{T} E_{n}
\end{aligned}
$$

onde $s_{i j k l}$ representa 81 termos de flexibilidade mecânica e os sobrescritos $T$ e $E$ indicam a condição em constante tensão mecânica e constante campo elétrico, respectivamente. As Eqs. 2.5 e 2.6 podem ser representadas pela forma compacta,

$$
\left\{\begin{array}{l}
S \\
D
\end{array}\right\}=\left[\begin{array}{ll}
\bar{s} & d \\
d & \varepsilon
\end{array}\right]\left\{\begin{array}{l}
T \\
E
\end{array}\right\}
$$

O material piezelétrico depende tanto das suas propriedades mecânicas quanto das suas propriedades elétricas, como mostra a Eq. 2.7. Considerando novamente o volume elementar do material piezoelétrico apresentado na Fig. 3, cujo deslocamento mecânico é medido de acordo com a tensão elétrica aplicada, um parâmetro importante será a condição de contorno elétrica que existe entre as faces opostas do piezelétrico. 

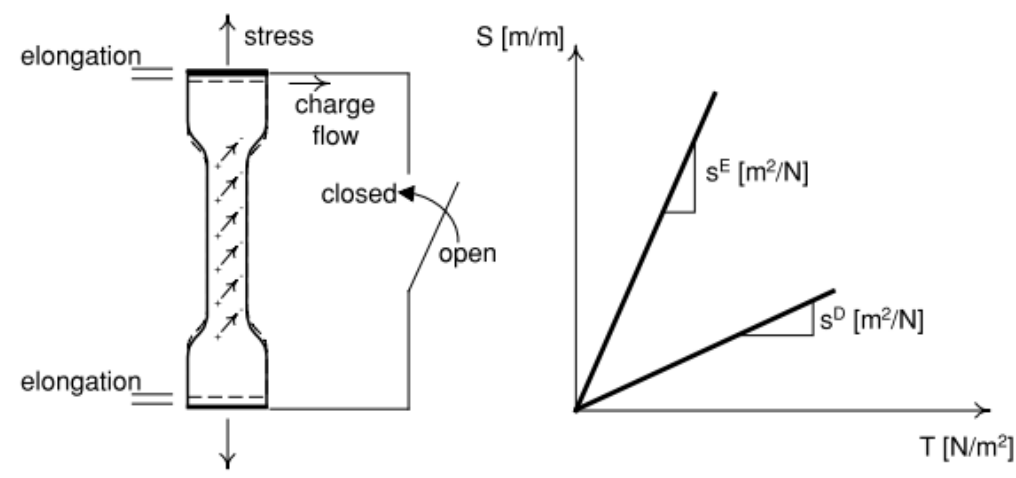

Figura 4 - Relação entre tensão mecânica e deformação de um material elástico em função da condição de contorno elétrica. (Leo (2007)).

Em um primeiro momento, o material piezelétrico é submetido a condição de curto circuito (chave fechada na Fig. 4), onde o campo elétrico entre as faces do material é igual a zero, mas a carga elétrica flui entre os terminais positivo e negativo. Substituindo $\mathrm{E}=0$ na Eq. 2.7, a equação constitutiva do material piezelétrico na condição de curto circuito (cc) pode ser representada como

$$
S=\bar{s} T \quad D=d T
$$

Considerando que os terminais do material piezelétrico abrem de tal forma que nenhuma carga possa fluir entre as faces do material (chave aberta na Fig. 4), essa condição é denominada de circuito aberto, onde o deslocamento elétrico entre as faces do material é igual zero. Substituindo $D=0$ na Eq. 2.7, a equação constitutiva do material piezelétrico na condição de circuito aberto (ca) pode ser representada como

$$
T=\frac{1}{\bar{s}\left(1-k^{2}\right)} S \quad E=\frac{k^{2}}{d\left(1-k^{2}\right)} S \quad k=\frac{d}{\sqrt{\bar{s} \varepsilon}} \quad 0<k<1
$$

onde $k$ é o coeficiente de acoplamento piezelétrico e indica qual a fração da energia (elétrica-mecânica-elétrica) é convertida.

Reorganizando as Eqs. 2.8 e 2.9 no seguinte formato

$$
\begin{array}{cc}
S=\bar{s} T & \rightarrow c c \\
S=\left[\bar{s}\left(1-k^{2}\right)\right] T & \rightarrow c a
\end{array}
$$

verifica-se que a flexibilidade (ou rigidez) do material piezelétrico depende da condição de contorno elétrica utilizada. Na condição de curto circuito, a rigidez é menor que em circuito aberto, consequentemente, a frequência de ressonância do sistema na condição de curto circuito também é menor que em circuito aberto. 


\subsection{Estratégias de Controle de Vibrações utilizando Ma- teriais Piezelétricos}

Os sistemas de controle utilizando materiais piezelétricos podem ser divididos em dois grandes grupos, ativos e passivos. Recentemente, novos sistemas surgiram sendo classificados como semipassivos e semiativos. Os controladores passivos não utilizam energia externa para o seu funcionamento. Nos controladores ativos, energia externa é aplicada nos atuadores piezelétricos. No caso de controlador semipassivo, o material piezelétrico trabalha de forma passiva durante todo tempo e uma fonte de energia externa é necessária para fazer o chaveamento entre a condição de circuito aberto e condição de curto circuito. Já no caso semiativo, uma diferença de potencial é aplicada ao elemento piezelétrico em curtos períodos de tempo, enquanto este trabalha de forma passiva na maior parte do ciclo de trabalho.

\subsubsection{Controle Passivo}

Nos sistemas de controle passivo, a energia de vibração mecânica é transformada em energia elétrica através do efeito piezelétrico. A energia dissipada nos circuitos externos faz com que o sistema tenha um amortecimento adicional ao amortecimento estrutural (efeito shunt damping).

Dentre as diferentes técnicas de controle passivo, as mais estudadas são: resistiva, resistiva-indutiva em série e resistiva-capacitiva em série.

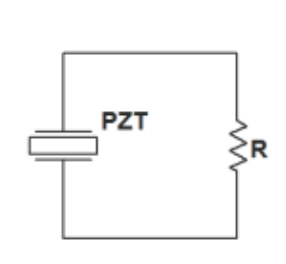

(a)

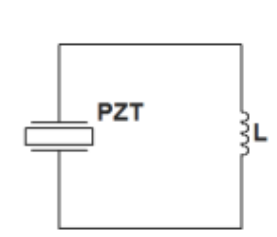

(b)

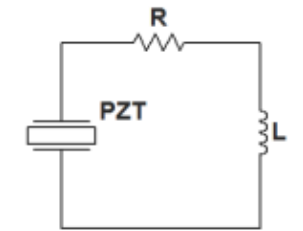

(c)

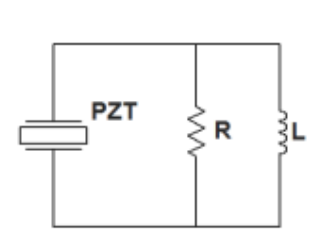

(d)

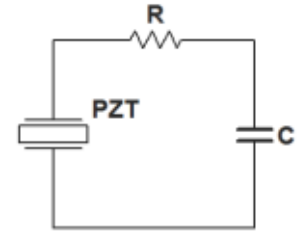

(e)

Figura 5 - Diferentes técnicas de controle passivo: a) resistivo puro; b) indutivo puro; c) resistivo-indutivo em série; d) resistivo-indutivo em paralelo; e e) resistivocapacitivo em série. Modificado de D’Assunção (2013).

No circuito resistivo puro (Fig. 5(a)), o amortecimento adicional ocorre devido a dissipação de energia no resistor em forma de calor (Johnson (1995)). Como as propriedades elásticas do piezelétrico dependem da condição de contorno elétrica aplicada, há também variação na rigidez total do sistema, consequentemente, a frequência de ressonância em 
curto circuito é menor do que em circuito aberto (Erturk e Inman (2008)).

Forward (1979) investigou a utilização de um indutor puro no circuito elétrico de um sistema piezelétrico (Fig. 5(b)) e o efeito encontrado é semelhante a um absorvedor mecânico de vibração não-amortecido, pois o elemento indutivo é equivalente a uma massa extra no sistema (funcionando como um absorvedor), mas não há o elemento resistivo, ou seja, o sistema passa a ser não-amortecido.

Já Hagood e Flotow (1991) utilizam um controlador passivo resistivo-indutivo em série (Fig. 5(c)) e mostram que o ramo indutor-resistor equivale a um absorvedor mecânico de vibração amortecido, pois o indutor é equivalente a uma massa extra no sistema (funcionando como um absorvedor) e o elemento resistivo equivale a um amortecedor (ver Apêndice 5). Mas Wu (1996) diz que no caso de Hagood, o circuito indutivo-resistivo em série dificulta a escolha do valores ótimos de indutância e resistência, pois os elementos elétricos operam dependentemente um do outro. Então Wu propõe um circuito indutivoresistivo em paralelo (Fig. 5(d)) afim de que todos os elementos elétricos possam operar independentemente.

Pouco estudado, o circuito resistivo-capacitivo em série (Fig. 5(e)) causa efeito de variação da rigidez equivalente do material piezelétrico e, consequentemente, variação da rigidez total do sistema.

Cada configuração de controlador passivo adiciona algum efeito ao sistema mecânico. O efeito vai depender de qual elemento elétrico passivo é utilizado (Apêndice A - Analogia entre Sistema Mecânico de Translação e Sistema Elétrico) e qual condição de contorno elétrica é aplicada ao sistema.

Os controladores passivos tem o benefício de serem estáveis por não utilizarem fonte externa de energia. Os casos que utilizam indutores possuem bom desempenho em uma frequência específica ou em uma faixa pequena de frequências, pois a indutância é inversamente proporcional a frequência das oscilações que se deseja atenuar, exigindo elevados valores de indutância para faixas de baixas frequências. Há a possibilidade de utilizar indutâncias sintéticas, mas a resistência parasita inerente ao indutor sintético é muita alta (Viana (2005)), reduzindo o desempenho do sistema.

\subsubsection{Controle Ativo}

A segunda estratégia de controle utilizando materiais piezelétricos é o controle ativo. Nesse caso, a energia elétrica é transformada em energia mecânica através do efeito pieze- 
létrico inverso, ou seja, o material piezelétrico é utilizado exclusivamente como atuador. A fonte de energia externa é aplicada diretamente no material piezelétrico de acordo com uma lei de controle projetada. A literatura apresenta uma vasta aplicação e tipos de controladores que vêm sendo utilizados para a supressão ativa de vibrações. Os primeiros trabalhos sobre controle ativo foram apresentados por Lazarus, Crawley e Lin (1995) e Crawley e Luis (1987).

Heeg (1992) faz um estudo teórico e experimental da utilização de atuadores (controle ativo) na supressão de flutter. Um modelo de asa de túnel de vento com dois graus de liberdade (deslocamento linear e angular) foi analisado e testado. Uma lei de controle de supressão de flutter foi desenvolvida, implementada em um sistema digital e testa em $20 \%$ acima da velocidade de flutter do modelo. As análises mostraram que a velocidade de flutter poderia ser aumentada por um fator de $15,7 \%$ com a lei de controle e, experimentalmente, esse fator foi de $20 \%$ de aumento.

Anthony e Elliott (2000) investigam como as posições dos atuadores piezelétricos e a quantidade deles acoplados na estrutura afetam o desempenho do controlador ativo na redução da vibração de uma viga com dois graus de liberdade. Os autores também investigam a influência da rigidez da viga na redução de vibração.

E Wang e Inman (2012) apresentam a investigação para minimizar o consumo de energia de controladores ativos. Os autores apresentam várias técnicas de controle de vibrações, entre elas o controlador ativo. A partir desse estudo, espera-se que novas perspectivas sejam exploradas possibilitando a alimentação de tais controladores com energia coletada com a conversão eletromecânica de energia (energy harvesting).

A vantagem desse tipo de controlador é grande atenuação de vibração mecânica. Mas a desvantagem é a utilização de fonte de tensão externa e as leis de controle são mais complexas.

\subsubsection{Controles semipassivos e semiativos}

Os controladores semipassivos e semiativos surgiram com o intuito de suprir as deficiências dos sistemas de controles passivo e ativo. Os controladores mais representativos são os que utilizam a técnica de chaveamento do sinal elétrico (Guyomar, Richard e Mohammadi (2007)). Essa técnica consiste no chaveamento da saída elétrica do material piezelétrico com um circuito elétrico externo, conectando-o ou desconectando-o em diferentes momentos. 
As técnicas de chaveamento para controle de vibração podem ser divididas em semipassivo e semiativo. O controle semipassivo é um sistema chaveado que não utiliza fonte de tensão externa aplicada diretamente na piezocerâmica. Pode haver necessidade de utilizar fonte de tensão externa somente para alimentar o circuito chaveador, por isso da nomenclatura "semi" passivo. Já o controle semiativo utiliza fonte de tensão externa aplicada diretamente na piezocerâmica (não somente no elemento chaveador) e em curtos períodos de tempo (durante o chaveamento), por isso é conhecido como "semi" ativo.

\subsubsection{Controle Semipassivo}

A técnica de controle não linear utilizando circuito semipassivo é caracterizada por não utilizar fonte de tensão externa aplicada diretamente a piezocerâmica. Os principais tipos de controladores semipassivos são: State Switching (SS), Synchronized Switch Damping on Short (SSDS) e Synchronized Switch Damping on Inductor (SSDI).

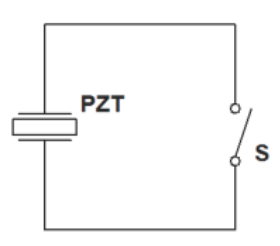

(a)

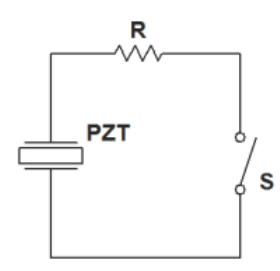

(b)

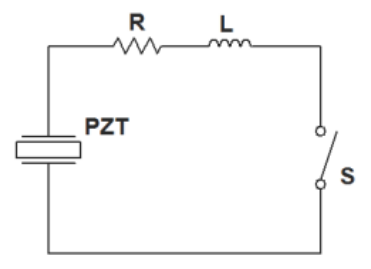

(c)

Figura 6 - Principais tipos de controladores semipassivos: a) SS; b) SSDS; e c) SSDI. (D’Assunção (2013)).

O conceito SS (Larson (1996)) consiste em detectar os momentos em que há pontos de máximo e mínimo das oscilações mecânicas e chavear o sistema de circuito aberto (máxima tensão e maior rigidez) para curto circuito (mínima tensão e menor rigidez) (Fig. 6(a)). Ao detectar o deslocamento máximo para a condição de circuito aberto, o sistema é curto circuitado até que esse deslocamento se torne nulo. Nesse momento, o sistema é novamente chaveado para circuito aberto, se afastando novamente do equilíbrio. O mesmo acontece quando o deslocamento mínimo é detectado (condição de circuito aberto), o sistema é chaveado para a condição de curto circuito até que o deslocamento seja nulo novamente. Clark (2000) mostrou que dependendo do modo de operação do material piezelétrico, a rigidez efetiva de uma viga pode ter aumento de um fator de dois.

Semelhante ao conceito anterior, o conceito SSDS (Fig. 6(b)) detecta os pontos de máximo e mínimo, mas desta vez, os pontos são detectados a cada ciclo e um resistor no circuito elétrico é utilizado. O princípio consiste detectar os pontos de máximo e 
mínimo das oscilações mecânicas e chavear o sistema da condição de circuito aberto, onde a tensão elétrica dos piezelétricos é máxima, para curto circuito, descarregando a tensão elétrica das piezocerâmicas (Fig. 7(b)). Richard et al. (1999) mostra resultados de um sistema submetido a técnica SSDS, cujo chaveamento entre circuito aberto e curto circuito (utilizando um valor de resistor baixo) era feito por um circuito elétrico composto de transistores e diodos. A conseqüência foi o aumento do amortecimento do sistema.

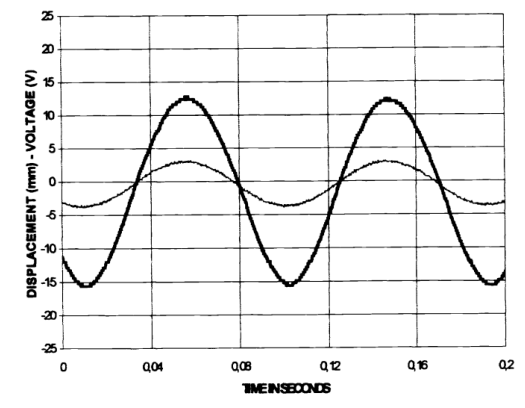

(a)

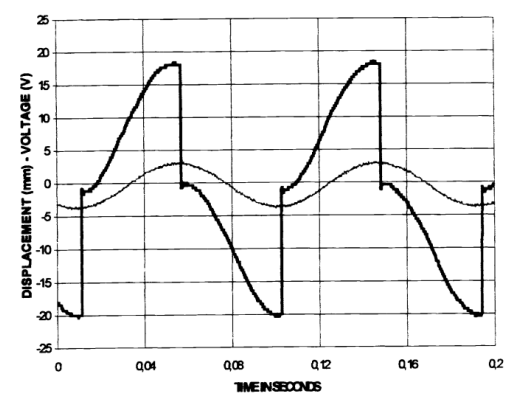

(b)

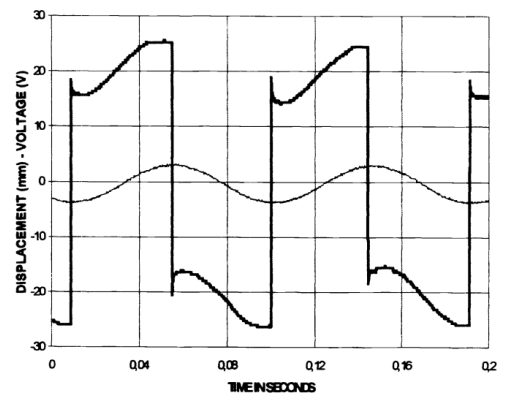

(c)

Figura 7 - Comparação das tensões elétricas: a) circuito aberto; b) SSDS; e c) SSDI. (Richard et al. (2000)).

A terceira técnica de controle semipassiva apresentada é o SSDI (Fig. 6(c)). Quando há deslocamento mecânico máximo ou mínimo, o circuito originalmente aberto, é chaveado para um circuito indutivo, assim é formado um circuito ressonante (circuito RLC). O elemento indutivo causa a inversão quase instantânea da tensão na resposta elétrica (Fig. 7(c)) e o surgimento de uma força mecânica dissipativa proveniente do efeito piezelétrico inverso. Assim, o efeito shunt damping é muito mais evidente no caso SSDI se comparado aos casos anteriormente discutidos. A inversão de tensão não é completa, pois há resistência interna inerente do sistema. A vantagem desse tipo de controle é quanto a escolha dos indutores para faixas de frequências baixas. Ao contrário do controlador indutivo puro (Fig. 5(b)) onde o valor do indutor é muito elevado para baixas frequências, o controlador semipassivo SSDI permite que a indutância utilizada seja baixa, na ordem de $\mathrm{mH}$ (mili Henries). Isso é possível devido ao fato de que a frequência de ressonância elétrica é muito maior do que a frequência de ressonância mecânica. Uma característica desse tipo de controlador é a possibilidade de escolher um valor de indutor que otimize o tempo em que o sistema ficará chaveado. Richard et al. (2000) mostra que houve uma redução de $90 \%$ na amplitude de vibração de uma viga utilizando um controlador SSDI e o tempo de decaimento foi reduzido em 93\% para uma frequência perto de $12 \mathrm{~Hz}$.

Nas técnicas semipassivas apresentadas, o chaveamento é feito de forma sincronizada com o máximo deslocamento da estrutura, sendo necessário identificar os pontos de má- 


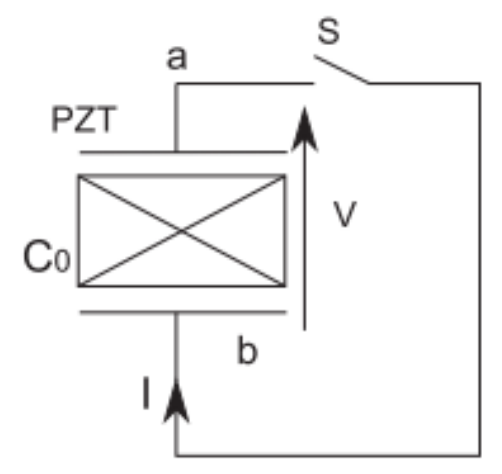

(a)

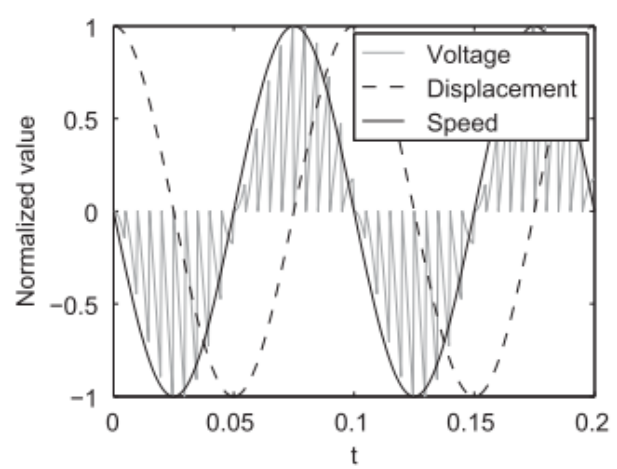

(b)

Figura 8 - a) circuito básico BSDS; e b) Formas das ondas do controlador BSDS. (Lallart et al. (2009)).

ximo e mínimo do sinal elétrico. Na prática, essa identificação pode ser feita utilizando circuitos elétricos como o apresentado por Richard, Guyomar e Lefeuvre (2007), circuito formado basicamente de filtro passa-baixa RC, comparador e chave (apresentado no Apêndice B.2).

Lallart et al. (2009) propõem uma nova técnica semipassiva, chamada de Blind Switch Damping on Short Circuit (BSDS), que consiste em chavear o sistema para a condição de curto circuito (Fig. 8(a)) com uma frequência $f_{s}[\mathrm{~Hz}], n$ vezes maior que a frequência de ressonância do sistema mecânico $f_{0}[\mathrm{~Hz}]$,

$$
f_{s}=n f_{0}
$$

A tensão elétrica está em fase com a velocidade (Fig. 8(b)) e o circuito é chaveado $n$ vezes durante um período. O controlador BSDS tem a vantagem de ser independente das características de vibração da estrutura, ou seja, não é necessário conhecimento prévio do comportamento oscilatório do sistema. Lallart et al. (2009) mostram que a atenuação de vibração é inversamente proporcional ao valor de $n$. Assim, a atenuação da vibração utilizando o controlador BSDS é menor do que a atenuação causada por um controlador SSDS. Para melhorar o desempenho do BSDS, os autores propõem um outro tipo de controlador que utiliza uma fonte de tensão externa para complementar a saída elétrica (controlador BSDV - Blind Switch Damping on Voltage Source), semelhante ao controlador SSDV (conceito explicado a seguir). 


\subsubsection{Controle Semiativo}

O controlador semiativo é bem semelhante ao controlador SSDI, com a exceção de que ele utiliza fonte de tensão externa aplicada diretamente na piezocerâmica durante curtos períodos de tempo (Fig. 9) para complementar a inversão da tensão elétrica. Conhecido como Synchronized Switch Damping on Voltage (SSDV), essa técnica visa ampliar artificialmente o acoplamento eletromecânico já que as perdas na inversão presentes no SSDI são complementadas artificialmente e a inversão da tensão elétrica passa a ser completa.

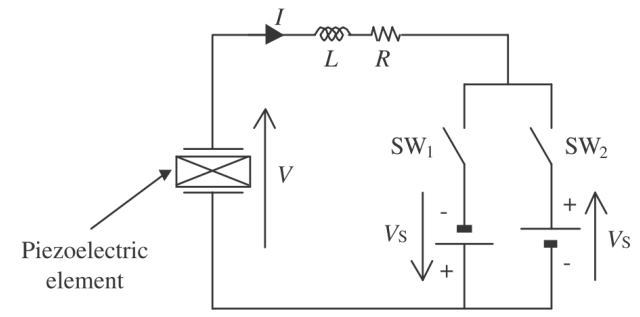

Figura 9 - Circuito elétrico SSDV. (Lefeuvre et al. (2006)).

A chave $S W_{1}$ (Fig. 9) é ligada quando um pico positivo na tensão elétrica for identificado. Nesse ponto, haverá a inversão quase instantânea da tensão elétrica por causa do elemento indutivo no circuito. Devido a resistência interna do circuito elétrico, a inversão da tensão não será completa e então haverá uma complementação na tensão elétrica através da fonte de tensão $V_{s}$. Depois a chave é novamente aberta até que o próximo ponto (pico negativo) seja identificado. Quando o ponto mínimo de tensão elétrica for identificado, a chave $S W_{2}$ será fechada e o comportamento da tensão será semelhante, ou seja, ela será invertida quase instantânea e será complementada pela fonte de tensão.

Se a fonte de tensão aplicada nas piezocerâmicas for constante, o sistema pode se tornar instável a medida que a amplitude das oscilações forem diminuindo, pois a oscilação mecânica diminuirá a ponto de inverter o comportamento do sistema, ou seja, ao invés de atenuar as vibrações, a tensão extra no sistema poderá excitar a estrutura. Uma solução para esse problema é controlar a quantidade de tensão aplicada ao sistema, afim de que ela seja proporcional a tensão de saída das piezocerâmicas. Para isso, pode ser utilizada uma outra piezocerâmica para gerar uma tensão proporcional a vibração presente, assim, se a amplitude de vibração diminuir com o passar do tempo, a fonte de tensão externa do circuito SSDV (tensão gerada por outra piezocerâmica) também diminuirá proporcionalmente, evitando a instabilidade do sistema. 


\subsection{Utilização de Materiais Inteligentes em Asas Rota- tivas}

O desenvolvimento de sistemas de controle de vibrações para helicópteros tem recebido grande atenção da comunidade científica nas últimas décadas. Conforme apresentado em Feszty e Nitzsche (2011), estes controladores podem ser ativos ou passivos. Os controladores passivos representam os sistemas atualmente em uso na indústria. Estes sistemas são absorvedores (tipo massa-mola) e possuem a vantagem de serem simples. Entretanto, sua faixa de aplicação é restrita, ou seja, funcionam adequadamente para uma condição de vôo em específico. Por outro lado, os controladores ativos podem se adaptar a diferentes condições de vôo e atenuar condições indesejadas em quase todo o envelope de vôo do helicóptero.
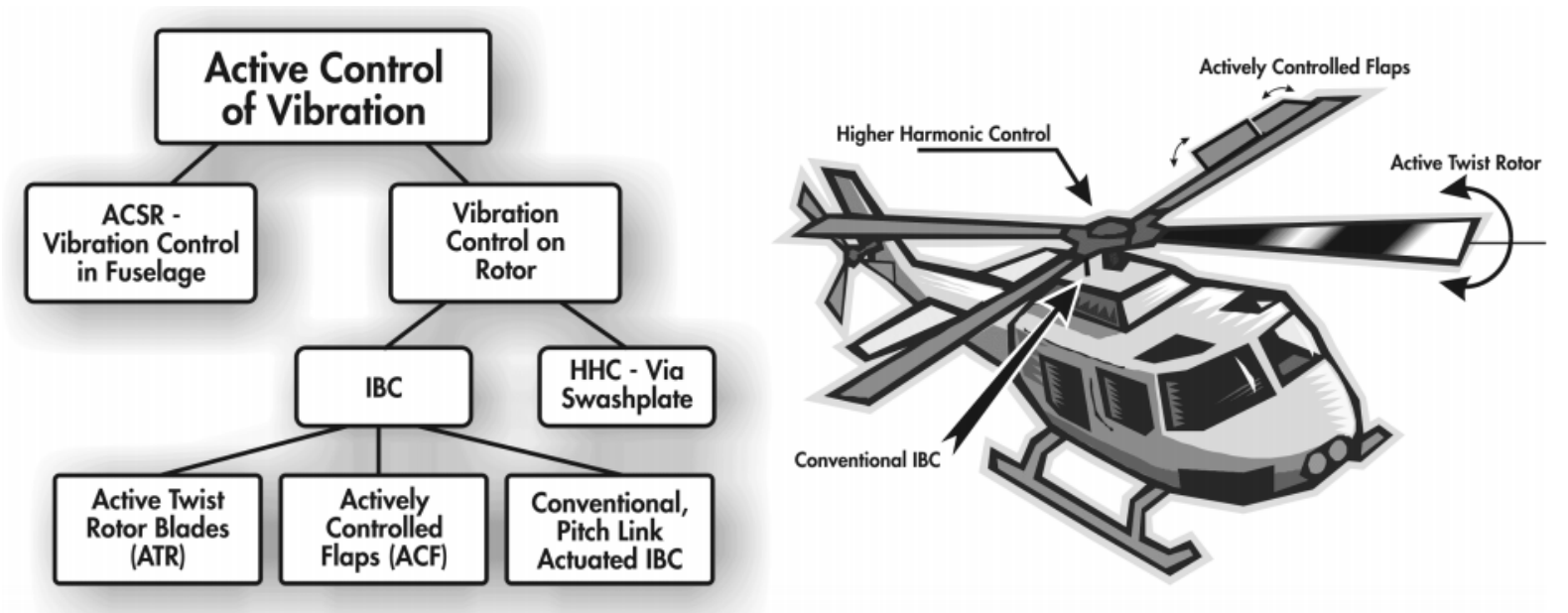

Figura 10 - Resumo de técnicas de controle ativo em helicópteros. (Patt et al. (2004)).

Esse controladores ativos podem ser classificados em duas categorias (Fig. 10): a) controladores ativos localizados no rotor para atenuação de vibração antes de se propagar até a fuselagem e b) controladores ativos localizados diretamente na fuselagem (ACSR - Active Control of Structural Response). No caso de controladores na fuselagem, sua função é aliviar vibrações na cabine e aumentar conforto no vôo (Hanagud e Babu (1994)). Entretanto, as fontes de vibrações (rotor e pás) continuam presentes. Assim, julga-se que o controle realizado nas pás (ou no rotor) pode ser mais eficiente por tratar o problema em sua origem.

Duas abordagens se destacam em relação aos controladores ativos localizados diretamente no rotor: a) HHC (Higher Harmonic Control), onde as pás são controladas com a alteração do passo através da swash plate (prato oscilante) e b) IBC (Individual Blade Control), onde as pás são controladas individualmente e independentes da swash plate. 
Essa última, IBC, pode ser classificada basicamente em quatro tipos: ACF, ATR, ACT e APL. No ACF (Active Controlled Flap), os flapes de bordo de fuga são utilizados para o controle de vibrações e ruído. Estes flapes podem ser acionados por diferentes materiais inteligentes. Em alguns casos eles podem ser eletromecânicos, ou acionados por sistemas piezelétricos, como em Spangler (1989), Barrett (1990), Fabunmi (1991); em outros sistemas baseados em magnetoestricção (Bushko et al. (1996)) ou em ligas com memória de forma (Straub et al. (2004)). No ATR (Active Twist Rotor), os materiais inteligentes são distribuídos ao longo da pá para o controle ativo de vibrações (Cesnik e Shin (2001), Wall et al. (2008)). No ACT (Active Controlled Tip), o intuito é modificar a geometria na ponta da pá para a redução de ruído e vibrações (Nitzsche et al. (2005)). E no APL (Active Pitch Link), o princípio consiste no controle de rigidez na região da raiz da pá.

Nitzsche e Breitbach (1992) demonstraram numérica e experimentalmente que o controle de vibrações no caso da APL deve ser entendido como controle de rigidez na região da raiz da pá, ou seja, a variação periódica da rigidez na região da raiz da pá pode levar a uma redução significativa do nível de vibração. Esta tecnologia foi realizada através da smart spring (mola inteligente) desenvolvida e patenteada por Nitzsche e Feszty (2009).

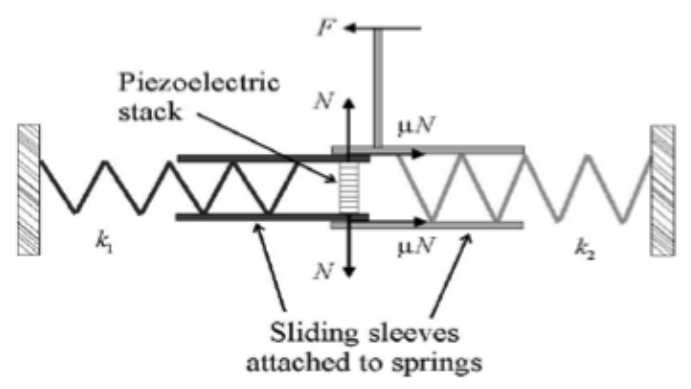

Figura 11 - Representação do princípio da smart spring. (Fred Nitzsche).

Ela envolve conceitos como a associação de molas, atrito e atuadores piezelétricos. $\mathrm{Na}$ prática as molas estão alinhadas com a direção do eixo do rotor enquanto que o atuador piezelétrico (um piezo-stack, no caso) normal às mesmas. Quando o atuador piezelétrico é acionado (através de uma tensão elétrica de entrada), ele se expande e acopla as molas e a rigidez equivalente total passa a ser a associação das duas molas $\mathrm{k} 1+\mathrm{k} 2$, consequentemente, aumentando a rigidez total do sistema. Quando o atuador não é acionado, as molas não estão acopladas e a rigidez do sistema é somente k2. Ensaios experimentais com a Smart Spring foram recentemente realizados na whirl tower da Carleton University, no Canadá. O sistema possibilitou a atenuação de um harmônico de N/rev específico, no caso, $2 /$ rev já que um rotor de 1 pá estava sendo testado na whirl tower, como mostra a Fig. 12 . 


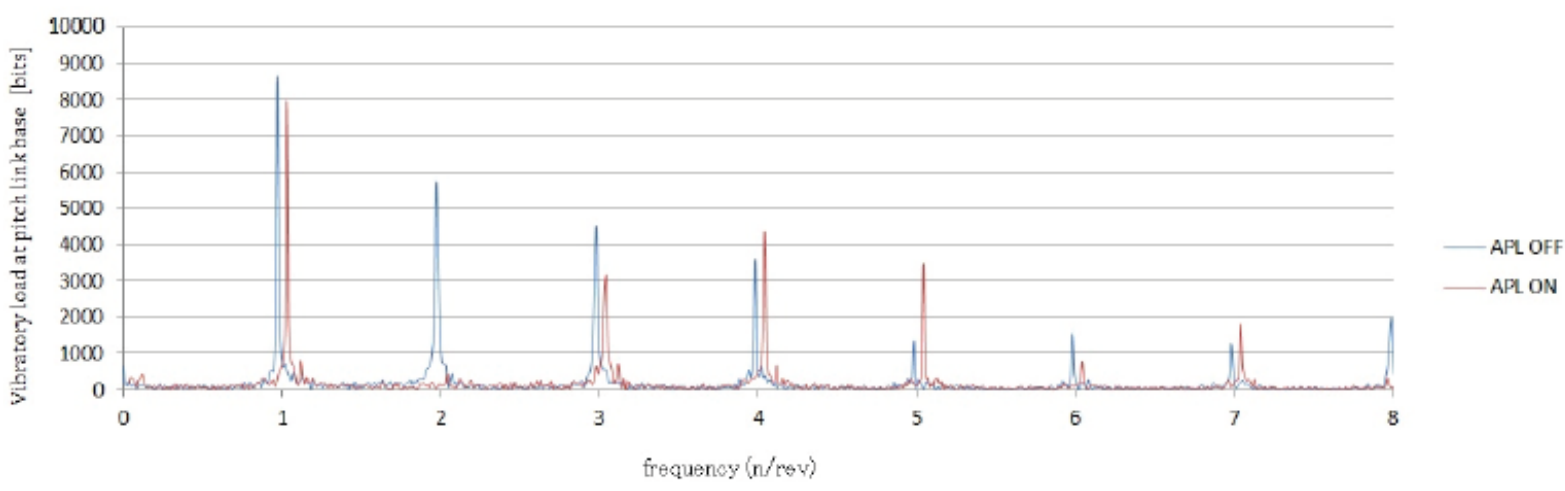

Figura 12 - Atenuação da frequência 2/rev usando o APL. (Fred Nitzsche).

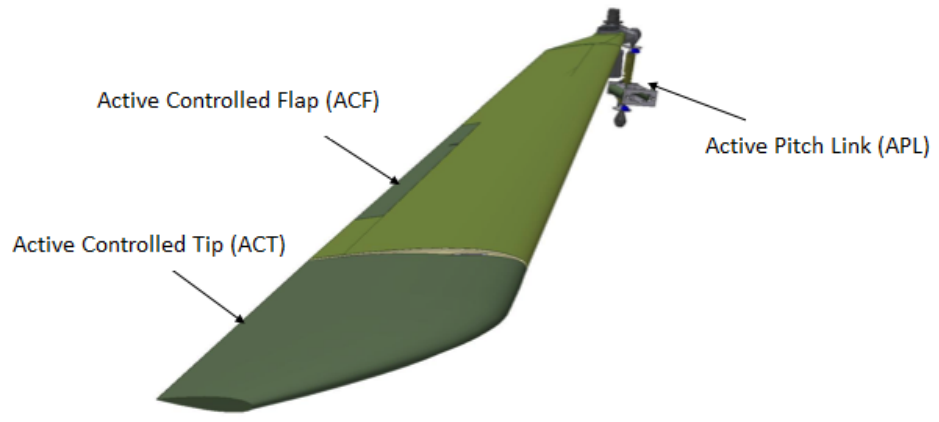

Figura 13 - Associação de um controlador do tipo ACT, outro ACF e um APL representando o controle híbrido. (Fred Nitzsche).

Em Kloeppel e Enenkl (2005) demonstra-se que, isoladamente, um dos quatro sistemas anteriormente apresentados dificilmente será capaz de controlar diferentes fenômenos simultaneamente. Por exemplo, os autores citam que para um rotor com quatro pás, um sinal de controle na frequência $2 /$ rev deveria ser aplicado para o controle de vibrações induzidas pela interação das pás com vórtices induzidos na passagem de outras pás (BVI - Blade Vortex Interaction). Por outro lado, frequências entre 3/rev e 5/rev seriam necessárias para reduzir vibrações em cabine. Assim, uma única forma de controle (ACF, ATR, ACT e APL) não seria capaz de atenuar dois fenômenos simultaneamente. Em alguns casos (Kloeppel e Enenkl (2005)) os autores mostram que o controle de um fenômeno implicaria em deterioração do outro.

Uma alternativa investigada é a possibilidade de controle híbrido, onde dois ou mais tipos de controle independentes seriam utilizados em uma única pá (Feszty et al. (2009)). Os autores propõe um controlador do tipo ACT e outro ACF, ou seja, um para modificar a ponta da pá e conseqüentemente o desprendimento de vórtices (acionados com liga com memória de forma) e outro um flape de bordo de fuga para controle de carregamento, associados com um APL (Fig. 13). Assim, os dois primeiros são relacionados ao escoamento (controle de escoamento) e o terceiro relacionado ao controle de vibrações na estrutura. 


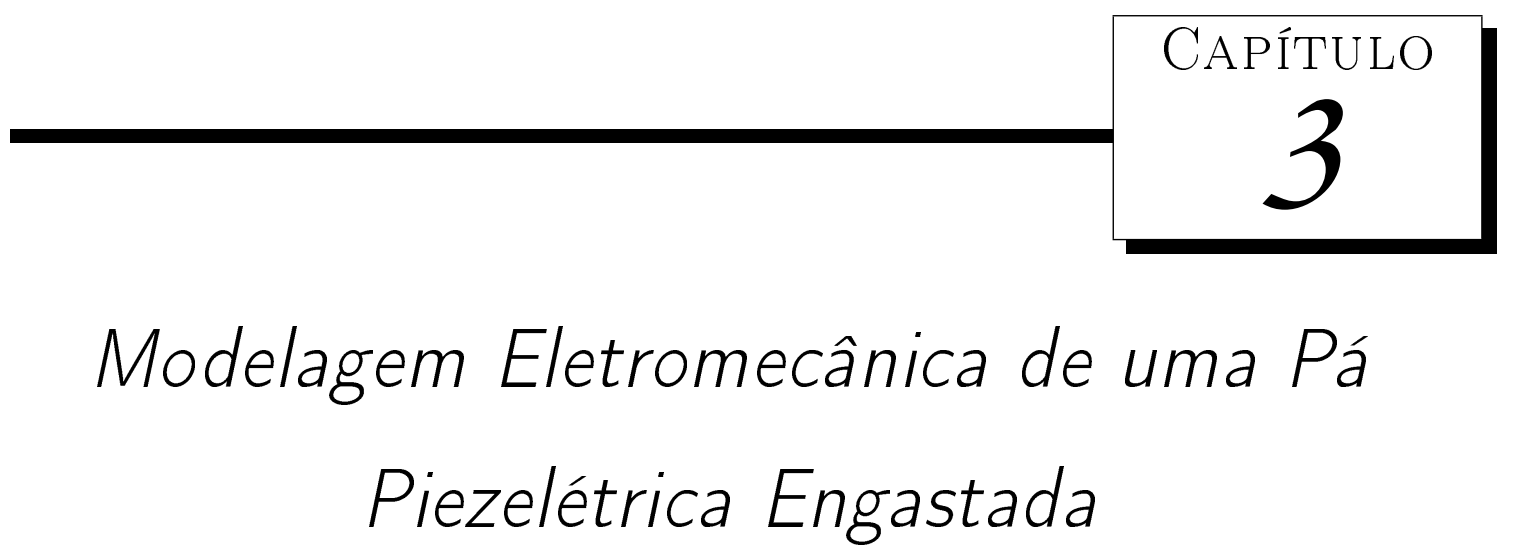

$\mathrm{E}$ ste capítulo aborda a modelagem de uma pá de helicóptero como uma viga elástica rotativa, engastada em uma de suas extremidades e dotada de piezocerâmicas na região da raiz para conversão piezelétrica de energia. No primeiro momento, a modelagem da pá não levará em conta o material piezelétrico, o qual será inserido posteriormente no modelo numérico. O modelo eletromecânico não linear da pá piezelétrica é baseado no Variational-Asymptotic Method (VAM). Devido a possibilidade de incluir o material piezelétrico, o Variational Asymptotic Beam Section (VABS) é utilizado também como ferramenta na modelagem.

\subsection{Modelagem de uma Viga Elástica Rotativa}

A modelagem de uma pá de helicóptero considerando pequenas deformações lineares é obtida a partir do método VAM proposto por Hodges (1990) para modelagem de vigas compósitas em rotação. O VAM é uma representação geométrica exata não linear de uma viga elástica rotativa, descrita como um sistema dinâmico não linear de equações algébricas diferenciais mista de primeira ordem. O termo "geometricamente exato" se refere a representação das grandes deformações angulares. Para representação dessa geometria exata e inclusão de material piezelétrico (Sec. 3.2), o VABS usa o conceito de rotações finitas virtuais.

Para modelagem completa da pá, quatro diferentes sistemas de referência são utilizados, $I$ é o sistema de referência inercial, $a$ é o sistema de referência associado com o centro de rotação do rotor, seu movimento é descrito como a rotação em torno do eixo z do 
sistema de referência inercial, $b$ é o sistema de coordenadas fixado na viga não deformada e $B$ é o sistema de coordenadas fixado na viga deformada (Fig. 14).

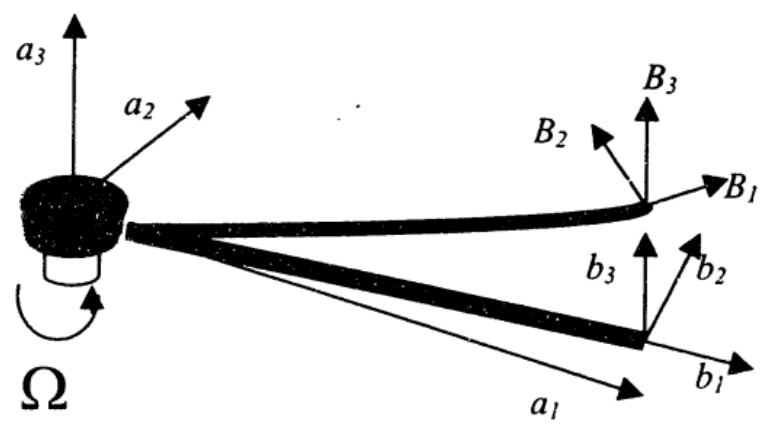

Figura 14 - Sistemas de referência de uma viga rotativa (Cheng (2002)).

A representação da energia virtual é baseada no Hamilton Weak Principle (HWP) (Borri et al. (1985)), que pode ser descrito como,

$$
\delta U=\int_{t_{1}}^{t_{2}} \int_{0}^{l}[\delta E+\delta W] d x d t-\delta A=0
$$

onde $t_{1}$ e $t_{2}$ são tempos fixados arbitrariamente, $\delta E$ é a energia interna virtual, $\delta W$ é o trabalho virtual das forças aplicadas e $\delta A$ é a medida virtual na ponta da viga e no fim do intervalo de tempo.

A energia virtual interna é descrita como,

$$
\delta E=F^{*} \delta \gamma^{*}+M^{*} \delta V^{*}
$$

onde $F^{*}$ é o vetor de forças e momentos, $\delta \gamma^{*}$ é o vetor de deformação e curvatura virtual generalizado, $M^{*}$ é o vetor de momentos angular e linear e $\delta V^{*}$ é o vetor de velocidades angular e linear. O primeiro termo do lado direito da Eq. 3.2 é relacionado a energia potencial do sistema e o segundo termo é relacionado a energia cinética.

Segundo Hodges (1990), as derivadas parciais da energia potencial e da energia cinética são

$$
\begin{aligned}
& F_{B}=\left(\frac{\partial U}{\partial \gamma}\right)^{T}, M_{B}=\left(\frac{\partial U}{\partial \kappa}\right)^{T} \\
& P_{B}=\left(\frac{\partial K}{\partial V_{B}}\right)^{T}, H_{B}=\left(\frac{\partial K}{\partial \Omega_{B}}\right)^{T}
\end{aligned}
$$

onde $K$ é a energia cinética, $U$ é a energia potencial, $\gamma$ é o vetor coluna de deformações e $\kappa$ é o vetor coluna de curvaturas, $V_{B}$ é o vetor coluna de velocidade linear, $\Omega_{B}$ é o vetor coluna de velocidade angular, $F_{B}$ é o vetor coluna de força interna, $M_{B}$ é o vetor coluna de momento interno, $P_{B}$ é o vetor coluna de momento linear e $H_{B}$ é o vetor coluna 
de momento angular. O subscrito B significa que a unidade foi medida no sistema de referência B. O primeiro elemento do vetor $F_{B}$ é a força axial e o segundo e terceiro elementos são as forças de cisalhamento. O primeiro elemento do vetor $M_{B}$ é o momento de torção e o segundo e terceiro elementos são momentos de flexão.

A partir das derivadas parciais da energia interna, é possível identificar as equações constitutivas mecânicas,

$$
\left\{\begin{array}{l}
F \\
M
\end{array}\right\}=\left[\begin{array}{ll}
A & B \\
B & D
\end{array}\right]\left\{\begin{array}{l}
\gamma \\
\kappa
\end{array}\right\}
$$

e as relações velocidade-momento,

$$
\left\{\begin{array}{l}
P \\
H
\end{array}\right\}=\left[\begin{array}{ll}
m & S \\
S & I
\end{array}\right]\left\{\begin{array}{l}
V \\
\Omega
\end{array}\right\}
$$

onde $F$ é o vetor de forças, $M$ é o vetor de momentos, $A$ é a matriz de rigidez no plano de rotação, $B$ é a matriz de rigidez de acoplamento no plano de rotação e fora do plano de rotação, $D$ é a matriz de rigidez fora do plano de rotação, $P$ é o vetor de momento linear, $H$ é o vetor de momento angular, $m$ é a matriz de massa, $S$ é o primeiro momento de massa, $I$ é a matriz de inércia, $V$ é o vetor de velocidade linear e $\Omega$ é o vetor de velocidade angular.

Cada variável está associada a um sistema de referência. Na modelagem da pá abordado nesse trabalho, todas as variáveis serão descritas no sistema de coordenadas $a$. As variáveis que não estão descritas originalmente em $a$, serão rotacionadas de um sistema de referência para outro. O VABS não considera aproximações ou truncamentos. Assim, as equações não lineares são capazes de lidar com grandes deslocamentos, resultado nas seguintes expressões de deformação, curvatura e velocidades linear e angular (Shang, Hodges e Peters (1999)),

$$
\begin{gathered}
\gamma=C^{B a}\left(C^{b a} e_{1}+u_{a}^{\prime}\right)-e_{1} \\
\kappa=C^{b a}\left(\frac{\Delta-\frac{\tilde{\theta}}{2}}{1+\frac{\theta^{T} \theta}{4}}\right) \theta^{\prime} \\
V_{B}=C^{B a}\left(\nu_{a}+\dot{u}_{a}+\tilde{\omega}_{a} u_{a}\right) \\
\Omega_{B}=C^{b a}\left(\frac{\Delta-\frac{\tilde{\theta}}{2}}{1+\frac{\theta^{T} \theta}{4}}\right) \dot{\theta}+C^{B a} \omega_{a}
\end{gathered}
$$

onde $u_{a}$ é o deslocamento, $\omega_{a}$ é a velocidade angular, $\theta$ é o ângulo de orientação, $\nu_{a}$ é a velocidade linear, $e_{1}$ é o vetor unitário, $C^{B a}$ é a matriz de rotação do sistema de referência 
$a$ para $B, C^{b a}$ é a matriz de rotação do sistema de referência $a$ para $b$ e $B$ é a matriz identidade de ordem 3. O sobre-ponto em algumas variáveis representa a diferenciação delas com o respectivo tempo, a aspa simples representa a diferenciação ao longo da envergadura e o til representa a operação entre produtos.

A matriz de rotação $C=C^{a b} C^{B a}$ é expressada em termos de $\theta$ como,

$$
C=\frac{\left(1-\frac{\theta^{T} \theta}{4}\right) \Delta-\tilde{\theta}+\frac{\theta \theta^{T}}{2}}{1+\frac{\theta^{T} \theta}{4}}
$$

onde $\tilde{\theta}$ é igual a

$$
\tilde{\theta}=\left[\begin{array}{ccc}
0 & -\theta_{3} & \theta_{2} \\
\theta_{3} & 0 & -\theta_{1} \\
-\theta_{2} & \theta_{1} & 0
\end{array}\right]
$$

A medida virtual na ponta da viga e no fim de um intervalo de tempo $\delta A$ (Eq. 3.1) é o trabalho realizado pela condição de contorno e de acordo com o HWP deve ser contabilizado na somatória da energia virtual. O trabalho no contorno é devido ao efeito da ponta da viga contra a presença de forças e momentos concentrados,

$$
\delta A=\left|\delta q^{T} \hat{F}+\delta \Psi^{T} \hat{M}-\delta F^{T} \hat{u}-\delta M^{T} \hat{\theta}\right|_{0}^{l}
$$

onde $\delta q^{T}$ é o vetor de deslocamento virtual, $\hat{F}$ é o vetor força, $\delta \Psi^{T}$ é o vetor rotação finita virtual, $\hat{M}$ é o vetor momento, $u$ é o vetor deslocamento, $F^{T}$ é o vetor força virtual, $\delta M^{T}$ é o vetor momento virtual e $\hat{\theta}$ é o vetor de ângulos de orientação.

A deformação e a curvatura (Eqs. 3.6 e 3.7) geralmente são representados como um conjunto de polinômios que apresentam termos de deslocamento linear e orientação angular, levando a relações pesadas indesejáveis, que requerem a truncagem na representação dos termos de alta ordem geométrica (Hodges (1990)). Nesse caso, os multiplicadores de Lagrange são utilizados para transformar as relações cinemáticas em um conjunto de equações restritas com a utilização de rotações finitas virtuais. Uma relação simples é obtida e as características não-lineares geometricamente exatas do sistema são preservadas. No entanto, novas equações algébricas são adicionadas às equações diferenciais originais, levando a um sistema de equações algébricas diferenciais. Assim, a utilização de métodos numéricos de dissipação de alta frequência devem ser utilizados para obter uma solução estável para esse sistema rígido (Bauchau e Theron (1996)).

Utilizando os multiplicadores de Lagrange, as equações de energia interna são obtidas baseadas no HWP. As equações de energia interna são integradas espacialmente utilizando 
o método de elementos finitos. Essa formulação tem a vantagem de garantir a escolha de funções de forma simples para o deslocamento virtual (Hodges (1990)). Desta maneira, a distribuição de variáveis virtuais sobre cada elemento é descrita como uma função linear dos valores nos nós. Após a integração espacial em um elemento simples de viga, as seguintes equações são obtidas,

$$
\begin{gathered}
f_{u_{i}}=-C^{T} C^{a b} F_{i}+\frac{\Delta l}{2} \tilde{\omega}_{a} C^{T} C^{a b} P_{i}+\frac{\Delta l}{2}\left(C^{T} \dot{C}^{a b} P_{i}\right)-f_{i} \\
f_{\psi_{i}}=-C^{T} C^{a b} M_{i}-\frac{\Delta l}{2} C^{T} C^{a b}\left(\tilde{e}_{1}+\tilde{\gamma}_{1}\right) F_{i}+\frac{\Delta l}{2}\left(\tilde{\omega}_{a} C^{T} C^{a b} H_{i}\right) \\
+\frac{\Delta l}{2}\left(C^{T} \dot{C}^{a b} H_{i}\right)+\frac{\Delta l}{2} \tilde{\omega} \tilde{u} P+\frac{\Delta l}{2} \tilde{u}\left(C^{T} \dot{C}^{a b} P_{i}\right)-m_{1} \\
f_{F_{1}}=u_{i}-\frac{\Delta l_{i}}{2}\left(C^{T} C^{a b}\left(e_{1}+\gamma_{i}\right)-C^{a b} e_{1}\right) \\
f_{M_{1}}=\theta_{i}-\frac{\Delta l_{i}}{2}\left(\Delta+\frac{\tilde{\theta}_{i}}{2}+\frac{\theta_{i} \theta_{i}^{T}}{4}\right) C^{a b} \kappa_{i} \\
f_{P_{i}}=C^{T} C^{a b} V_{i}-v_{a}-\tilde{\omega}_{a}\left(u_{i}+d_{i}\right)-\dot{u}_{i} \\
f_{H_{i}}=\Omega_{i}-C^{b a} C \omega_{a}-C^{b a}\left(\frac{\Delta-\frac{\tilde{\theta}_{i}}{2}}{1+\frac{\theta_{i}^{T} \theta_{i}}{4}}\right) \dot{\theta}_{i} \\
=C^{T} C^{a b} F_{i}+\frac{\Delta l}{2} \tilde{\omega}_{a} C^{T} C^{a b} P_{i}+\frac{\Delta l}{2}\left(C^{T} \dot{C}^{a b} P_{i}\right)-f_{i+1} \\
f_{u_{i+1}} C^{T} C^{a b} M_{i}-\frac{\Delta l}{2} C^{T} C^{a b}\left(\tilde{e}_{1}+\tilde{\gamma}_{i}\right) F_{i}+\frac{\Delta l}{2}\left(\tilde{\omega}_{a} C^{T} C^{a b} H_{i}\right) \\
+\frac{\Delta l}{2}\left(C^{T} \dot{C}^{a b} H_{i}\right)+\frac{\Delta l}{2} \tilde{\omega} \tilde{u} P+\frac{\Delta l}{2} \tilde{u}\left(C^{T} \dot{C}^{a b} P_{i}\right)-m_{1+1} \\
f_{F_{i+1}}=-u_{i}-\frac{\Delta l_{i}}{2}\left(C^{T} C^{a b}\left(e_{1}+\gamma_{i}\right)-C^{a b} e_{1}\right) \\
f_{M_{i+1}}=-\theta_{i}-\frac{\Delta l_{i}}{2}\left(\Delta+\frac{\tilde{\theta}_{i}}{2}+\frac{\theta_{i} \theta_{i}^{T}}{4}\right) C^{a b} \kappa_{i}
\end{gathered}
$$

As equações descritas anteriormente são aplicáveis a um simples elemento finito. Mas a modelagem de elementos finitos de uma pá inclui a combinação de vários elemenos finitos e seus nós. Assim, a equação de movimento da pá como um todo é obtida baseando-se em cada coeficiente de variável virtual nodal. As equações que descrevem o movimento mecânico de uma viga são,

$$
\begin{aligned}
& \sum_{i=1}^{N}\left\{\delta u_{i}^{T} f_{u_{i}}+\delta \psi_{i}^{T} f_{\psi_{i}}+\delta F_{i}^{T} f_{F_{i}}+\delta M_{i}^{T} f_{M_{i}}+\delta P_{i}^{T} f_{P_{i}}+\delta H_{i}^{T} f_{H_{i}}+\right. \\
& \left.\delta u_{i+1}^{T} f_{u_{i+1}}+\delta \psi_{i+1}^{T} f_{\psi_{i+1}}+\delta F_{i+1}^{T} f_{F_{i+1}}+\delta M_{i+1}^{T} f_{M_{i+1}}\right\}+ \\
& -\delta u_{N+1}^{T} \hat{F}_{N+1}-\delta \psi_{N+1}^{T} \hat{M}_{N+1}+\delta F_{N+1}^{T} \hat{u}_{N+1}+ \\
& +\delta M_{N+1}^{T} \hat{\theta}_{N+1}+\delta u_{1}^{T} \hat{F}_{1}+\delta \psi_{1}^{T} \hat{M}_{1}-\delta F_{1}^{T} \hat{u}_{1}-\delta M_{1}^{T} \hat{\theta}_{1}=0
\end{aligned}
$$


onde os valores fora dos colchetes são relacionados às condições de contorno da viga e $N$ se refere ao número de discretização total da viga. Para representar uma viga engastadalivre, os deslocamentos linear e angular na região engastada são iguais a zero e a força e o momento na ponta livre da viga são iguais a zero,

$$
\begin{gathered}
\hat{u}_{1}=\hat{\theta}_{1}=0 \\
\hat{F}_{N+1}=\hat{M}_{N+1}=0
\end{gathered}
$$

A Eq. 3.23 pode ser reescrita em notação matricial da seguinte forma

$$
F_{S}(X, \dot{X})-F_{L}=0
$$

onde $F_{S}$ é o operador estrutural, $F_{L}$ é o operador de carga e $X$ é o vetor de variáveis de carga. As variáveis $F_{i}$ e $M_{i}$ são parâmetros de entrada dependentes do tempo e são associados com $F_{S}$. 
As expressões explícitas dos operadores estrutural e de carga são,

$$
F_{S}=\left[\begin{array}{c}
f_{u_{1}}^{(1)}+\hat{F}_{1} \\
f_{\psi_{1}}^{(1)}+\hat{M}_{1} \\
f_{F_{1}}^{(1)}-\hat{u}_{1} \\
f_{M_{1}}^{(1)}-\hat{\theta}_{1} \\
f_{P_{1}}^{(1)} \\
f_{H_{1}}^{(1)} \\
f_{u_{2}}^{(1)}+f_{u_{2}}^{(2)} \\
f_{\psi_{2}}^{(1)}+f_{\psi_{2}}^{(2)} \\
f_{F_{2}}^{(1)}+f_{F_{2}}^{(2)} \\
f_{M_{2}}^{(1)}+f_{M_{2}}^{(2)} \\
f_{P_{2}}^{(2)} \\
f_{H_{2}}^{(2)} \\
f_{u_{3}}^{(2)}+f_{u_{3}}^{(3)} \\
f_{\psi_{3}}^{(2)}+f_{\psi_{3}}^{(3)} \\
f_{F_{3}}^{(2)}+f_{F_{3}}^{(3)} \\
f_{M_{3}}^{(2)}+f_{M_{3}}^{(3)} \\
\vdots \\
f_{u_{N+1}}^{(N)}-\hat{F}_{N+1} \\
f_{\psi_{N+1}}^{(N)}-\hat{M}_{N+1} \\
f_{F_{N+1}}^{(N)}+\hat{u}_{N+1} \\
f_{M_{N+1}}^{(N)}+\hat{\theta}_{N+1}
\end{array}\right], F_{L}=\left[\begin{array}{c}
\bar{f}_{1}^{(1)} \\
\bar{m}_{1}^{(1)} \\
0 \\
0 \\
0 \\
0 \\
f_{2}^{(1)}+f_{2}^{(2)} \\
m_{2}^{(1)}+m_{2}^{(2)} \\
0 \\
0 \\
0 \\
0 \\
f_{3}^{(2)}+f_{3}^{(3)} \\
m_{3}^{(2)}+m_{3}^{(3)} \\
0 \\
0 \\
\vdots \\
f_{N+1}^{(N)} \\
m_{N+1}^{(N)} \\
0 \\
0 \\
\end{array}\right]
$$

onde o sobrescrito indica o número do elemento e o subescrito indica o número do nó. A dimensão de $F_{S}$ e $F_{L}$ é $18 N+12$. Os componentes da variável $X$ dependem das condições de contorno e podem ser organizadas como um vetor

$$
X=\left[\begin{array}{ccccccccc}
\hat{F}_{1}^{T} & \hat{M}_{1}^{T} & u_{1}^{T} & \theta_{1}^{T} & F_{1}^{T} & M_{1}^{T} & P_{1}^{T} & H_{1}^{T} & \cdots \\
& u_{N}^{T} & \theta_{N}^{T} & F_{N}^{T} & M_{N}^{T} & P_{N}^{T} & H_{N}^{T} & \hat{u}_{N+1}^{T} & \hat{\theta}_{N+1}^{T}
\end{array}\right]^{T}
$$

O conjunto de equações do movimento é descrito em sistema diferencial algébrico misto, o que leva a um sistema rígido. Este sistema numérico tem um pólo instável não-físico no infinito. Assim, é necessário a utilização de métodos de dissipação de alta frequência para se obter uma solução estável.

O método generalizado-alfa (Chung e Hulbert (1993)) é usado para adicionar amortecimento em altas freqüências, sem adição de amortecimento considerável para as baixas 
freqüências (relacionados com as frequências do sistema físico). O método é apresentado no Apêndice C.

Depois da discretização em elementos finitos e em espaço de estados (Eq. 3.25), as equações de movimento são discretizadas no tempo utilizando diferenças finitas atrasadas de segunda ordem (método de Euler de segunda ordem),

$$
\begin{aligned}
\dot{P}_{i}^{n} & =\frac{3 P_{i}^{n}-4 P_{i}^{n-1}+P_{i}^{n-2}}{2 \Delta t} \\
\dot{H}_{i}^{n} & =\frac{3 H_{i}^{n}-4 H_{i}^{n-1}+H_{i}^{n-2}}{2 \Delta t} \\
\dot{u}_{i}^{n} & =\frac{3 u_{i}^{n}-4 u_{i}^{n-1}+u_{i}^{n-2}}{2 \Delta t} \\
\dot{\theta}_{i}^{n} & =\frac{3 \theta_{i}^{n}-4 \theta_{i}^{n-1}+\theta_{i}^{n-2}}{2 \Delta t}
\end{aligned}
$$

onde $n$ é o passo de tempo. Os sobrescritos indicam o passo de tempo e os subescritos indicam o número do nó.

Reescrevendo a Eq. 3.25 no passo de tempo n, uma equação algébrica não linear é obtida,

$$
F_{S}\left(X^{n}\right)-F_{L}=0
$$

Para resolver essa equação algébrica não linear, o método de Newton-Raphson (ver Seção 3.3) é utilizado e a matriz Jacobiana pode ser obtida explicitamente como

$$
[J]=\left[\frac{\partial F_{S}}{\partial X}\right]
$$

cujas expressões podem ser conferidas em Cheng (2002) (Apêndice A).

\subsection{Modelagem de uma Viga Elástica Rotativa Pieze- létrica (Pá + Piezo)}

Quando uma viga elástica é dotada de piezocerâmicas, uma contribuição elétrica é inserida na equação de energia interna da viga,

$$
\delta E=F^{*} \delta \gamma^{*}+M^{*} \delta V^{*}+Q \delta V_{p}
$$

onde $Q$ é a carga elétrica e $\delta V_{p}$ é o potencial elétrico. O terceiro termo do lado direito da Eq. 3.31 é relacionado a energia potencial elétrica.

A energia interna pode ser expandida utilizando relações constitutivas lineares para 
o acoplamento eletromecânico,

$$
\left\{\begin{array}{l}
F \\
M \\
Q
\end{array}\right\}=\left[\begin{array}{ccc}
A & B & -k_{1} \\
B & D & -k_{2} \\
k_{1} & k_{2} & C_{p}
\end{array}\right]\left\{\begin{array}{c}
\gamma \\
\kappa \\
V_{p}
\end{array}\right\}
$$

onde $k_{1}$ é o acoplamento eletromecânico linear, $k_{1}$ é o acoplamento eletromecânico de flexão e $C_{p}$ é a capacitância piezelétrica.

Assume-se que a componente do campo elétrico é uniforme no sentido da espessura e que o potencial elétrico varia linearmente entre o par de eletrodos.

Baseado no HWP, as novas equações de energia interna são também obtidas utilizando os multiplicadores de Lagrange e integrando espacialmente através do método de elementos finitos. O conjunto de equações obtidas para um elemento simples de viga (Eqs. 3.13 - 3.22) é acrescido da equação elétrica do elemento simples piezelétrico,

$$
f_{V_{\text {olt }}}=\frac{\Delta l}{2}\left(C_{p_{i}} V_{p_{i}}+\left[\begin{array}{ll}
k_{1_{i}} & k_{2_{i}}
\end{array}\right]\left[\begin{array}{c}
\gamma_{i} \\
\kappa_{i}
\end{array}\right]\right)+q_{i}
$$

Assim, as equações de movimento de uma pá piezelétrica engastada e eletromecânicamente acoplada são

$$
\begin{aligned}
& \sum_{i=1}^{N}\left\{\delta u_{i}^{T} f_{u_{i}}+\delta \psi_{i}^{T} f_{\psi_{i}}+\delta F_{i}^{T} f_{F_{i}}+\delta M_{i}^{T} f_{M_{i}}+\delta P_{i}^{T} f_{P_{i}}+\delta H_{i}^{T} f_{H_{i}}+\right. \\
& \left.\delta u_{i+1}^{T} f_{u_{i+1}}+\delta \psi_{i+1}^{T} f_{\psi_{i+1}}+\delta F_{i+1}^{T} f_{F_{i+1}}+\delta M_{i+1}^{T} f_{M_{i+1}}\right\}+ \\
& +\sum_{j=1}^{N_{1}}\left\{\delta V_{p_{j}} f_{V o l t}\right\}-\delta u_{N+1}^{T} \hat{F}_{N+1}-\delta \psi_{N+1}^{T} \hat{M}_{N+1}+\delta F_{N+1}^{T} \hat{u}_{N+1}+ \\
& +\delta M_{N+1}^{T} \hat{\theta}_{N+1}+\delta u_{1}^{T} \hat{F}_{1}+\delta \psi_{1}^{T} \hat{M}_{1}-\delta F_{1}^{T} \hat{u}_{1}-\delta M_{1}^{T} \hat{\theta}_{1}=0
\end{aligned}
$$

onde $N_{1}$ se ao número de discretização total do piezelétrico.

A Eq. 3.26 é acrescida do elemento $f_{V o l t}$ referente a tensão elétrica do piezelétrico e o vetor $X$ (Eq. 3.27) também possui um elemento a mais, a tensão elétrica $V_{p}$.

Considera-se que a piezocerâmica é montada com eletrodos condutivos contínuos. Então é possível assumir que a modelagem de elementos finitos de uma piezocerâmica tem a mesma saída elétrica. 
Derivando no tempo a equação elétrica (Eq. 3.32),

$$
C_{P} \dot{V}_{P}+\sum_{i=1}^{N_{1}}\left(\left[\begin{array}{ll}
k_{1_{i}} & k_{2_{i}}
\end{array}\right]\left\{\begin{array}{c}
\dot{\gamma}_{i} \\
\dot{\kappa}_{i}
\end{array}\right\}\right)=-I
$$

onde $I$ é a corrente elétrica, a capacitância piezelétrica equivalente é

$$
C_{P}=\sum_{i=1}^{N_{1}} C_{p_{i}}
$$

e o vetor acoplamento eletromecânico é

$$
\sum_{i=1}^{N_{1}}\left(\left[\begin{array}{ll}
k_{1_{i}} & k_{2_{i}}
\end{array}\right]\left\{\begin{array}{c}
\dot{\gamma}_{i} \\
\dot{\kappa}_{i}
\end{array}\right\}\right)
$$

Quando uma resistência é considerada no domínio elétrico tem-se

$$
C_{P} \dot{V}_{P}+\sum_{i=1}^{N_{1}}\left(\left[\begin{array}{ll}
k_{1_{i}} & k_{2_{i}}
\end{array}\right]\left\{\begin{array}{c}
\dot{\gamma}_{i} \\
\dot{\kappa}_{i}
\end{array}\right\}\right)+\frac{V_{P}}{R}=0
$$

\subsection{Fluxograma de Solução}

A Fig. 15 apresenta um fluxograma do processo de solução da análise estrutural da pá piezelétrica.

O primeiro bloco contém as entradas do sistema, como por exemplo, as dimensões e a velocidade de rotação da pá, o passo de tempo para integração e as propriedades do material (pá e piezelétrico). As forças externas aplicadas a pá são funções que dependem do tempo. Após as entradas, o método de solução definirá o vetor de variáveis $X$ e passará para o processo de integração numérica no tempo.

Para cada passo de tempo, o Método de Newton-Raphson é utilizado para resolver a equação não linear de movimento da pá. Primeiramente, as forças externas aplicada no passo de tempo atual são lidas e depois a velocidade inicial, a matriz de rotação $C^{a b}$ e as forças atuantes para cada elemento finito da pá são definidos. Então, o método de Newton-Raphson é utilizado para resolver a equação não linear, como mostra a Fig. 16.

No método de solução Newton-Raphson, a matriz Jacobiana é calculada para a solução de um sistema linear. $O$ valor do vetor $X$ é corrigido até que o erro seja menor que um valor pré-estabelecido, afim de convergir a solução. O valor pré-estabelecido nesse trabalho foi de 0,003, ou seja, o erro na análise de convergência deveria ser menor do que 0,003 . 


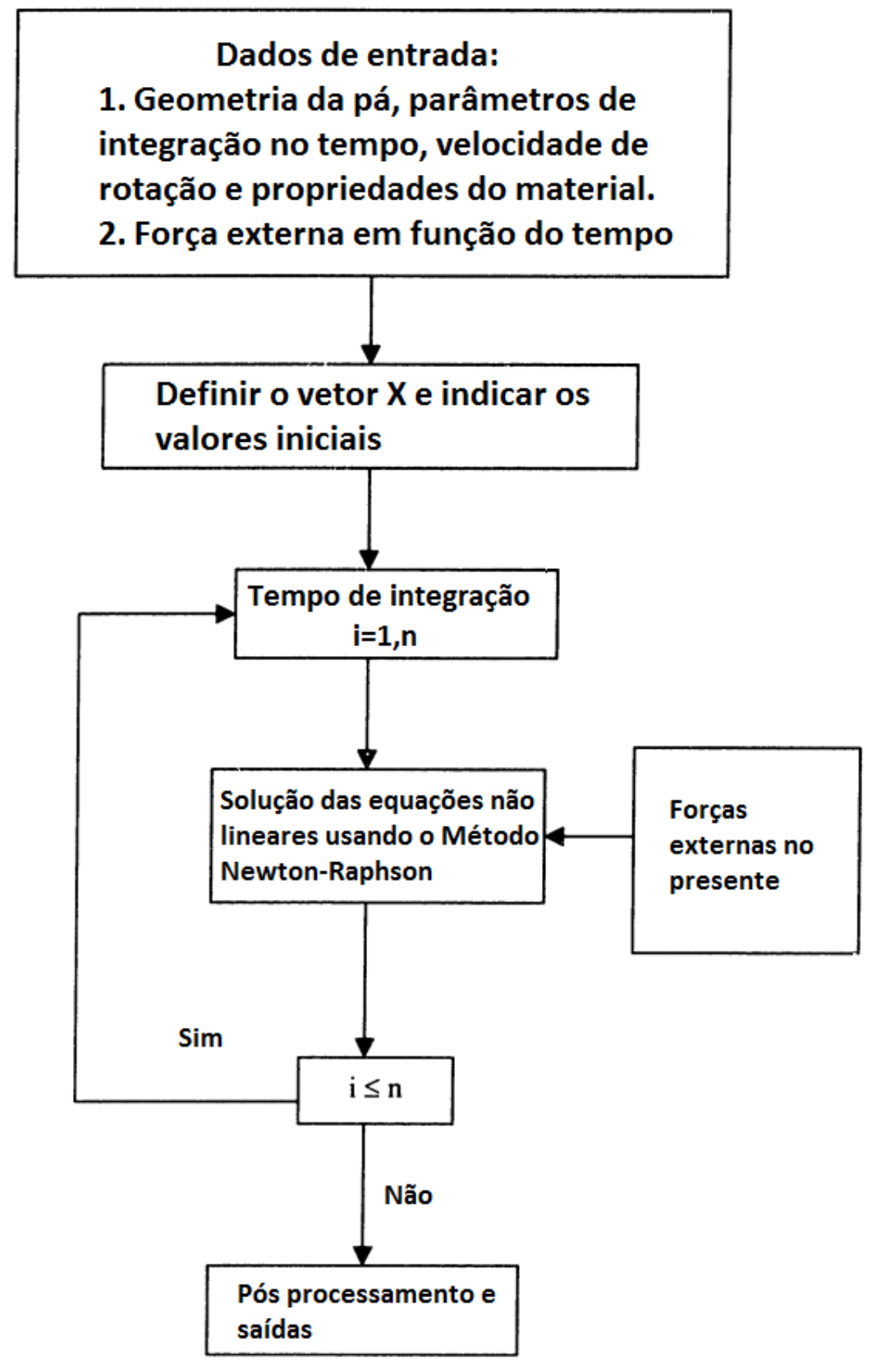

Figura 15 - Fluxograma do processo de solução para a análise estrutural da pá (Cheng (2002)).

Após a análise de convergência, o valor de $X$ é salvo para o passo de tempo atual e uma nova integração numérica no tempo é realizada.

O último bloco da Fig. 15 refere-se ao pós-processamento da solução e às repostas do sistema. 


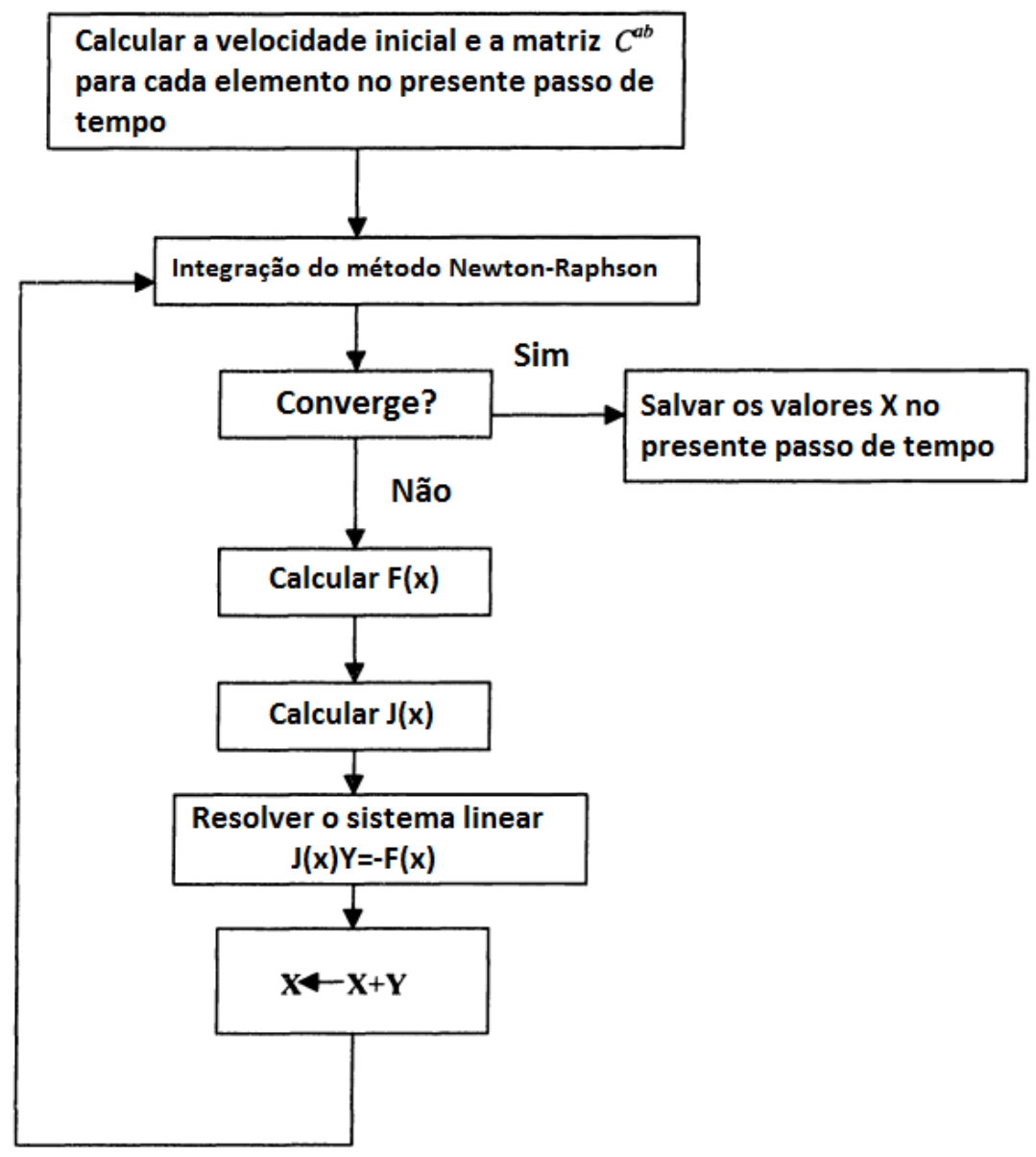

Figura 16 - Fluxograma do método de solução Newton-Raphson (Cheng (2002)). 


\section{CAPÍTULO \\ 4 \\ Resultados Numéricos de uma Pá Piezelétrica \\ Engastada}

E

ste capítulo aborda a simulação numérica de uma pá piezelétrica engastada, onde

os eletrodos do material piezelétrico são conectados a diversos controladores. Os circuitos dos controladores são considerados como ideais, sem atrasos (sem resistências internas), pois a troca de resistores é feita sem considerar um circuito chaveador externo. Os pontos de máximo e mínimo foram identificados e o valor da resistência foi alterado para simular as condições de contorno de curto circuito e circuito aberto, não sendo necessário o uso de um circuito chaveador externo.

Primeiramente, a verificação do modelo numérico utilizado é feita utilizando os resultados apresentados em Cheng (2002) para uma pá sem rotação. Após a verificação do método numérico utilizado, novas simulações foram realizadas utilizando um controlador resistivo puro e posteriormente os controladores semipassivos SSDS e BSDS para atenuação de vibração.

Em seguida, são apresentados alguns resultados das simulações que mostram o funcionamento dos métodos de controle de vibração em uma pá piezelétrica engastada.

\subsection{Verificação do Método Numérico}

O método numérico foi desenvolvido de acordo com a modelagem apresentada nas Seções 3.1 a 3.3 no ambiente do MATLAB e foi verificado com o caso dinâmico 1 apresentado em Cheng (2002). O caso dinâmico 1 consiste de uma viga não rotativa submetida a diversas forças dinâmicas ao longo da direção $a_{3}$, como mostra a Fig. 17. As propriedades 
do material são descritas na Tab. 1.

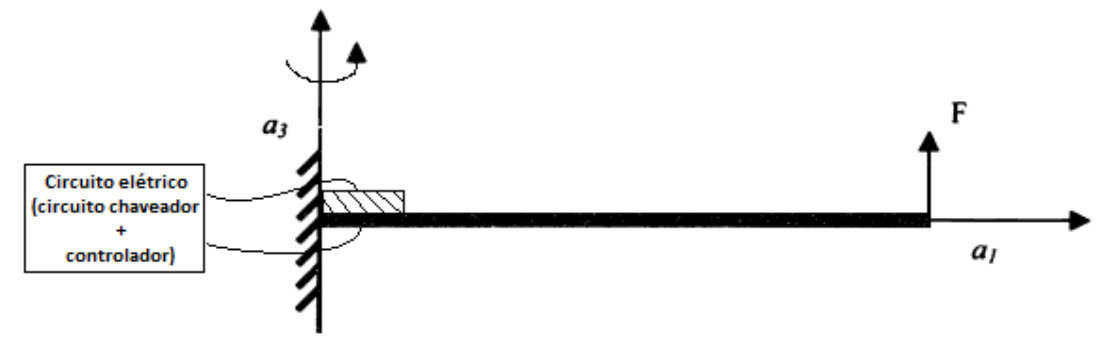

Figura 17 - Modelo da pá piezelétrica.

Tabela 1 - Propriedades do material apresentadas em Cheng (2002)

\begin{tabular}{cl}
\hline Massa por unidade de comprimento $[\mathrm{kg} / \mathrm{m}]$ & 0.2 \\
Comprimento da viga $[\mathrm{m}]$ & 1. \\
$I_{x x}[\mathrm{kgm}]$ & $1.0 * 10^{-4}$ \\
$I_{y y}[\mathrm{kgm}]$ & $1.0 * 10^{-6}$ \\
$I_{z z}[\mathrm{kgm}]$ & $1.0 * 10^{-4}$ \\
$K_{11}[\mathrm{~N}]$ & $1.0 * 10^{6}$ \\
$K_{22}[\mathrm{~N}]$ & $1.0 * 10^{20}$ \\
$K_{33}[\mathrm{~N}]$ & $1.0 * 10^{20}$ \\
$K_{44}[\mathrm{~N}]$ & 50. \\
$K_{55}[\mathrm{~N}]$ & 50. \\
$K_{66}[\mathrm{~N}]$ & $1.0 * 10^{3}$ \\
\hline
\end{tabular}

A viga apresentada por Cheng não considera uma piezocerâmica no seu domínio físico. Assim, para efeito de verificação, a resistência do circuito elétrico, a capacitância do piezelétrico e o acoplamento elétrico foram considerados iguais ou próximos de zero.

A força de excitação testada foi $10 \sin (55.6 * t)$, sendo que $55.6 \mathrm{rad} / \mathrm{s}$ é a frequência de ressonância da estrutura. A resposta do sistema para esse tipo de excitação pode ser comparada com a resposta do sistema apresentada por Cheng (2002), como mostra a Fig. 18.

Na Fig. 18(e), a tensão elétrica é nula, demonstrando que não houve influência do elemento piezelétrico na resposta. Comparando as respostas de deslocamentos linear e angular do modelo numérico desenvolvido com os resultados apresentados por Cheng (2002), pode-se afirmar que o modelo numérico desenvolvido consegue prever a resposta de uma pá piezelétrica engastada eletromecanicamente acoplada, com um erro de frequência de oscilação menor que $15 \%$. 


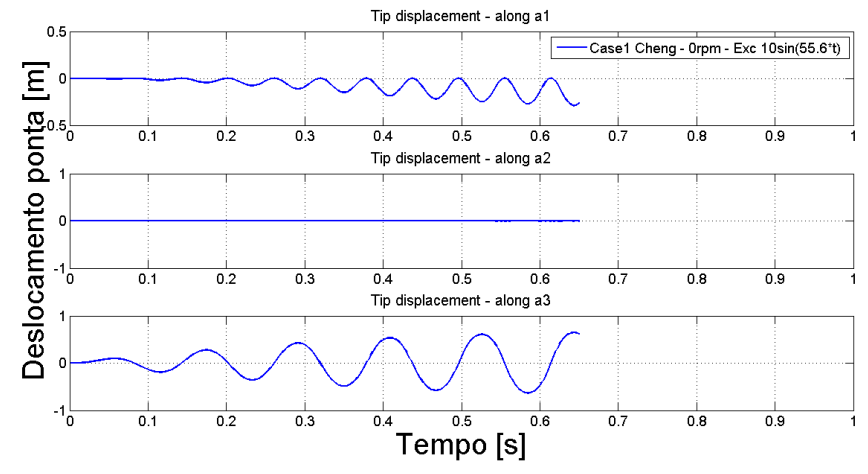

(a)

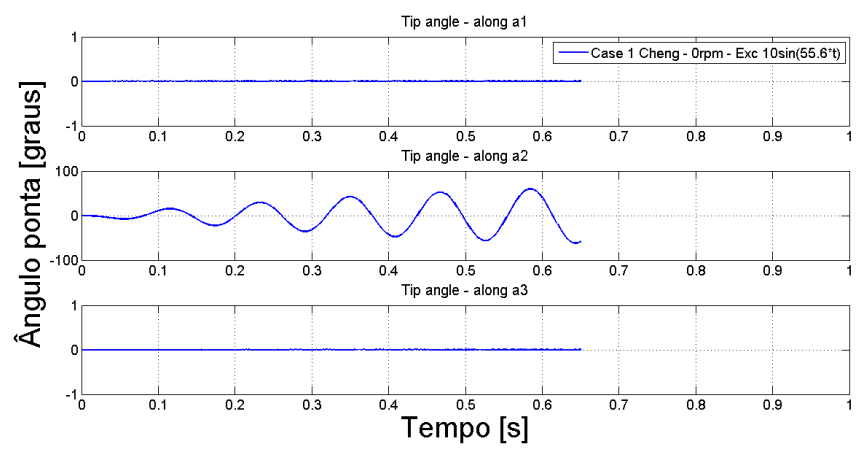

(c)

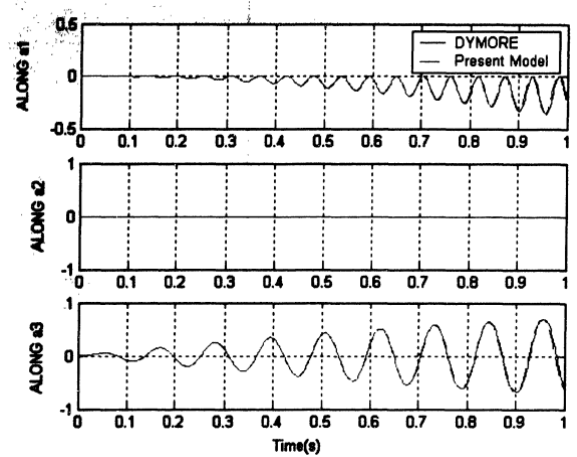

(b)

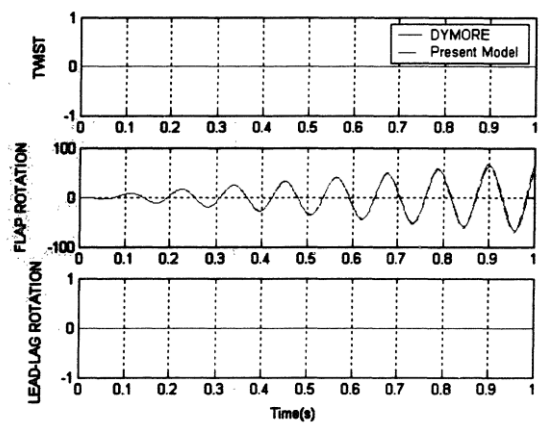

(d)

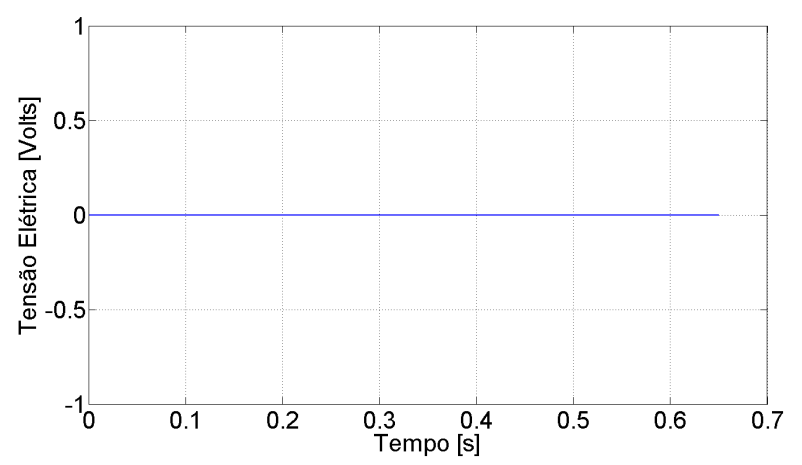

(e)

Figura 18 - Comparação entre: a) deslocamento da ponta da viga do modelo numérico; b) deslocamento da ponta da viga apresentada por Cheng; c) ângulo da ponta da viga do modelo numérico; d) ângulo da ponta da viga apresentada por Cheng; e e)tensão elétrica do modelo numérico. (Cheng (2002)).

\subsection{Controlador Passivo Resistivo Puro}

Uma pá engastada com elementos piezelétricos tem as propriedades descritas na Tab.

2. Os eletrodos do piezelétrico foi conectado a um circuito puramente resistivo para investigar o comportamento não linear do sistema em diversas rotações $(0,50,100,150$, 200, 250, 300, 350 e $400 \mathrm{rpm})$. O comportamento da pá também foi investigado para diversos valores de resistência elétrica $\left(10^{2}, 10^{3}, 10^{4}, 10^{5}\right.$ e $\left.10^{6} \Omega\right)$. Já demonstrado na 
literatura (Erturk e Inman (2008)), os resistores de $10^{2} \Omega$ e $10^{6} \Omega$ conferem ao sistema as condições de contorno de curto circuito e circuito aberto, respectivamente.

Tabela 2 - Propriedades da pá piezelétrica

\begin{tabular}{cl}
\hline Comprimento da pá $[\mathrm{m}]$ & $350 * 10^{-3}$ \\
Espessura da pá $[\mathrm{m}]$ & $0.6 * 10^{-3}$ \\
Largura da pá $[\mathrm{m}]$ & $24 . * 10^{-3}$ \\
Módulo de Young da pá $[\mathrm{Pa}]$ & $18.5 * 10^{9}$ \\
Densidade da pá $\left[\mathrm{kg} / \mathrm{m}^{3}\right]$ & 1865. \\
& \\
Comprimento do piezo $[\mathrm{m}]$ & $60 . * 10^{-3}$ \\
Espessura do piezo $[\mathrm{m}]$ & $0.8 * 10^{-3}$ \\
Largura do piezo $[\mathrm{m}]$ & $23.10^{-3}$ \\
Módulo de Young do piezo $[\mathrm{Pa}]$ & $64 . * 10^{9}$ \\
Densidade do piezo $\left[\mathrm{kg} / \mathrm{m}^{3}\right]$ & 7700. \\
\hline
\end{tabular}

Inicialmente, o material piezelétrico foi conectado a um circuito resistivo puro na condição de circuito aberto $\left(R=10^{6} \Omega\right)$ e foi submetida a uma força de excitação do tipo chirp na extremidade livre da pá. Para cada rotação, investigou-se o deslocamento da ponta da pá para uma faixa de frequências de excitação.

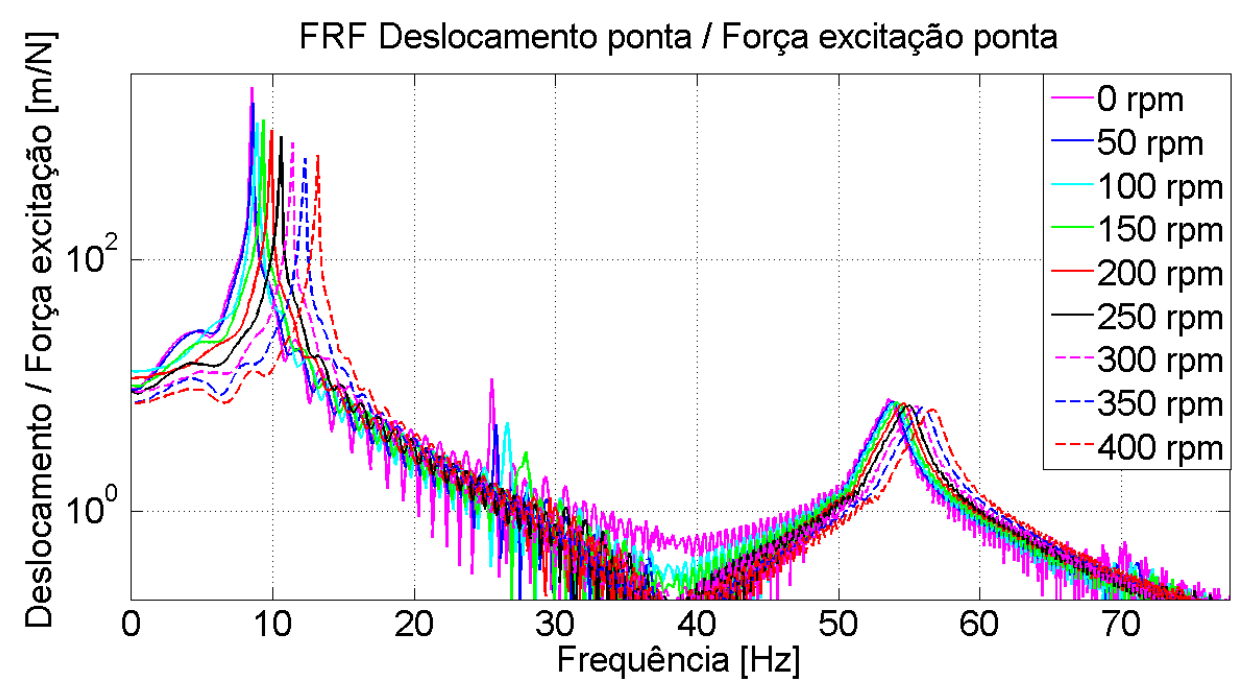

Figura 19 - FRF (deslocamento da ponta / Força de excitação) de uma pá piezelétrica engastada na condição de circuito aberto $\left(R=10^{6} \Omega\right)$.

A Fig. 19 mostra que a amplitude de vibração da ponta da pá decresce com o aumento da rotação da pá (nos dois modos de vibração analisados). Este efeito é esperado devido ao enrijecimento da estrutura com o aumento da velocidade de rotação. Pela mesma razão, verifica-se, para os dois modos apresentados, que o pico de ressonância se desloca para a direita com o aumento da frequência de rotação da pá. A existência da força centrífuga adiciona rigidez (rigidez aparente) a pá quando ela é rotacionada. Quanto maior a rotação, 
maior a força centrífuga e maior o incremento na rigidez total da viga. Desta forma, há incremento na frequência de ressonância e a amplitude de vibração decresce.

Investigou-se também a influência da resistência elétrica no comportamento do sistema para algumas rotações. Em 0 rpm (Fig. 20), observa-se que a frequência de ressonância do primeiro modo na condição de curto circuito $\left(R=10^{2} \Omega\right)$ é menor do que a frequência de ressonância de circuito aberto $\left(R=10^{6} \Omega\right)$. A condição de contorno elétrica aplicada altera a flexibilidade do material piezelétrico (Eq. 2.10) e, consequentemente, altera a frequência de ressonância do sistema. Entre as resistências testadas, existe uma resistência ótima que confere o máximo efeito shunt damping resistivo e, consequentemente, maior atenuação de vibração na ponta da pá. Nesse caso de não-rotação (0 rpm), a resistência ótima encontrada foi a de $10^{5} \Omega$.

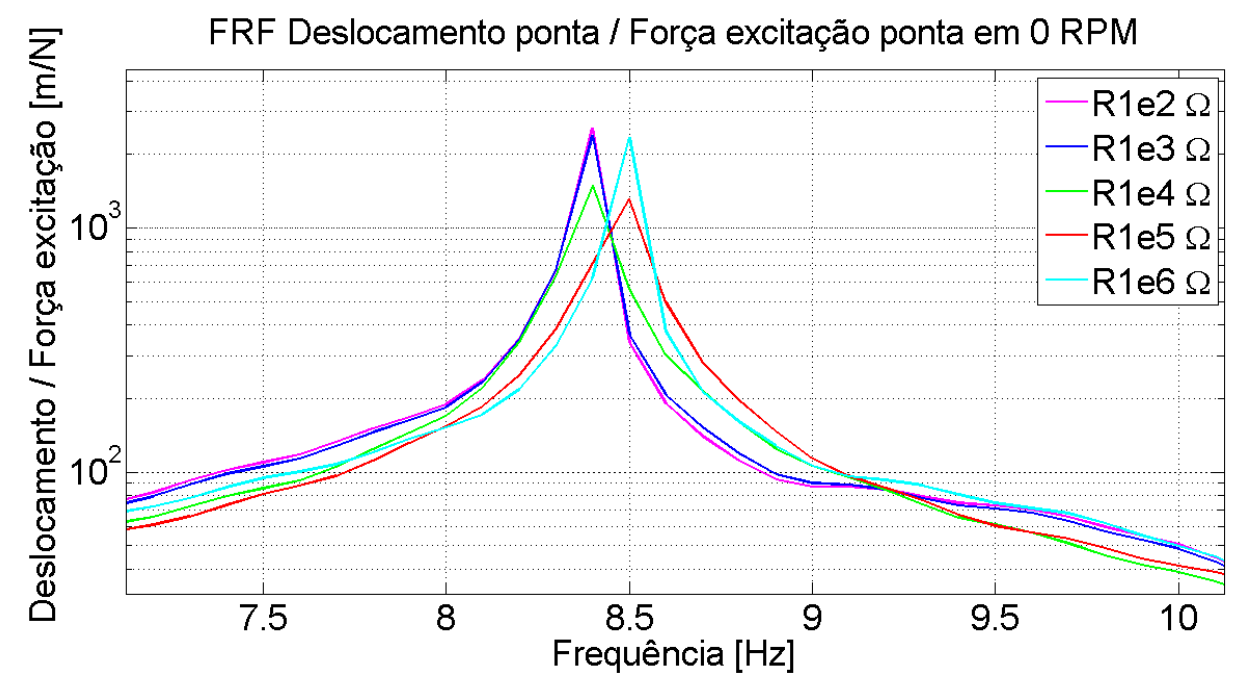

Figura 20 - FRF (deslocamento da ponta / Força de excitação) de uma pá piezelétrica engastada na condição de circuito aberto $\left(R=10^{6} \Omega\right)$ em $0 \mathrm{rpm}$.

Em 200 rpm (Fig. 21), o aumento na frequência de ressonância também é observado devido a mudança da condição de contorno elétrica aplicada. Neste caso, o valor da resistência ótima não é evidenciada tão claramente como no caso anterior, pois as resistências de $R=10^{4} \Omega$ e $R=10^{5} \Omega$ são as que conferem maior atenuação de vibração (quase o mesmo valor de atenuação). Observa-se também que a frequência de ressonância de todas as resistências aumentou em relação ao caso anterior ( $0 \mathrm{rpm})$ devido ao aumento da rotação. Por exemplo, a frequência de ressonância em curto circuito $\left(R=10^{2} \Omega\right)$ em 0 rpm é de aproximadamente $8.4 \mathrm{~Hz}$ e em $200 \mathrm{rpm}$ é de aproximadamente $9.8 \mathrm{~Hz}$, houve um incremento de $16,66 \%$.

Já em 400 rpm (Fig. 22), a mudança no valor da resistência ótima se torna mais perceptível, sendo $R=10^{4} \Omega$ a resistência elétrica que corresponde a maior atenuação de 


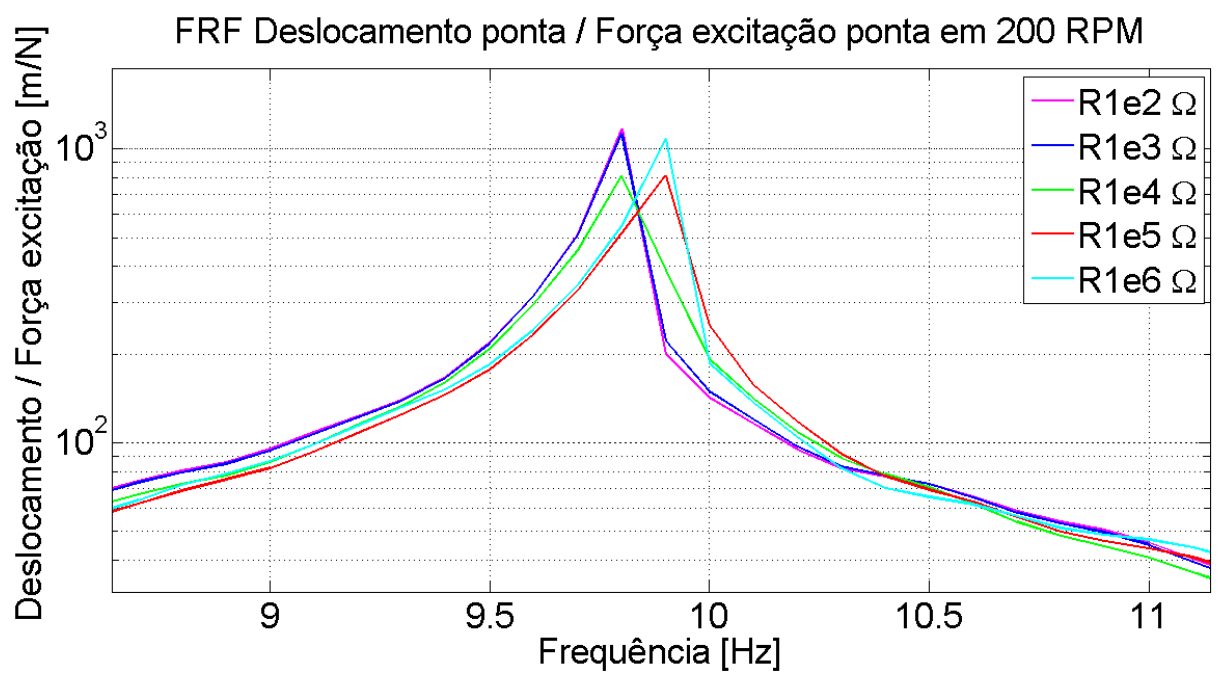

Figura 21 - FRF (deslocamento da ponta / Força de excitação) de uma pá piezelétrica engastada na condição de circuito aberto $\left(R=10^{6} \Omega\right)$ em $200 \mathrm{rpm}$.

vibração do sistema. Observa-se novamente a diferença entre as frequências de ressonância entre curto circuito e circuito aberto e também o incremento na frequência de ressonância com a mudança de rotação. Por exemplo, a frequência de ressonância de circuito aberto $\left(R=10^{6} \Omega\right)$ em 0 rpm é de aproximadamente $8,5 \mathrm{~Hz}$, em $200 \mathrm{rpm}$ é aproximadamente 9,9 Hz e em $400 \mathrm{rpm}$ é aproximadamente 13,2 Hz. Houve incremento na frequência de ressonância com o aumento da rotação devido ao aumento da rigidez aparente da pá (aumento da força centrífuga).

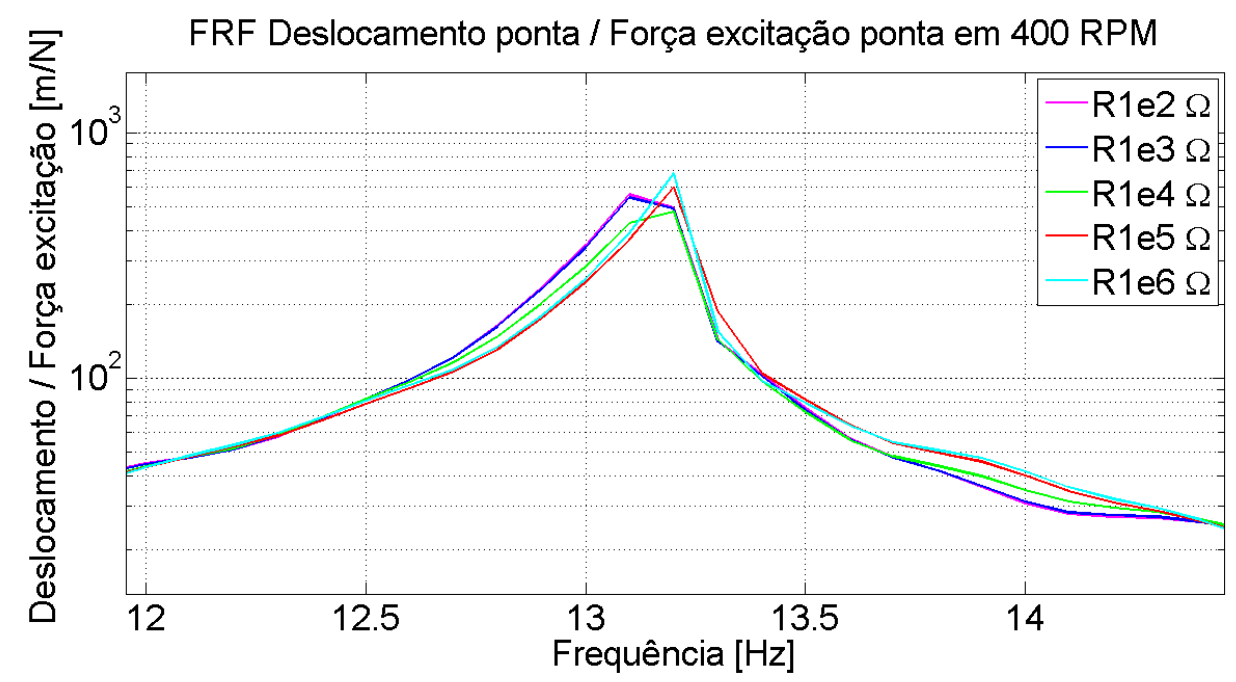

Figura 22 - FRF (deslocamento da ponta / Força de excitação) de uma pá piezelétrica engastada na condição de circuito aberto $\left(R=10^{6} \Omega\right)$ em $400 \mathrm{rpm}$.

Percebe-se que a rigidez adicionada ao sistema devido ao aumento da velocidade de rotação também altera o valor da resistência ótima que confere maior atenuação de vibração ao sistema. Em baixas rotações, observou-se que a resistência ótima encontrada 
foi $R=10^{5} \Omega$. Em médias rotações, a resistência ótima encontrada é algum valor entre $R=10^{4} \Omega$ e $R=10^{5} \Omega$. E em altas rotações, a resistência ótima encontrada foi $R=10^{4} \Omega$.

\subsection{Controlador Semipassivo SSDS}

O controlador semipassivo SSDS utilizado nesse trabalho foi um circuito ideal, sem atrasos ou resistência interna, pois houve a troca de resistores nos pontos de chaveamento, sem considerar um circuito chaveador externo. Essa troca de resistores alterna as condições de contorno elétrica do sistema (de circuito aberto para curto circuito) toda vez que um ponto de máximo ou mínimo no deslocamento linear ou na tensão elétrica é detectado (Seção 2.2.3.1).

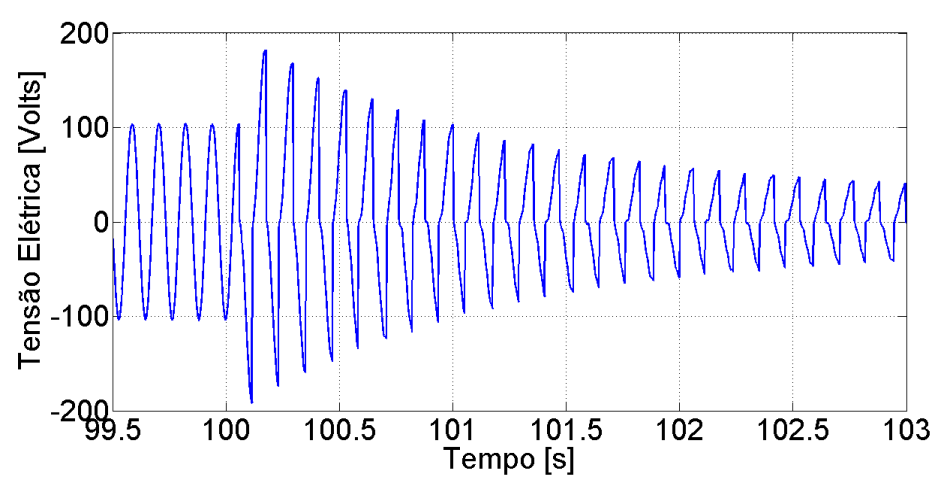

Figura 23 - Tensão elétrica de uma pá piezelétrica engastada em 0 rpm - controlador SSDS.

O sistema sofre uma perturbação na ponta da pá (ao longo da direção a3) com uma força de excitação senoidal de amplitude 0.01 e frequência de excitação igual a frequência de ressonância do sistema. Após 100 segundos de simulação na condição de circuito aberto, o processo de chaveamento do sinal elétrico proveniente do piezelétrico é iniciado (Fig. 23). Inicialmente há um aumento na tensão elétrica do sistema, mas que volta a descrescer rapidamente com a resposta do sistema ao controlador SSDS. O aumento da tensão elétrica é consequência do processo de chaveamento e traz o efeito benéfico de aumento da conversão eletromecânica e maior efeito shunt damping. Quando o chaveamento é iniciado (condição de circuito aberto para curto circuito), a tensão piezelétrica é quase que instantaneamente descarregada. Após o descarregamento da tensão elétrica, a chave volta a abrir novamente e a condição de circuito aberto é reestabelecida (Fig. 24).

Nota-se nas Figs. 25 e 26 que o deslocamento da ponta da pá ao longo da direção a3 (mesma direção da força excitadora) decai 46,48\% (em 1 segundo de chaveamento) quando o processo de chaveamento é iniciado. O mesmo acontece com o ângulo da ponta 

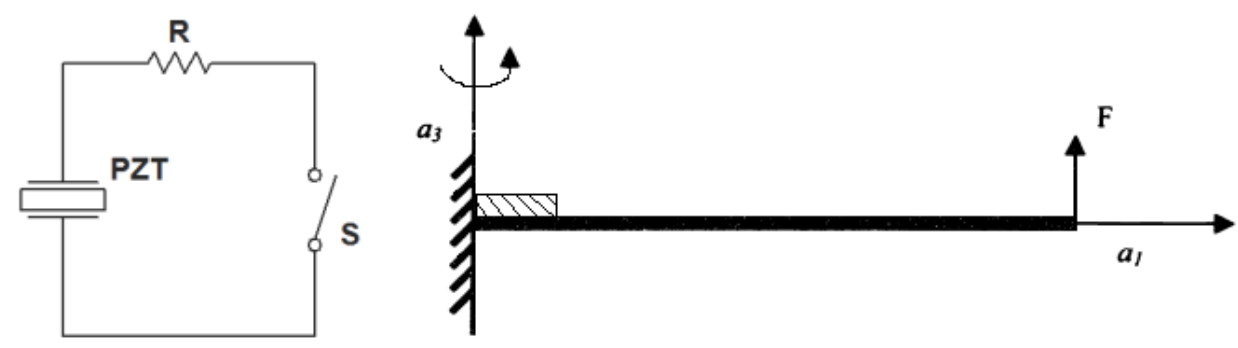

Figura 24 - Representação da pá piezelétrica e do circuito chaveador.

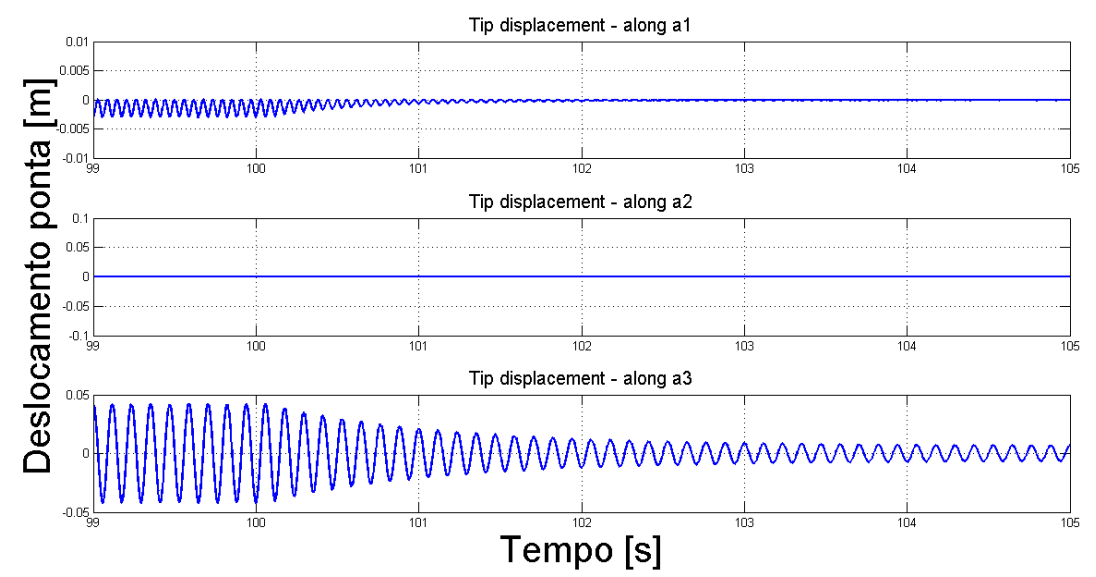

Figura 25 - Deslocamento da ponta da pá piezelétrica em 0 rpm - controlador SSDS.

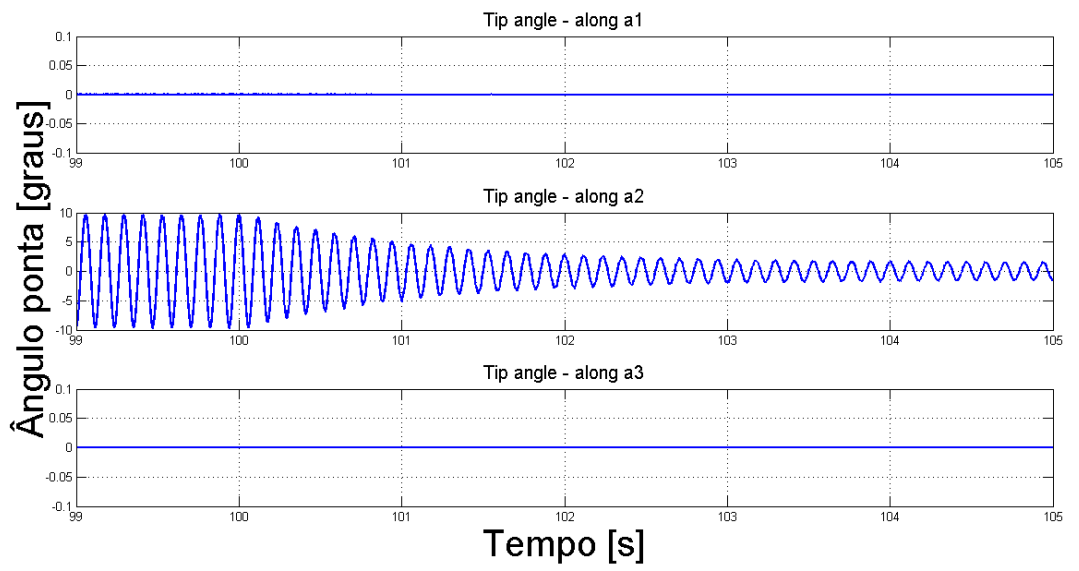

Figura 26 - Ângulos na ponta da pá piezelétrica em 0 rpm - controlador SSDS

da pá na direção a2, mas com decaimento de 48,90\% (em 1 segundo de chaveamento). O controlador SSDS confere aumento do efeito shunt damping (aumento do amortecimento) devido ao aumento da conversão eletromecânica. Se aumentar o tempo de simulação, será possível perceber que o sistema terá máxima atenuação de vibração (vibração igual a zero).

Para médias rotações (200 rpm), a pá piezelétrica engastada se comporta analoga- 


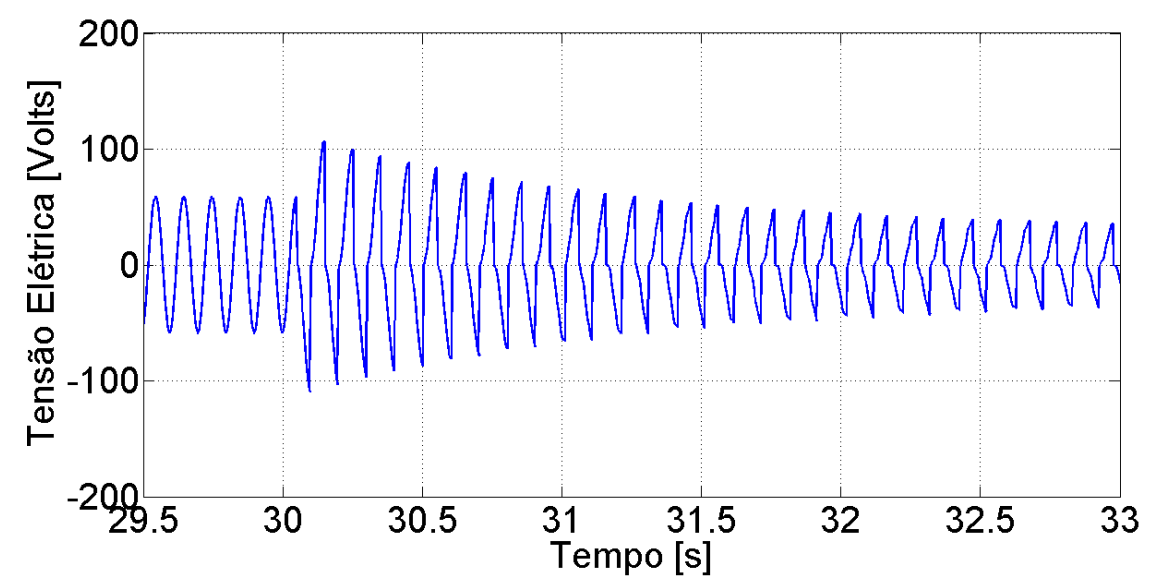

Figura 27 - Tensão elétrica de uma pá piezelétrica em 200 rpm - controlador SSDS.

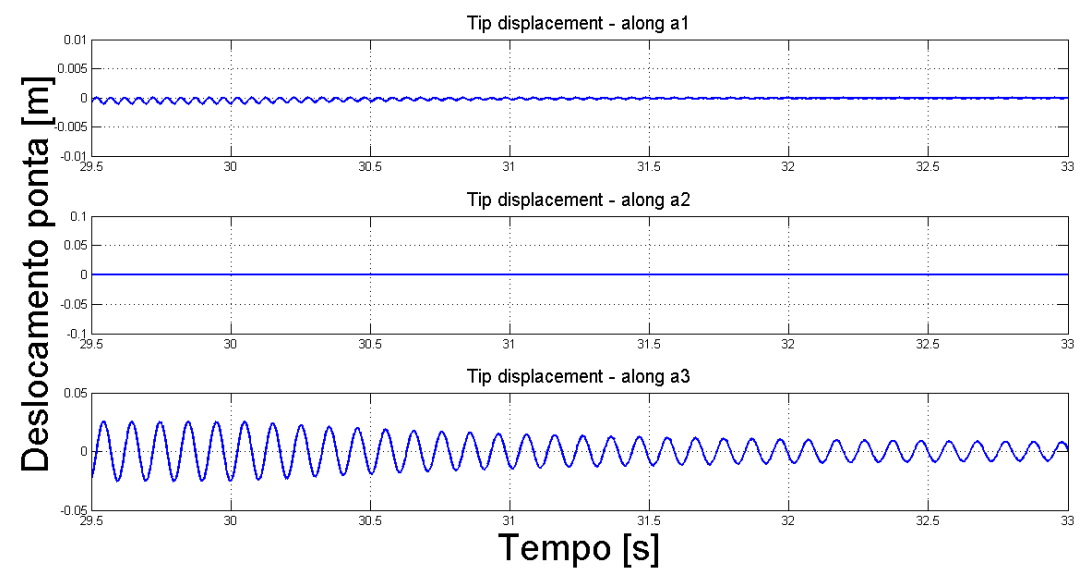

Figura 28 - Deslocamento da ponta da pá piezelétrica em 200 rpm - controlador SSDS.

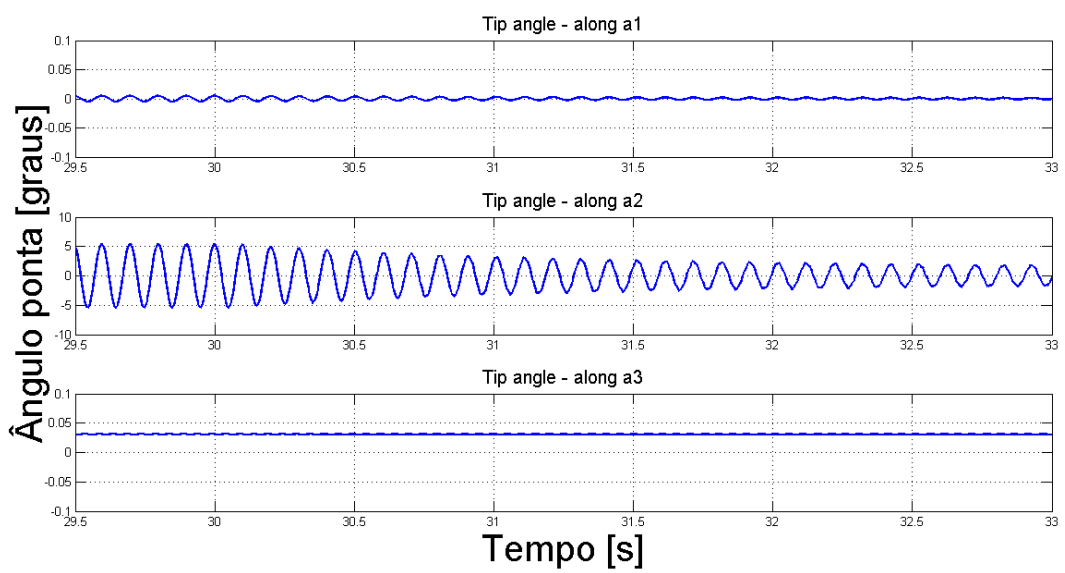

Figura 29 - Ângulos na ponta da pá piezelétrica em 200 rpm - controlador SSDS.

mente ao caso de baixa rotação. Em 200rpm, o processo de chaveamento é iniciado após 30 segundos de rotação. A Fig. 27 mostra que a tensão elétrica em $200 \mathrm{rpm}$ é menor do que a tensão elétrica em 0 rpm antes do chaveamento ser iniciado, ou seja, quanto maior 
a velocidade de rotação, menor a saída elétrica do sistema devido ao aumento da rigidez da pá. Comparado com o caso 0 rpm, o mesmo é observado em relação ao deslocamento e ao ângulo da ponta da pá, ambos são atenuados quando o processo de chaveamento SSDS é iniciado (Figs. 28 e 29). Em 1 segundo de chaveamento, o deslocamento na ponta da pá (ao longo da direção a3) decai 41,91\% e o ângulo na ponta da pá (ao longo da direção a2) decai $40,23 \%$.

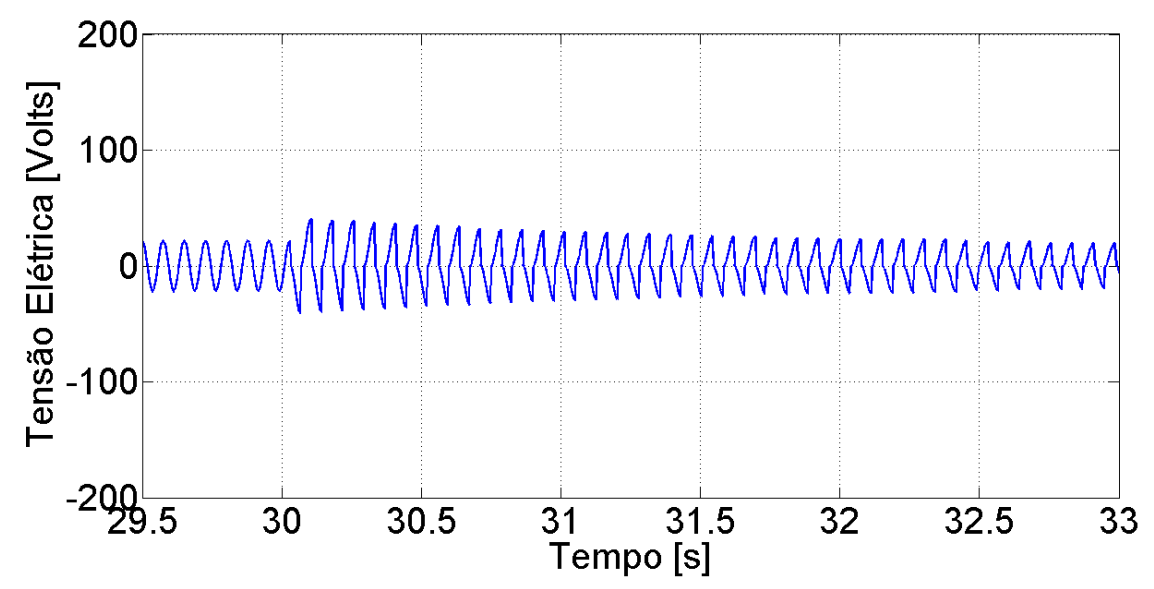

Figura 30 - Tensão elétrica de uma pá piezelétrica em 400 rpm - controlador SSDS.

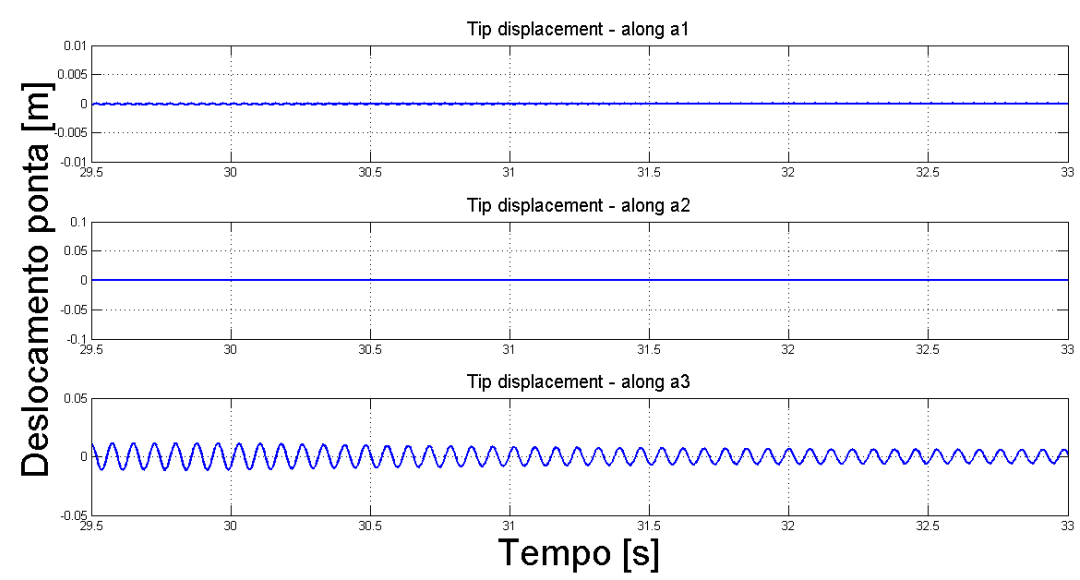

Figura 31 - Deslocamento da ponta da pá piezelétrica em 400 rpm - controlador SSDS.

O mesmo é observado em altas rotações, como por exemplo, em 400 rpm (Figs. 30 a 32). Em 1 segundo de chaveamento, o deslocamento na ponta da pá (ao longo da direção a3) decai 20,73\% e o ângulo na ponta da pá (ao longo da direção a2) decai 23,12\%.

Quando a atenuação da vibração for máxima (vibração igual a zero), o sistema começará a ser excitado pelo controlador SSDS.

O controlador semipassivo SSDS é capaz de atenuar a vibração de uma pá piezelétrica em diversos níveis de rotação. O comportamento é semelhante, o deslocamento e o ângulo 


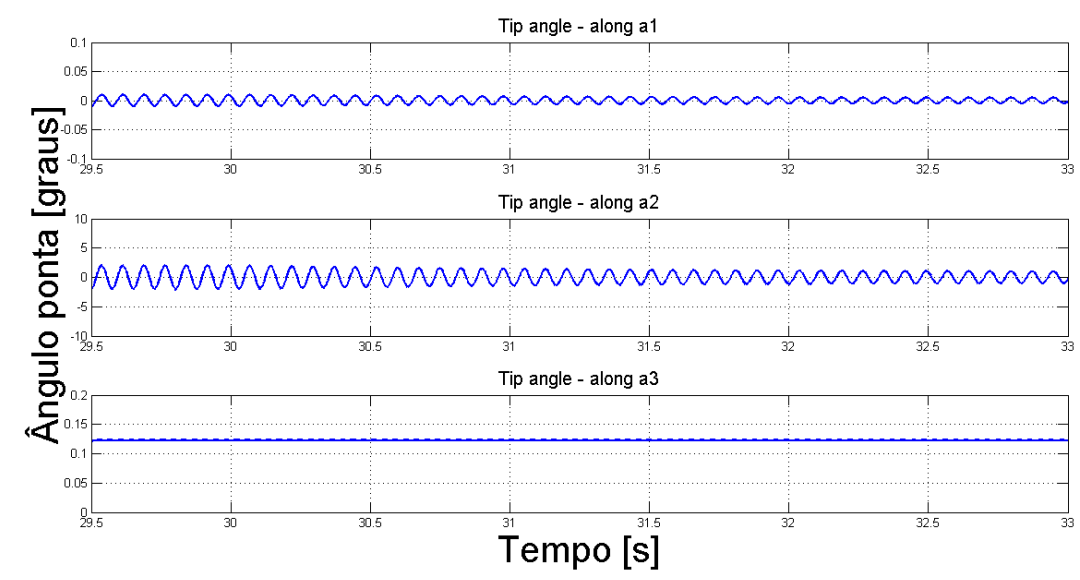

Figura 32 - Ângulos na ponta da pá piezelétrica em 400 rpm - controlador SSDS.

da ponta da pá são atenuados quando o processo de chaveamento é iniciado, aumentando o amortecimento do sistema. Quanto maior a rotação, menor a taxa de decaimento (ou amortecimento) do sistema, devido ao enrijecimento da estrutura causado pela força centrífuga.

\subsection{Controlador Semipassivo BSDS}

O controlador semipassivo BSDS é semelhante ao controlador SSDS, mas consiste em chavear o sistema para a condição de curto circuito com uma frequência $f_{s}, n$ vezes maior que a frequência de ressonância do sistema $f_{0}$ (Eq. 2.11). A tensão elétrica é chaveada $n$ vezes durante um período de tempo.

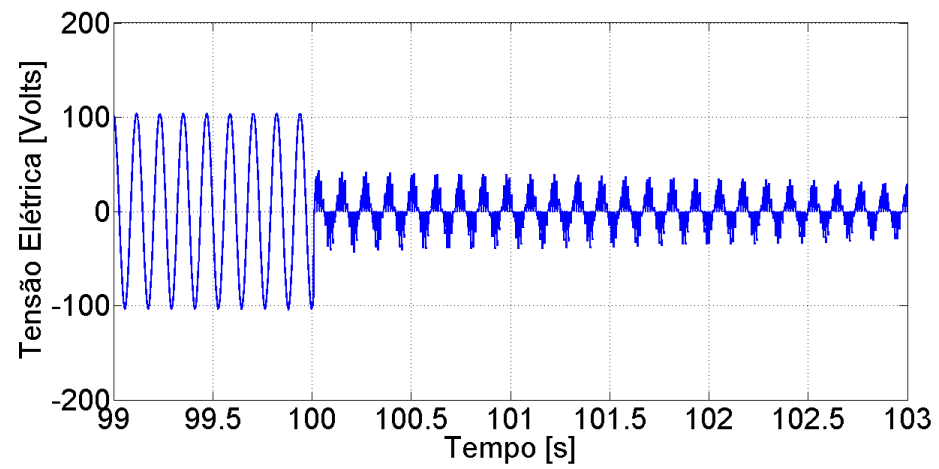

Figura 33 - Tensão elétrica de uma pá piezelétrica em 0 rpm - controlador BSDS.

A primeira verificação do controlador BSDS é para a pá em rotação de 0 rpm (Fig. 33) com $n$ igual a 5. Dentro de um período de oscilação, o sistema é chaveado 5 vezes, com frequência de ressonância do sistema mecânico igual a 8,5 Hz para $0 \mathrm{rpm}, 9,9 \mathrm{~Hz}$ para $200 \mathrm{rpm}$ e 13,2 Hz para $400 \mathrm{rpm}$. O controlador consegue atenuar a vibração do sistema 


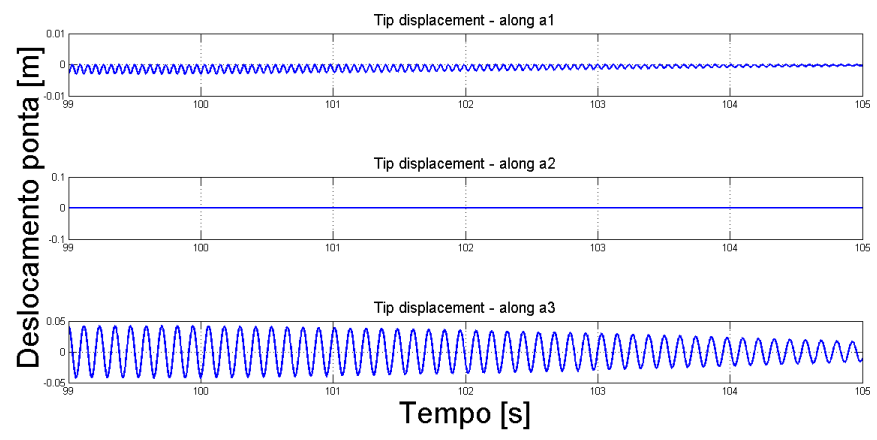

Figura 34 - Deslocamento da ponta da pá piezelétrica em 0 rpm - controlador BSDS.

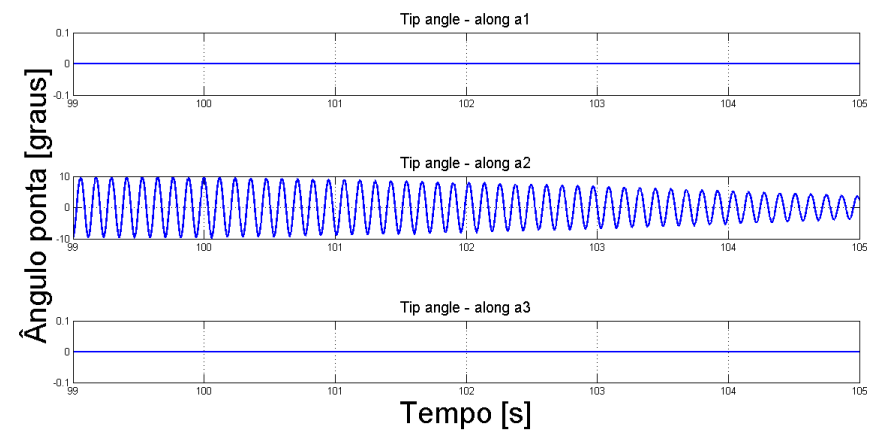

Figura 35 - Ângulos na ponta da pá piezelétrica em 0 rpm - controlador BSDS.

(Figs. 34 e 35), mas com uma taxa de atenuação menor do que o controlador SSDS.

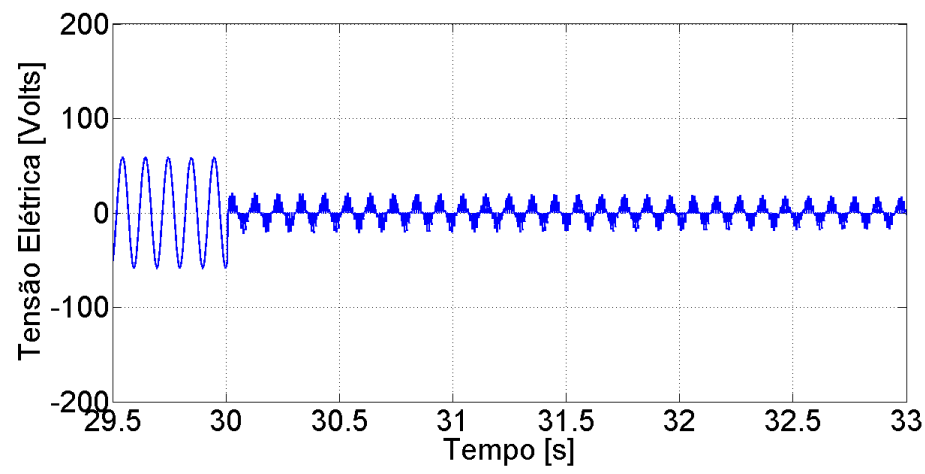

Figura 36 - Tensão elétrica de uma pá piezelétrica em 200 rpm - controlador BSDS.

Para médias rotações e altas rotações, o sistema se comporta analogamente a baixas rotações (Figs. 36 a 41). A saída elétrica diminui com o aumento da rotação e a atenuação de vibração fica menos evidente do que em rotações baixas.

O controlador BSDS tem a vantagem de ser independente das vibrações da estrutura, ou seja, não é necessário identificar os pontos de máximo e mínimo do sistema. Lallart et al. (2009) mostram que a atenuação de vibração é inversamente proporcional ao valor de $n$. Assim, a atenuação da vibração utilizando o controlador BSDS é menor do que a 


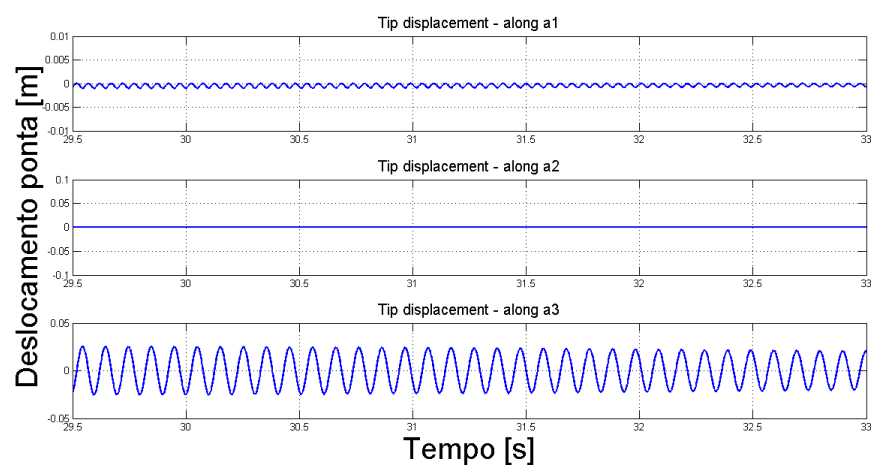

Figura 37 - Deslocamento da ponta da pá piezelétrica em 200 rpm - controlador BSDS.

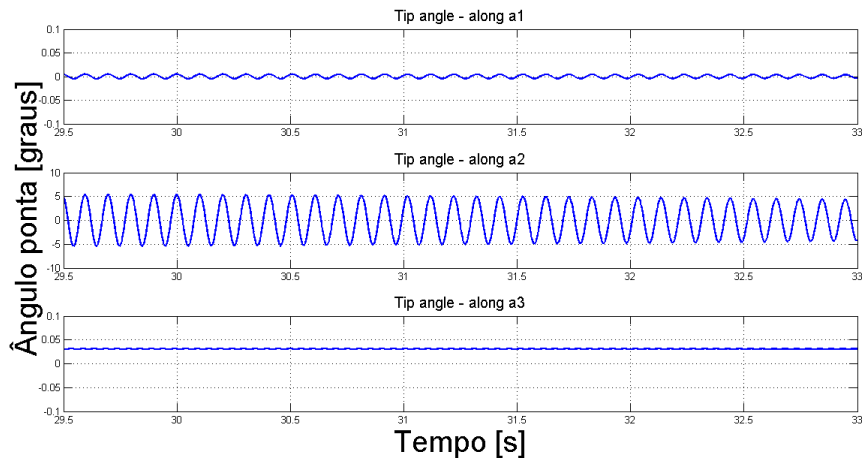

Figura 38 - Ângulos na ponta da pá piezelétrica em 200 rpm - controlador BSDS.

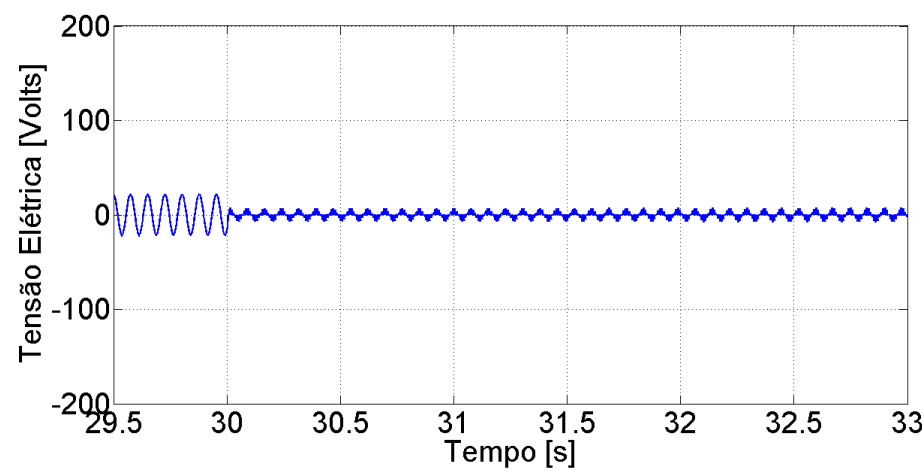

Figura 39 - Tensão elétrica de uma pá piezelétrica em 400 rpm - controlador BSDS.

atenuação causada por um controlador SSDS, o que foi verificado para vários niveis de rotação, como mostra a seção a seguir.

\subsection{Comparação entre os controladores Semipassivos SSDS e BSDS}

A Fig. 42 compara o sinal elétrico do controlador SSDS com o controlador BSDS para uma pá piezelétrica em 0 rpm (não rotativa). É possível notar que no controlador BSDS, 


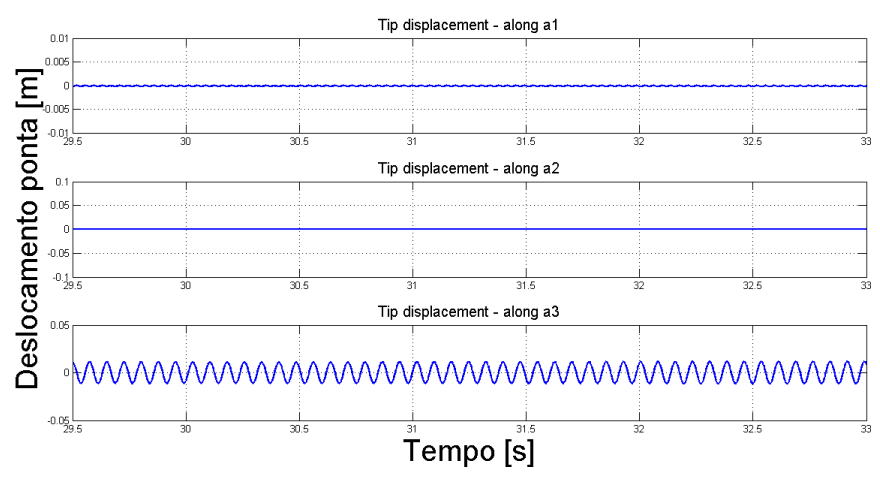

Figura 40 - Deslocamento da ponta da pá piezelétrica em 400 rpm - controlador BSDS.

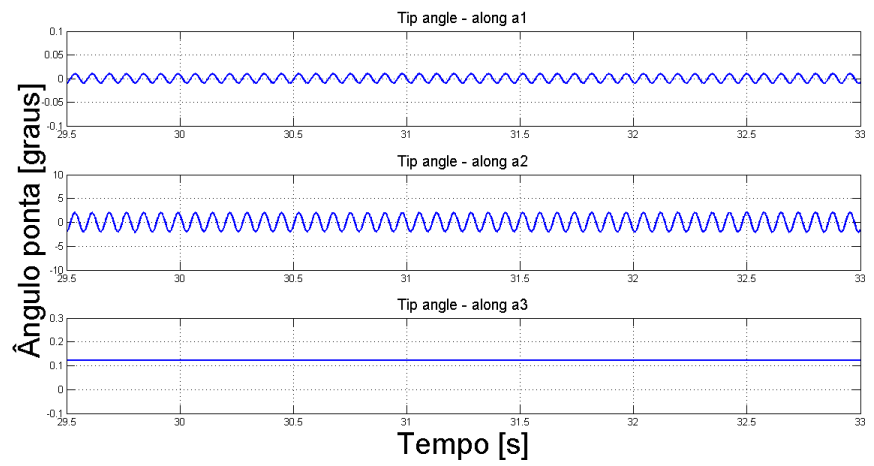

Figura 41 - Ângulos na ponta da pá piezelétrica em 400 rpm - controlador BSDS.

a pá piezelétrica é chaveada 5 vezes a cada período de tempo e que há pouca diferença de fase entre as tensões elétricas. Observa-se também que a amplitude do sinal elétrico do contorlador BSDS é bem menor do que o sinal elétrico do controlador SSDS.

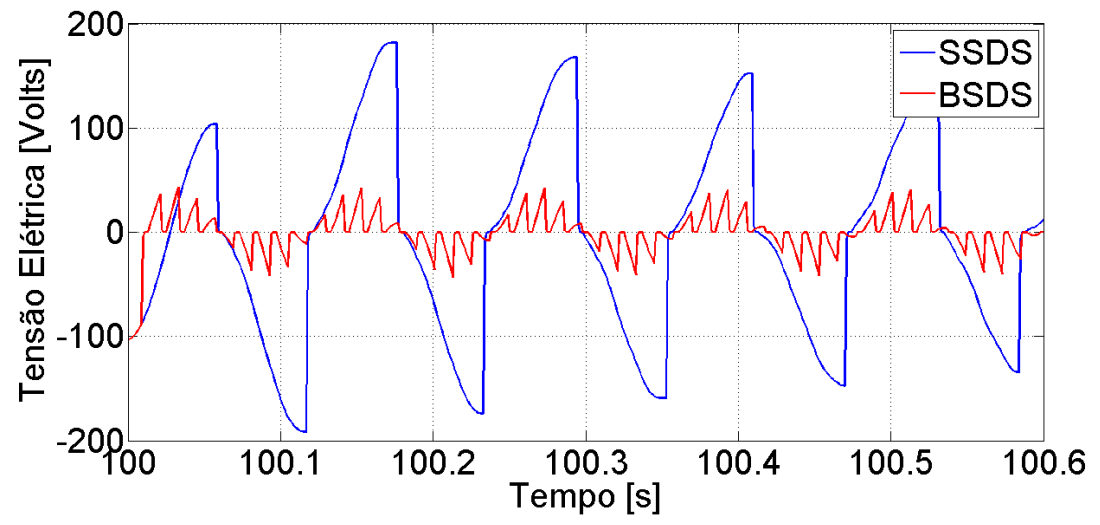

Figura 42 - Comparação entre a tensão elétrica de uma pá piezelétrica em 0 rpm - controladores SSDS e BSDS.

Comparando os deslocamentos e ângulos na ponta da pá para os casos SSDS e BSDS (Figs. 43 e 44), é possível perceber que o controlador SSDS atenua a vibração mais rapidamente do que o controlador BSDS, ou seja, a taxa de atenuação do controlador 
SSDS é maior do que a taxa de atenuação do controlador BSDS.

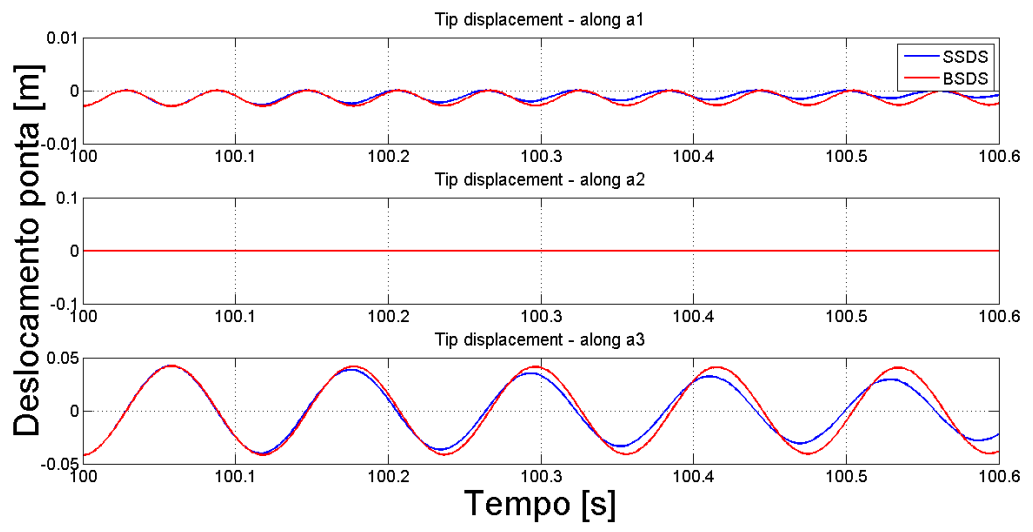

Figura 43 - Comparação entre os deslocamentos da ponta de uma pá piezelétrica em 0 rpm - controlador SSDS e BSDS.

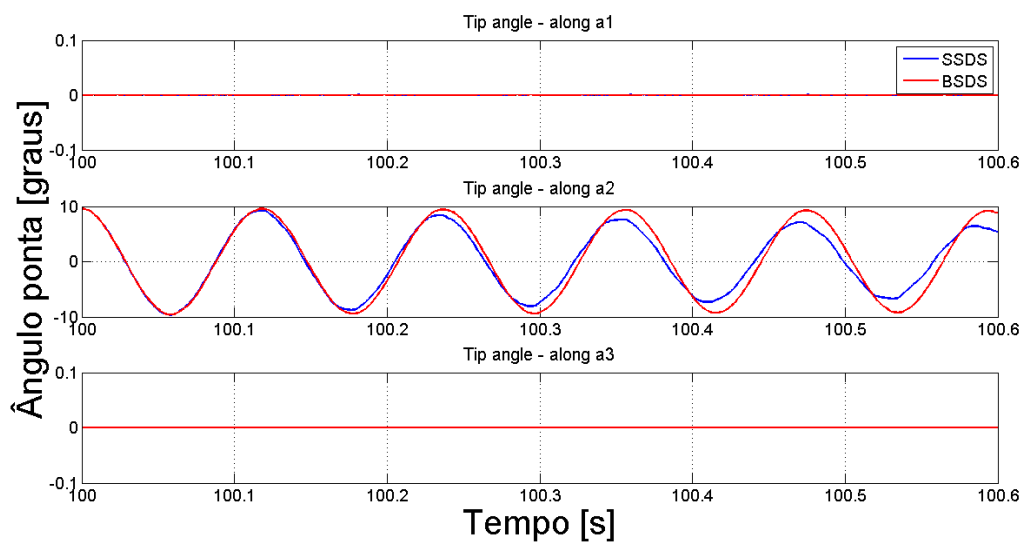

Figura 44 - Comparação entre os ângulos da ponta de uma pá piezelétrica em 0 rpm controlador SSDS e BSDS.

Lallart et al. (2009) mostra que quanto menor o valor de $n$ (Eq. 2.11), maior a atenuação de vibração. E isso é evidenciado, pois o controlador SSDS se assemelha ao controlador BSDS quando $n$ igual a 1 , ou seja, o chaveamento acontecerá no ponto de máximo e mínimo da tensão elétrica. 


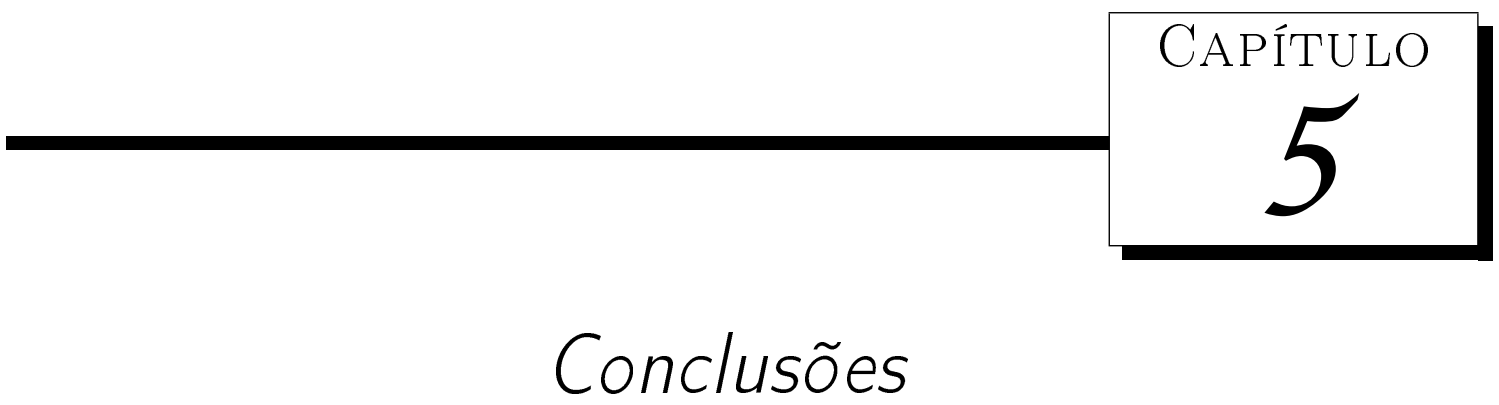

T ma revisão bibliográfica acerca de materiais inteligentes, suas aplicações e as principais técnicas de controle de vibração foi apresentada.

Dentre essas técnicas, foram apresentados os circuitos de controle passivo, ativo, semipassivo e semi-ativo. Quando o efeito piezelétrico inverso é utilizado temos os controladores ativos e a necessidade de alimentação dos atuadores. Em outros casos, utiliza-se circuitos compostos por elementos passivos conectados aos piezelétricos, resultando em controladores passivos, os quais não necessitam de alimentação externa. Quando os piezelétricos estão conectados a circuitos chaveados, que podem ou não conter fontes de tensão para alimentar os atuadores, resulta em controladores semi-passivos e semi-ativos, respectivamente.

Para estudar e investigar o comportamento dessas técnicas de controle em uma pá de helicóptero, uma viga elástica rotativa, engastada em uma de suas extremidades e dotada de piezocerâmicas na região da raiz para conversão piezelétrica de energia foi considerada. O modelo eletromecânico não linear da pá piezelétrica é obtido a partir do método Variational-Asymptotic Method (VAM). Devido a possibilidade de incluir o material piezelétrico, o Variational Asymptotic Beam Section (VABS) é utilizado também como ferramenta na modelagem. O sistema rotativo acoplado não linear é resolvido no domínio do tempo, utilizando o método de integração alfa-generalizado a fim de garantir a estabilidade numérica. O método de Newton-Raphson foi utilizado para garantir a solução da equação algébrica não linear. As simulações foram realizadas para uma vasta gama de velocidades de rotação e um conjunto de resistências (variando de condição de curto-circuito para a condição de circuito aberto) foi considerado.

O modelo numérico foi verificado com o teste dinâmico 1 apresentado por Cheng 
(2002), onde uma força de excitação foi aplicada na ponta da pá ao longo da direção $a_{3}$. A resposta do modelo numérico se assemelha a resposta apresentada por Cheng (erro menor que 15\%), confirmando a boa representação do modelo numérico para uma pá de helicóptero.

Os eletrodos do material piezelétrico foram conectados a um circuito resistivo puro. Foi verificado que as propriedades elásticas da piezocerâmica dependem da condição de contorno elétrica ao qual está submetida, variando a rigidez do sistema (rigidez em curto circuito menor do que em circuito aberto). Para determinada resistência, observou-se aumento na frequência de ressonância e atenuação na vibração da ponta da pá com o aumento da rotação, devido ao aumento da força centrífuga. Para cada rotação estudada, observou-se que há uma resistência ótima que confere maior atenuação na vibração. O valor dessa resistência ótima varia de acordo com a rotação da pá.

A influência do controlador SSDS na pá piezelétrica também foi investigada. No controlador SSDS, os pontos de máximo e mínimo das oscilações mecânicas foram detectados e o sistema foi chaveado da condição de circuito aberto para curto circuito, descarregando a tensão elétrica. Depois que a tensão elétrica foi descarregada, a chave voltou a ser aberta. Esse chaveamento provocou aumento no amortecimento do sistema e, consequentemente, atenuação nas oscilações não-lineares da pá com o aumento da velocidade de rotação. A atenuação da vibração é mais evidente em baixas rotações, já que a rigidez do sistema é maior em altas rotações devido ao efeito da força centrífuga.

De forma semelhante ao SSDS, o controlador BSDS também chaveia o sistema da condição de circuito aberto para curto circuito, mas consiste em chavear o sistema para a condição de curto circuito com uma frequência $f_{s}, n$ vezes maior que a frequência de ressonância do sistema $f_{0}$ (Eq. 2.11). O controlador BSDS também atenuou as vibrações da pá, mas a uma taxa de atenuação menor do que o controlador SSDS. Esse fato já tinha sido evidenciado por Lallart et al. (2009) e foi verificado novamente.

Dentre os controladores testados, o controlador SSDS se mostrou mais efetivo quanto a atenuação de vibração em uma viga piezelétrica engastada, apesar da tensão elétrica do sistema ser maior. A utilização do controlador SSDS no modelo de viga eletroelástica rotativa (modelo de pás de helicópteros) reduziu a vibração da ponta da pá, tanto o deslocamento linear quanto o deslocamento angular.

Originalmente, o projeto previa a verificação do controlador semi-ativo SSDV na atenuação de vibração da pá, mas várias dificuldades surgiram e inviabilizaram o andamento da ideia inicial, como mostra o Apêndice D. Trabalhos futuros podem ser realizados uti- 
lizando outros tipos de controladores, como por exemplo, controladores semiativos para investigar a atenuação de vibração. 


\section{Referências Bibliográficas}

ANTHONY, D.; ELLIOTT, S. Comparison of the effectiveness of minimizing cost function parameters for active control of vibrational energy transmission in a lightly damped structure. Journal of sound and vibration, Elsevier, v. 237, n. 2, p. 223-244, 2000 .

BARRETT, R. M. Intelligent rotor blade and structures development using directionally attached piezoelectric crystals. Tese (Doutorado) — University of Maryland at College Park, 1990.

BAUCHAU, O.; THERON, N. Energy decaying scheme for non-linear beam models. Computer Methods in Applied Mechanics and Engineering, Elsevier, v. 134, n. 1, p. 37-56, 1996.

BORRI, M. et al. Dynamic response of mechanical systems by a weak hamiltonian formulation. Computers \& Structures, Elsevier, v. 20, n. 1, p. 495-508, 1985.

BUSHKO, D. A. et al. Integrated actuation system for individual control of helicopter rotor blades. In: INTERNATIONAL SOCIETY FOR OPTICS AND PHOTONICS. 1996 Symposium on Smart Structures and Materials. [S.1.], 1996. p. 80-90.

CESNIK, C. E.; SHIN, S. On the modeling of integrally actuated helicopter blades. International Journal of Solids and Structures, Elsevier, v. 38, n. 10, p. 1765-1789, 2001.

CHENG, T. Structural dynamics modeling of helicopter blades for computational aeroelasticity. Tese (Doutorado) — Massachusetts Institute of Technology, 2002.

CHUNG, J.; HULBERT, G. A time integration algorithm for structural dynamics with improved numerical dissipation: the generalized-alpha method. Journal of Applied Mechanics, p. 371-375, 1993.

CLARK, W. W. Vibration control with state-switched piezoelectric materials. Journal of intelligent material systems and structures, Sage Publications, v. 11, n. 4, p. 263-271, 2000.

CRAWLEY, E. F.; LUIS, J. D. Use of piezoelectric actuators as elements of intelligent structures. AIAA journal, v. 25, n. 10, p. 1373-1385, 1987.

D'ASSUNçãO, D. Circuito piezelétrico chaveado para controle de vibrações e coleta de energia em uma seção típica aeroelástica. Dissertação (Mestrado) - Engineering School of Sao Carlos, University of Sao Paulo, 2013. 
De Marqui Jr, C. et al. Linear and nonlinear modeling and experiments of a piezoaeroelastic energy harvester. In: AMERICAN SOCIETY OF MECHANICAL ENGINEERS. ASME 2010 Conference on Smart Materials, Adaptive Structures and Intelligent Systems. [S.1.], 2010. p. 221-229.

DE MARQUI JR, C.; ERTURK, A.; INMAN, D. J. An electromechanical finite element model for piezoelectric energy harvester plates. Journal of Sound and Vibration, Elsevier, v. 327 , n. 1, p. 9-25, 2009.

ELVIN, N. G.; ELVIN, A. A. A general equivalent circuit model for piezoelectric generators. Journal of Intelligent Material Systems and Structures, SAGE Publications, v. 20 , n. 1 , p. 3-9, 2009.

ERTURK, A.; INMAN, D. J. A distributed parameter electromechanical model for cantilevered piezoelectric energy harvesters. Journal of Vibration and Acoustics, American Society of Mechanical Engineers, v. 130, n. 4, p. 041002, 2008.

ERTURK, A.; INMAN, D. J. An experimentally validated bimorph cantilever model for piezoelectric energy harvesting from base excitations. Smart Materials and Structures, IOP Publishing, v. 18, n. 2, p. 025009, 2009.

FABUNMI, J. A. Control of helicopter rotorblade aerodynamics. [S.l.]: National Aeronautics and Space Administration, Office of Management, Scientific and Technical Information Program, 1991.

FESZTY, D.; NITZSCHE, F. Review of active rotor control research in Canada. International Journal of Aeronautical and Space Sciences, v. 12, p. 93-114, 2011.

FESZTY, D. et al. Whirl tower demonstrations of the sharcs hybrid control concept. In: American Helicopter Society 65th International Annual Forum. [S.1.: s.n.], 2009.

FORWARD, R. L. Electronic damping of vibrations in optical structures. Journal of Applied Optics, v. 18(5), p. 690-697, 1979.

GUYOMAR, D.; RICHARD, C.; MOHAMMADI, S. Damping behavior of semi-passive vibration control using shunted piezoelectric materials. Journal of Intelligent Material Systems and Structures, Sage Publications, 2007.

HAGOOD, N. W.; CHUNG, W. H.; FLOTOW, A. V. Modelling of piezoelectric actuator dynamics for active structural control. Journal of Intelligent Material Systems and Structures, SAGE Publications, v. 1, n. 3, p. 327-354, 1990.

HAGOOD, N. W.; FLOTOW, A. von. Damping of structural vibrations with piezoelectric materials and passive electrical networks. Journal of Sound and Vibration, Elsevier, v. 146, n. 2, p. 243-268, 1991.

HANAGUD, S.; BABU, G. Smart structures in the control of airframe vibrations. Journal of the American Helicopter Society, AHS International, v. 39, n. 2, p. 69-72, 1994.

HEEG, J. An analytical and experimental investigation of flutter suppression via piezoelectric actuation. [S.l.]: National Aeronautics and Space Administration, Langley Research Center, 1992. 
HODGES, D. H. A mixed variational formulation based on exact intrinsic equations for dynamics of moving beams. International journal of solids and structures, Elsevier, v. 26, n. 11, p. 1253-1273, 1990.

IEEE. IEEE standard on piezoelectricity. [S.l.], 1987.

INMAN, D. J.; SINGH, R. C. Engineering vibration. [S.l.]: Prentice Hall Upper Saddle River, 2001.

JOHNSON, C. D. Design of passive damping systems. Journal of Mechanical Design, Transactions of the ASME, v. 117B, p. 171-176, 1995.

KLOEPPEL, V.; ENENKL, B. Rotor blade control by active helicopter servo flaps. In: International Forum on Aeroelasticity and Structural Dynamics. [S.l.: s.n.], 2005.

LALLART, M. et al. Blind switch damping (bsd): A self-adaptive semi-active damping technique. Journal of Sound and vibration, Elsevier, v. 328, n. 1, p. 29-41, 2009.

LARSON, G. D. The analysis and realization of a state switched acoustic transducer. Georgia Institute of Technology, 1996.

LAZARUS, K. B.; CRAWLEY, E. E.; LIN, C. Y. Fundamental mechanisms of aeroelastic control with control surface and strain actuation. Journal of Guidance, Control, and Dynamics, v. 18, n. 1, p. 10-17, 1995.

LEFEUVRE, E. et al. Semi-passive piezoelectric structural damping by synchronized switching on voltage sources. Journal of Intelligent Material Systems and Structures, Sage Publications, v. 17, n. 8-9, p. 653-660, 2006.

LEO, D. J. Engineering Analysis of Smart Material Systems. [S.1.]: John Wiley \& Sons, Inc, 2007.

MEDEIROS, P. J. Modelos Dinâmicos. (Acessado em 17/06/2014). Disponível em: $<$ http://www.ufpi.br/subsiteFiles/medeiros/arquivos/files/modelos\%20dinamicos\%20$\% 20$ aula\%201(1).pdf $>$.

MOHAMMADI, S. Semi-passive vibration control using shunted piezoelectric materials. Tese (Doutorado) — Université Pierre et Marie Curie, 2008.

NITZSCHE, F.; BREITBACH, E. A study on the feasibility of using adaptive structures. 33rd AIAA SDM Conference, Dallas, TX, paper AIAA-92-2452, 1992.

NITZSCHE, F.; FESZTY, D. Hybrid device for vibration control. dez. 31 2009. US Patent 20,090,321,555.

NITZSCHE, F. et al. The sharcs project: Smart hybrid active rotor control system for noise and vibration attenuation of helicopter rotor blades. Citeseer, 2005.

PATT, D. et al. The hhc algorithm for helicopter vibration reduction revisited. In: Proc. 45th AIAA/ASME/ASCE/AHS/ASC SDM Conference. [S.l.: s.n.], 2004. p. 1-29.

RICHARD, C. et al. Semi-passive damping using continuous switching of a piezoelectric device. In: INTERNATIONAL SOCIETY FOR OPTICS AND PHOTONICS. 1999 Symposium on Smart Structures and Materials. [S.1.], 1999. p. 104-111. 
RICHARD, C. et al. Enhanced semi-passive damping using continuous switching of a piezoelectric device on an inductor. In: INTERNATIONAL SOCIETY FOR OPTICS AND PHOTONICS. SPIE's Yth Annual International Symposium on Smart Structures and Materials. [S.1.], 2000. p. 288-299.

RICHARD, C.; GUYOMAR, D.; LEFEUVRE, E. Self-powered electronic breaker with automatic switching by detecting maxima or minima of potential difference between its power electrodes. FR2005/003000, publication number: WO/2007/063194, 2007.

SHANG, X.; HODGES, D. H.; PETERS, D. A. Aeroelastic stability of composite hingeless rotors in hover with finite-state unsteady aerodynamics. Journal of the American Helicopter Society, AHS International, v. 44, n. 3, p. 206-221, 1999.

SODANO, H. A.; PARK, G.; INMAN, D. Estimation of electric charge output for piezoelectric energy harvesting. Strain, Wiley Online Library, v. 40, n. 2, p. 49-58, 2004.

SPANGLER, R. L. Piezoelectric actuators for helicopter rotor control. Tese (Doutorado) - Massachusetts Institute of Technology, 1989.

STRAUB, F. K. et al. Smart material-actuated rotor technology-smart. Journal of Intelligent Material Systems and Structures, Sage Publications, v. 15, n. 4, p. 249-260, 2004.

VALLEJO, C. M. P. et al. Low back pain in helicopter pilots. Current Aeromedical Issues in Rotary Wing Operations, v. 20, 1999.

VIANA, F. A. C. Amortecimento de Vibrações usando Pastilhas Piezelétricas e Circuitos Shunt Ressonantes. Tese (Doutorado) — Dissertação de Mestrado-Universidade Federal de Uberlândia, 2005.

WALL, A. et al. Modeling helicopter blade sailing: Dynamic formulation and validation. Journal of Applied Mechanics, American Society of Mechanical Engineers, v. 75, n. 6, p. $061004,2008$.

WANG, Y.; INMAN, D. J. A survey of control strategies for simultaneous vibration suppression and energy harvesting via piezoceramics. Journal of Intelligent Material Systems and Structures, Sage Publications, v. 23, n. 18, p. 2021-2037, 2012.

WU, S. Piezoelectric shunts with a parallel R-L circuit for structural damping and vibration control. In: . [s.n.], 1996. v. 2720, p. 259-269. Disponível em: $<$ http://dx.doi.org/10.1117/12.239093>.

ZHAO, Y. Vibration suppression of a quadrilateral plate using hybrid piezoelectric circuits. Journal of Vibration and Control, SAGE Publications, v. 16, n. 5, p. 701-720, 2010. 


\section{Apêndice A - Analogia entre Sistema Mecânico de Translação e Sistema Elétrico}

nalogia entre dois sistemas físicos acontece quando eles são descritos pelo mesmo
modelo matemático, apesar de possuírem características físicas diferentes. Essa analogia é obtida à partir das equações diferenciais de cada elemento físico, seja ele no domínio mecânico, elétrico, hidráulico, entre outros. Por exemplo, um sistema mecânico de translação possui grandezas análogas com um sistema elétrico, como mostrado na tabela a seguir.

Tabela 3 - Analogia força-tensão entre os sistemas mecânico de translação e elétrico

\begin{tabular}{cl}
\hline Sistema Mecânico & Sistema Elétrico \\
\hline Massa & Indutância \\
Rigidez & Inverso da Capacitância \\
Amortecimento & Resistência \\
Força & Tensão \\
Deslocamento & Carga Elétrica \\
Velocidade & Corrente \\
\hline
\end{tabular}

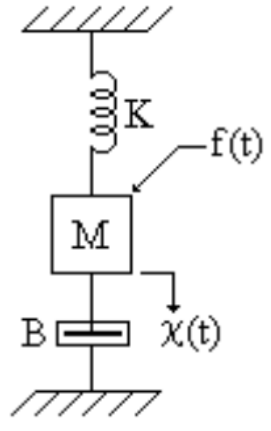

(a)

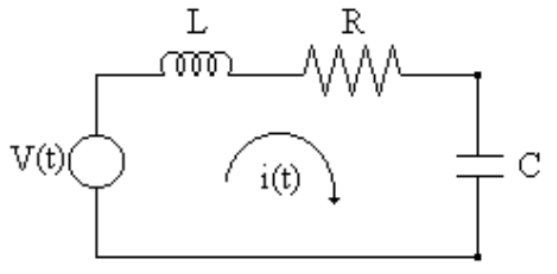

(b)

Figura 45 - Analogia entre a) sistema mecânico de translação e b) sistema elétrico. (Medeiros ((Acessado em 17/06/2014))).

Para exemplificar melhor essa analogia, considera-se um sistema simples massa-mola- 
amortecedor (Fig. 45(a)), cuja equação diferencial é representada como

$$
M \frac{d^{2} \chi(t)}{d t^{2}}+B \frac{d \chi(t)}{d t}+K \chi(t)=f(t)
$$

onde $M$ é a massa, $B$ é o amortecimento, $K$ é a rigidez, $\chi(t)$ é o deslocamento em função do tempo e $f(t)$ é a força aplicada em função do tempo.

De acordo com a Tab. 3, o equivalente elétrico desse sistema mecânico de translação (Fig. 45(a)) é um circuito constituído por uma indutância $L$, uma resistência $R$ e uma capacitância $C$ submetidos a uma fonte de tensão $V(t)$ (Fig. 45(b)). As equações diferenciais desse circuito elétrico podem ser representadas como

$$
\begin{gathered}
L \frac{d i(t)}{d t}+R i(t)+\frac{1}{C} \int i(t) d t=V(t) \\
i(t)=\frac{d q(t)}{d t} \\
L \frac{d^{2} q(t)}{d t^{2}}+R \frac{d q(t)}{d t}+\frac{1}{C} q(t)=V(t)
\end{gathered}
$$

onde $i(t)$ é a corrente elétrica e $q(t)$ é a carga elétrica.

As Eqs. A.1 e A.4 são descritas pelo mesmo modelo matemático, mostrando a analogia entre dois sistemas físicos.

\section{A.1 - Influência do Circuito Elétrico em um Sistema Piezelétrico Eletromecanicamente Acoplado}

Essa analogia é muito importante quando a contribuição de um elemento elétrico em um sistema eletromecânico é analisada. Como mostrado na Seção 2.2, quando um sistema mecânico piezelétrico é ligado a um circuito resistivo puro, é adicionado ao sistema um amortecimento extra ao amortecimento estrutural. Esse amortecimento adicional pode ser explicado pelo fato de que o resistor em um circuito elétrico desempenha o mesmo comportamento do que um amortecedor em um sistema mecânico (Tab. 3). Isso se deve ao fato de que o sistema é eletromecanicamente acoplado.

O mesmo acontece em outras configurações de circuitos elétricos, como por exemplo, no controlador indutivo-resistivo. Esse tipo de controlador é equivalente a um absorvedor mecânico de vibração amortecido, pois o elemento elétrico indutivo é análogo a uma massa no sistema mecânico. Se o indutor no circuito elétrico é escolhido de acordo com a frequência de ressonância mecânica, analogamente, o sistema mecânico tem uma massa 
extra absorvendo as vibrações durante a ressonância. Esse absorvedor é do tipo amortecido pelo fato de que o elemento elétrico resistivo é análogo a um amortecedor, como já discutido anteriormente.

Já no controlador passivo capacitivo-resistivo, o efeito é de variação na rigidez total do sistema, pois o capacitor no circuito elétrico é análogo a uma mola no sistema mecânico. E novamente, o elemento resistivo oferece amortecimento adicional ao sistema. 


\section{Apêndice B - Modelagem de uma Viga Piezelétrica Fixa}

$\mathrm{N}$ esse apêndice será mostrado os trabalhos realizados antes da modelagem da pá piezelétrica. Anteriormente, um modelo numérico de uma viga piezelétrica não rotativa foi desenvolvido e a atenuação de vibração dessa viga utilizando vários tipos de controladores, como por exemplo, SSDS, SSDI e SSDV, foi verificada.

Existem várias formas de representar uma viga em uma modelagem, seja ela por parâmetros concentrados (representação em espaço de estados, por exemplo) ou por parâmetros distribuídos. Aqui, neste trabalho, a modelagem Euler-Bernoulli para vigas finas (parâmetros distribuídos) foi considerada, assim como a formulação discreta de Rayleigh-Ritz. A teoria de viga Euler-Bernoulli envolve algumas hipóteses físicas, como por exemplo, a viga deve ser constituída de um material homogêneo e linearmente elástico e seu formato deve ser um prisma reto, cujo comprimento é muito maior que as outras dimensões.

Após a modelagem da viga, os circuitos elétricos também foram desenvolvidos, sendo que o circuito chaveador foi baseado no circuito proposto por Richard, Guyomar e Lefeuvre (2007).

A verificação do método numérico utilizado para modelar uma viga piezelétrica engastada fixa é feita utilizando os resultados apresentados em Erturk e Inman (2009) para uma viga bimorph em série. Após a verificação do método numérico utilizado, novas simulações foram realizadas para cada caso de controle de vibração citado acima, mas utilizando os dados de outra viga bimorph descrita na Seção 5. Em seguida, são apresentados alguns resultados experimentais que confirmam o funcionamento dos métodos de controle de vibração. 


\section{B.1 - Modelagem da Viga Piezelétrica Engastada}

Para modelagem da viga piezelétrica engastada foi considerado a teoria Euler-Bernoulli para vigas finas. O material piezelétrico utilizado possui plano de isotropia 1-2 (xy) e exibi simetria em torno da direção 3, que é a direção de polarização do material (Fig. 3). Assim, as equações constitutivas da piezeletricidade (Eqs. 2.5 e 2.6) podem ser escritas na forma matricial, como mostra a Eq. B.1. Observe que a matriz é transversalmente isotrópica $\left(s_{11}^{E}=s_{22}^{E}, d_{31}=d_{32} \ldots\right)$.

$$
\left\{\begin{array}{c}
S_{11} \\
S_{22} \\
S_{33} \\
2 S_{23} \\
2 S_{31} \\
2 S_{12} \\
D_{1} \\
D_{2} \\
D_{3}
\end{array}\right\}=\left[\begin{array}{ccccccccc}
s_{11}^{E} & s_{12}^{E} & s_{13}^{E} & 0 & 0 & 0 & 0 & 0 & d_{31} \\
s_{12}^{E} & s_{11}^{E} & s_{13}^{E} & 0 & 0 & 0 & 0 & 0 & d_{31} \\
s_{13}^{E} & s_{13}^{E} & s_{33}^{E} & 0 & 0 & 0 & 0 & 0 & d_{33} \\
0 & 0 & 0 & s_{44}^{E} & 0 & 0 & 0 & 0 & 0 \\
0 & 0 & 0 & 0 & s_{55}^{E} & 0 & 0 & d_{15} & 0 \\
0 & 0 & 0 & 0 & 0 & s_{66}^{E} & d_{15} & 0 & 0 \\
0 & 0 & 0 & 0 & 0 & d_{15} & \epsilon_{11}^{T} & 0 & 0 \\
0 & 0 & 0 & 0 & d_{15} & 0 & 0 & \epsilon_{11}^{T} & 0 \\
d_{31} & d_{31} & d_{33} & 0 & 0 & 0 & 0 & 0 & \epsilon_{33}^{T}
\end{array}\right]\left\{\begin{array}{c}
T_{11} \\
T_{22} \\
T_{33} \\
T_{23} \\
T_{31} \\
T_{12} \\
E_{1} \\
E_{2} \\
E_{3}
\end{array}\right\}
$$

Segundo a hipótese de viga Euler-Bernoulli, temos que as tensões mecânicas $T_{2}, T_{3}$, $T_{4}, T_{5}$ e $T_{6}$ são iguais a zero. Assim, as equações reduzidas de uma viga Euler Bernoulli (tensão mecânica somente na direção $1-T_{1}$ ) é dada pela Eq. B.2, podendo também ser representada na forma tensão-deslocamento elétrico, como mostra a Eqs. B.3 e B.4.

$$
\begin{gathered}
\left\{\begin{array}{l}
S_{1} \\
D_{3}
\end{array}\right\}=\left[\begin{array}{ll}
s_{11}^{E} & d_{31} \\
d_{31} & \varepsilon_{33}^{T}
\end{array}\right]\left\{\begin{array}{l}
T_{1} \\
E_{3}
\end{array}\right\} \\
\left\{\begin{array}{c}
T_{1} \\
D_{3}
\end{array}\right\}=\left[\begin{array}{cc}
\bar{c}_{11}^{E} & -\bar{e}_{31} \\
\bar{e}_{31} & \bar{\varepsilon}_{33}
\end{array}\right]\left\{\begin{array}{c}
S_{1} \\
E_{3}
\end{array}\right\} \\
\bar{c}_{11}^{E}=\frac{1}{s_{11}^{E}} \quad \bar{e}_{31}=\frac{d_{31}}{s_{11}^{E}} \quad \bar{\epsilon}_{33}=\epsilon-\frac{d_{31}^{2}}{s_{11}^{E}}
\end{gathered}
$$

Para obter as equações de movimento do sistema mecânico, o princípio generalizado de Hamilton para um corpo eletroelástico é utilizado (Hagood, Chung e Flotow (1990)), como mostra a Eq. B.5. Os termos da energia cinética total $T^{*}$, da energia potencial 
$U$ e da energia elétrica $W_{e}$ são definidos nas Eqs. B.6 a B.8, onde $u$ é o vetor de deslocamento mecânico $[\mathrm{m}]$ e $V_{s}$ ou $V_{p}$ é o volume da estrutura ou da piezocerâmica $\left[\mathrm{m}^{3}\right]$, respectivamente.

$$
\begin{gathered}
\int_{t_{1}}^{t_{2}}\left[\delta\left(T-U+W_{e}\right)+\delta W\right] d t=0 \\
T^{*}=\int_{V_{s}} \frac{1}{2} \rho_{s} \dot{u}^{t} \dot{u} d V_{s}+\int_{V_{p}} \frac{1}{2} \rho_{p} \dot{u}^{t} \dot{u} d V_{p} \\
U=\int_{V_{s}} \frac{1}{2}[S]^{t}[T] d V_{s}+\int_{V_{p}} \frac{1}{2}[S]^{t}[T] d V_{p} \\
W_{e}=\int_{V_{p}} \frac{1}{2}[E]^{t}[D] d V_{p}
\end{gathered}
$$

O trabalho $\delta W$ pode ser definido como mostra a Eq. B.11, onde uma força mecânica discreta $f$ é aplicada nos pontos $x_{i}$ e $y_{i}$, uma carga elétrica discreta $q$ é extraída nos pontos $x_{i}$ e $y_{i}$ e $\varphi$ é o potencial elétrico escalar.

$$
\delta W=\sum_{i=1}^{n f} \delta u\left(x_{i}, y_{i}, t\right) \cdot f\left(x_{i}, y_{i}, t\right)+\sum_{j=1}^{n q} \delta \varphi\left(x_{j}, y_{j}, t\right) \cdot q\left(x_{j}, y_{j}, t\right)
$$

Reescrevendo a equação constitutiva da piezeletricidade (Eq. B.3) de uma forma mais genérica (Eq. B.11) e utilizando essas relações na Eq. B.10, o princípio generalizado de Hamilton para um gerador de energia piezelétrico é representado pela Eq. B.11.

$$
\left\{\begin{array}{l}
T \\
D
\end{array}\right\}=\left[\begin{array}{cc}
c_{p}^{E} & -e^{t} \\
e & \varepsilon^{S}
\end{array}\right]\left\{\begin{array}{l}
S \\
E
\end{array}\right\}
$$




$$
\int_{t_{1}}^{t_{2}}\left[\begin{array}{l}
\int_{V_{s}} \rho_{s} \delta \dot{u}^{t} \dot{u} d V_{s}+\int_{V_{p}} \rho_{p} \delta \dot{u}^{t} \dot{u} d V_{p}-\int_{V_{s}} \delta S^{t} c_{s} S d V_{s}-\int_{V_{p}} \delta S^{t} c_{p}^{E} S d V_{p}+ \\
\sum_{j=1}^{n q} \delta \varphi\left(x_{j}, y_{j}, t\right) \cdot q\left(x_{j}, y_{j}, t\right)
\end{array}\right] d t=0
$$

Utilizando o procedimento de Rayleight-Ritz (Sodano, Park e Inman (2004)), o deslocamento $u$ pode ser discretizado segundo a Eq. B.12, onde $\phi$ é a matriz de modos e $r(t)$ é a coordenada temporal do deslocamento $u$.

$$
u(x, t)=\sum_{i=1}^{N} \phi_{i}(x) r_{i}(t)=\phi(x) r(t)
$$

Assim, a deformação da viga é assumida de acordo com a Eq. B.13 e o potencial elétrico $\psi$ é assumido para variar linearmente de acordo com a espessura do material piezelétrico $t_{p}$, como mostra a Eq. B.14, onde $v_{p}$ é a tensão elétrica gerada pela piezocerâmica (no caso desse trabalho, a tensão é constante ao longo da espessura da piezocerâmica, portanto é igual a 1).

$$
\begin{gathered}
{[S]=-y \frac{\partial^{2} u(x, t)}{\partial x^{2}}=-y \phi^{\prime \prime}(x) r(t)} \\
E(y, t)=\frac{\partial \psi(y, t)}{\partial y}=\psi_{y}=\frac{v_{p}}{t_{p}}
\end{gathered}
$$

Assim, a equação de movimento da viga piezelétrica engastada é representada pelas Eqs. B.15 e B.16 (DE MARQUI JR, Erturk e Inman (2009), Elvin e Elvin (2009)), onde $[M]$ é a matriz de massa, $[C]$ é a matriz de amortecimento, $[K]$ é a matriz de rigidez, $[\theta]$ é a matriz de acoplamento eletromecânico, $\left[M^{*}\right]$ é o vetor de força efetiva da aceleração de base, $\ddot{u}_{g}$ é a aceleração de base, $\left[C_{p}\right]$ é o vetor capacitância da piezocerâmica e $\dot{Q}(t)$ é a corrente elétrica (seu valor depende do circuito elétrico ao qual o sistema mecânico está ligado). Todos esses termos são descritos pelas Eq. B.17 - B.22, onde $L$ é o comprimento da viga, $\bar{m}$ é a massa da viga por unidade de comprimento e $\alpha e \beta$ são as constantes de proporcionalidade obtidas experimentalmente. 


$$
\begin{gathered}
{[M] \ddot{r}(t)+[C] \dot{r}(t)+[K] r(t)-[\theta] v_{p}=\left[M^{*}\right] \ddot{u}_{g}} \\
C_{p} \dot{v}_{p}(t)+[\theta]^{t} \dot{r}(t)=-\dot{Q}(t) \\
m_{i j}=\int_{0}^{L} \bar{m} \phi_{i}(x) \phi_{j}(x) d x \\
k_{i j}=\int_{V o l} Y^{E} y^{2} \phi_{i}^{\prime \prime}(x) \phi_{j}{ }^{\prime \prime}(x) d x d y d z \\
c_{i j}=\alpha m_{i j}+\beta k_{i j} \\
\theta_{i j}=\int_{V o l} y \phi_{i}^{\prime \prime}(x) e_{31} \psi_{j}(x) d x d y d z \\
c_{p_{i j}}=\int_{V o l}^{*} \varepsilon \psi_{i}(x) \psi_{j}(x) d x d y d z \\
m_{i j}^{L}=\int_{0} \phi_{i}(x) d x
\end{gathered}
$$

Para casos bimorph (duas piezocerâmicas coladas em uma subestrutura), os piezelétricos podem estar ligados em série (polarizados em sentidos opostos) ou em paralelo (polarizados no mesmo sentido). Para o caso de bimorph em série, a capacitância equivalente das duas piezocerâmicas é igual a metade da capacitância de uma camada (piezocerâmica) somente e o acoplamento equivalente é igual ao acoplamento de uma camada. Já para o caso bimorph em paralelo, a capacitância equivalente é igual a soma da capacitância de cada camada e o acoplamento é igual a soma de cada camada, como mostra o esquema explicativo abaixo:

$$
\begin{aligned}
\text { Serie } \rightarrow \quad C_{p_{\text {equivalente }}} & =\frac{1}{2} C_{p} \\
\theta_{\text {equivalente }} & =\theta \\
\text { Paralelo } \rightarrow \quad C_{p_{\text {equivalente }}} & =2 C_{p} \\
\theta_{\text {equivalente }} & =2 \theta
\end{aligned}
$$


A corrente elétrica $\dot{Q}(t)$ depende de qual circuito elétrico a placa está ligada, por exemplo, se é um circuito SSDS, SSDI ou SSDV. Para o caso SSDS (Fig. 6(b)), a corrente elétrica entre os terminais do piezelétrico pode ser representada pela Eq. B.23 a partir do equacionamento da tensão elétrica entre os terminais do piezelétrico, onde $R$ é a resistência elétrica.

$$
v_{p}=R \dot{Q} \rightarrow \dot{Q}=\frac{v_{p}}{R}
$$

Já para os casos SSDI (Fig. 6(c)) e SSDV (Fig. 9), a corrente elétrica é representada pelas Eqs. B.24 e B.25, respectivamente.

$$
\begin{gathered}
v_{p}=R \dot{Q}+L \ddot{Q} \rightarrow \dot{Q}=\frac{v_{p}}{R+L j \omega} \\
v_{p}+v_{S}=R \dot{Q}+L \ddot{Q} \rightarrow \dot{Q}=\frac{v_{p} \pm v_{S}}{R+L j \omega}
\end{gathered}
$$

Na aproximação de Rayleigh-Ritz, é assumido que os modos de deslocamento podem ser qualquer função que satisfaça as condições de contorno geométricas. Assim, foi assumido a função da Eq. B.26, apresentada por Inman e Singh (2001) para uma viga engastada-livre, onde $\beta_{n}$ e $\sigma_{n}$ são constantes indicadas no livro.

$$
\phi_{n}(x)=\cosh \beta_{n} x-\cos \beta_{n} x-\sigma_{n}\left(\sinh \beta_{n} x-\sin \beta_{n} x\right)
$$

Para facilitar a resolução, as equações foram representados em espaço de estados na forma indicada pela Eq. B.27, onde $[A]$ é a matriz de estado, $[B]$ é a matriz de entrada, $[C]$ é a matriz de saída, $[D]$ é a matriz de transmissão direta, $y$ é o vetor de saída, $u$ é o vetor de entrada e $x$ é o vetor de estados, todos representados pelas Eqs. B.28-B.34.

$$
\begin{array}{r}
\{\dot{x}\}=[A]\{x\}+[B]\{u\} \\
\{y\}=[C]\{x\}+[D]\{u\} \\
\{x\}=\left\{r(t) \dot{r}(t) \quad v_{p}\right\}^{t}
\end{array}
$$




$$
\begin{aligned}
& {[A]=\left[\begin{array}{ccc}
0_{n \times n} & I_{n \times n} & 0_{n \times 1} \\
-M^{-1} K & -M^{-1} C & M^{-1} \theta \\
0_{1 \times n} & -C_{p}^{-1} \theta^{t} & 0
\end{array}\right]} \\
& {[B]=\left[\begin{array}{cc}
0_{n \times 1} & 0_{n \times 1} \\
M^{-1} M^{*} & 0_{n \times 1} \\
0 & -C_{p}^{-1}
\end{array}\right]} \\
& {[C]=\left[\begin{array}{ccc}
I_{n \times n} & 0_{n \times n} & 0_{n \times 1} \\
0_{1 \times n} & 0_{1 \times n} & 1
\end{array}\right]} \\
& {[D]=\left[\begin{array}{cc}
0_{n \times 1} & 0_{n \times 1} \\
0 & 0
\end{array}\right]} \\
& \{y\}=\left\{r(t) \quad v_{p}\right\}^{t} \\
& \{u\}=\left\{\ddot{u}_{g}(t) \dot{Q}(t)\right\}^{t}
\end{aligned}
$$

\section{B.2 - Desenvolvimento dos Circuitos Elétricos e do Circuito Chaveador}

O circuito chaveador utilizado nos experimentos foi o circuito autônomo proposto originalmente por Richard, Guyomar e Lefeuvre (2007) e, posteriormente, utilizado por outros autores, como por exemplo, D’Assunção (2013). Esse circuito não necessita de uma fonte externa de tensão para fazer o chaveamento e é composto basicamente de filtro passa-baixa RC, um comparador e uma chave (Fig. 46). O circuito elétrico completo possui dois circuitos menores de chaveamento (destacado em vermelho). O circuito da esquerda é responsável por detectar os pontos de máximo e o circuito da direita detecta os pontos de mínimo.

O filtro passa-baixa é composto de uma resistência $R 1$, um diodo $D 1$ e uma capacitância $C 1$ e tem a função nesse circuito de gerar um sinal semelhante ao sinal gerado pelo piezelétrico. A resistência R1 do filtro é reponsável por ajustar o tempo de subida do sinal filtrado. O comparador é composto de duas resistências $R 2 \quad e \quad R 3$, três diodos $D 2$, $D 9$ e $D 11$ e um transistor $T 1$ e tem a função de comparar dois sinais. Os re- 


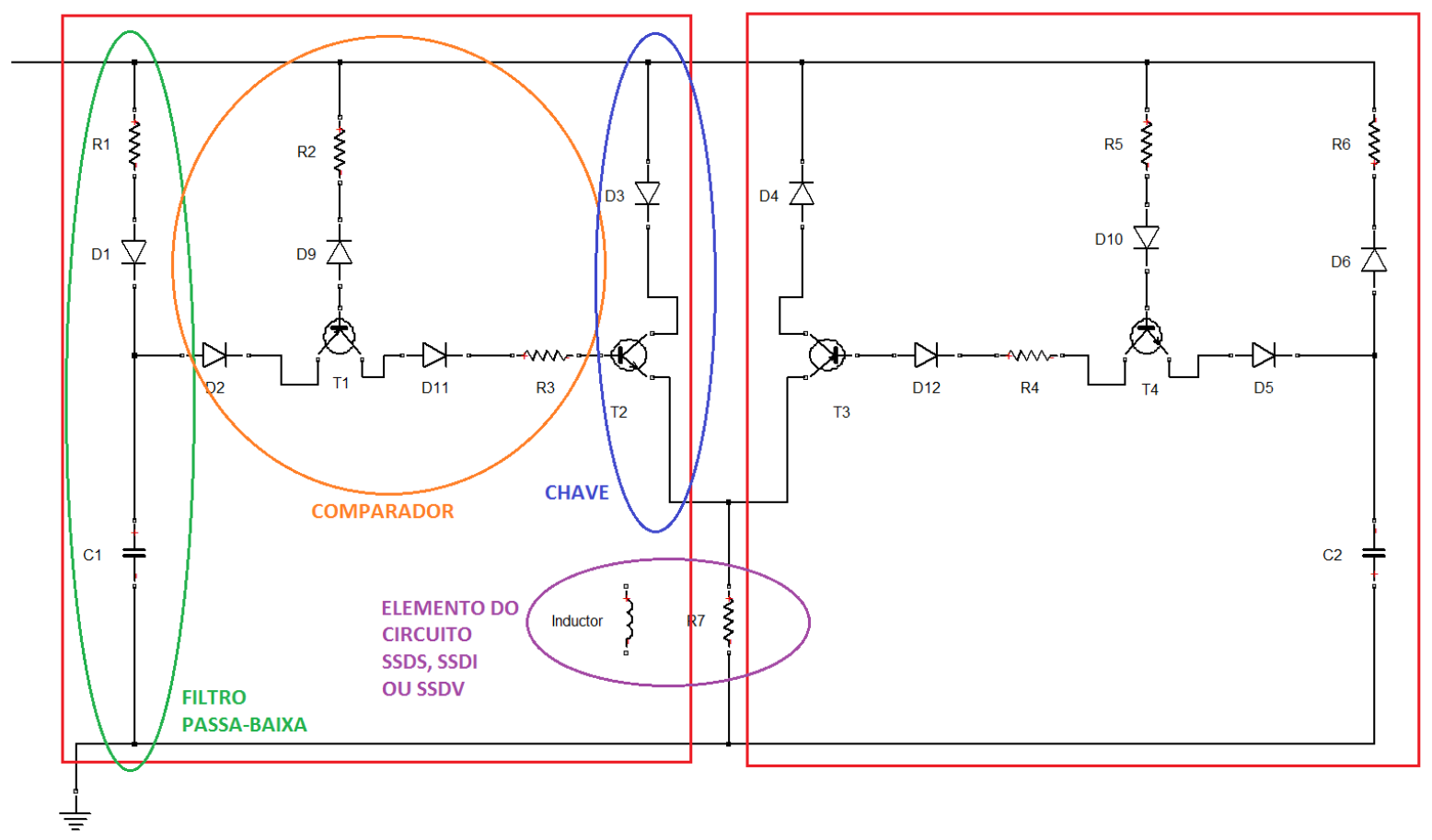

Figura 46 - Circuito chaveador autônomo.

sistores R2 e R3 servem para proteger os transistors T1 (comparador) e T2 (chave). Já a chave é composta por dois diodos D3 e D7 e um transistor $T 2$ e tem a função de chavear o sistema quando o valor de tensão na entrada do transistor T2 for maior que a tensão de threshold.

O sinal proveniente do filtro passa-baixa será comparado com o sinal gerado pelo piezelétrico. Quando a amplitude do sinal do filtro for menor do que o sinal do piezelétrico, o transistor T1 continuará fechado. Mas quando o sinal do filtro for maior do que o sinal piezelétrico e maior que o threshold do transistor $\mathrm{T} 1$, ele abre e permite a passagem da corrente elétrica até a chave (switch). Essa corrente é suficiente para abrir T2 (valor de threshold pequeno) e permitir que a corrente elétrica chegue até o circuito desejado (resistivo puro, SSDS, SSDI ou SSDV), iniciando de fato o chaveamento. O mesmo acontece com o lado direito do circuito completo e os valores dos elementos elétricos são também equivalentes $(\mathrm{R} 1=\mathrm{R} 6, \mathrm{R} 2=\mathrm{R} 5, \mathrm{R} 3=\mathrm{R} 4, \mathrm{D} 1=\mathrm{D} 6, \mathrm{D} 2=\mathrm{D} 5, \mathrm{D} 3=\mathrm{D} 4, \mathrm{D} 7=\mathrm{D} 8$, $\mathrm{D} 9=\mathrm{D} 10, \mathrm{D} 11=\mathrm{D} 12, \mathrm{C} 1=\mathrm{C} 2, \mathrm{~T} 1=\mathrm{T} 4$ e $\mathrm{T} 2=\mathrm{T} 3)$.

D’Assunção (2013) mostra o comportamento da tensão elétrica gerada pelo filtro passa-baixa e da tensão gerada pela piezocerâmica (Fig. 47) que serão analisados no comparador do circuito chaveador autônomo (Fig. 46).

Quando o chaveamento é realizado, o circuito pode ser tornar um circuito puramente 


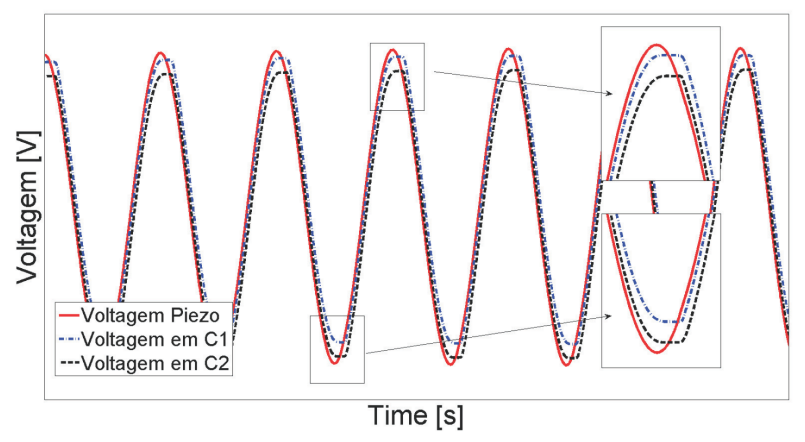

Figura 47 - Comparação entre o sinal de tensão gerado pelo filtro e o sinal de tensão gerado pelo piezelétrico.

resistivo ou um circuito ressonante (circuito RLC). A frequência natural do circuito elétrico $\omega_{n_{\text {circuito }}}$ no caso SSDI é representada pela Eq. B.35 (Mohammadi (2008)) e o tempo de inversão $\Delta t_{i}$ (tempo no qual o chaveamento acontece) é dado pela Eq. B.36 (D’Assunção (2013)).

$$
\begin{aligned}
& \omega_{n_{\text {circuito }}}=\left(f_{n_{\text {circuito }}}\right)^{-1}=\frac{1}{\sqrt{L C_{p}}} \\
& \Delta t_{i}=\left(2 f_{n_{\text {circuito }}}\right)^{-1}=\pi\left(C_{p} L\right)^{1 / 2}
\end{aligned}
$$

Nesse caso, o fator de inversão não é completo, pois uma parte da energia guardada no elemento capacitivo da piezocerâmica é perdida durante o processo de chaveamento. Essas perdas podem ser qualificadas modelando eletricamente um fator de qualidade elétrica $Q_{i}$, como mostra a Eq. B.37, onde $R_{i}$ é a resistência interna do circuito chaveador. Já o coeficiente de inversão $\gamma$ é definido como a porcentagem do sinal de tensão no início do chaveamento $v_{\text {antes }}$ que foi convertido em sinal de tensão no final de chaveamento $v_{\text {depois }}$ (Eq. B.38).

$$
\begin{gathered}
Q_{i}=\frac{L \omega_{n_{\text {circuito }}}}{R_{i}}=\frac{1}{R_{i}} \sqrt{\frac{L}{C_{p}}} \\
\gamma=-\frac{v_{\text {depois }}}{v_{\text {antes }}}=1^{\left(-\frac{\pi}{2 Q_{i}}\right)}
\end{gathered}
$$

Na teoria, nos circuitos SSDI, qualquer valor de indutância poderá ser escolhido, mas na prática, segundo Mohammadi (2008), a indutância deverá ser escolhida de forma que a frequência natural do circuito elétrico (Eq. B.35) seja de 10 à 50 vezes maior que a 
frequência natural do sistema mecânico.

\section{B.3 - Verificação do Método Numérico}

O método numérico foi desenvolvido de acordo com a modelagem apresentada nas Seções 5 e 5 no ambiente do MATLAB/SIMULINK. O sistema mecânico piezelétrico (em espaço de estados) e o circuito chaveador (incluindo o controlador) foram modelados no SIMULINK e os dados de entrada e saída foram organizados no MATLAB.

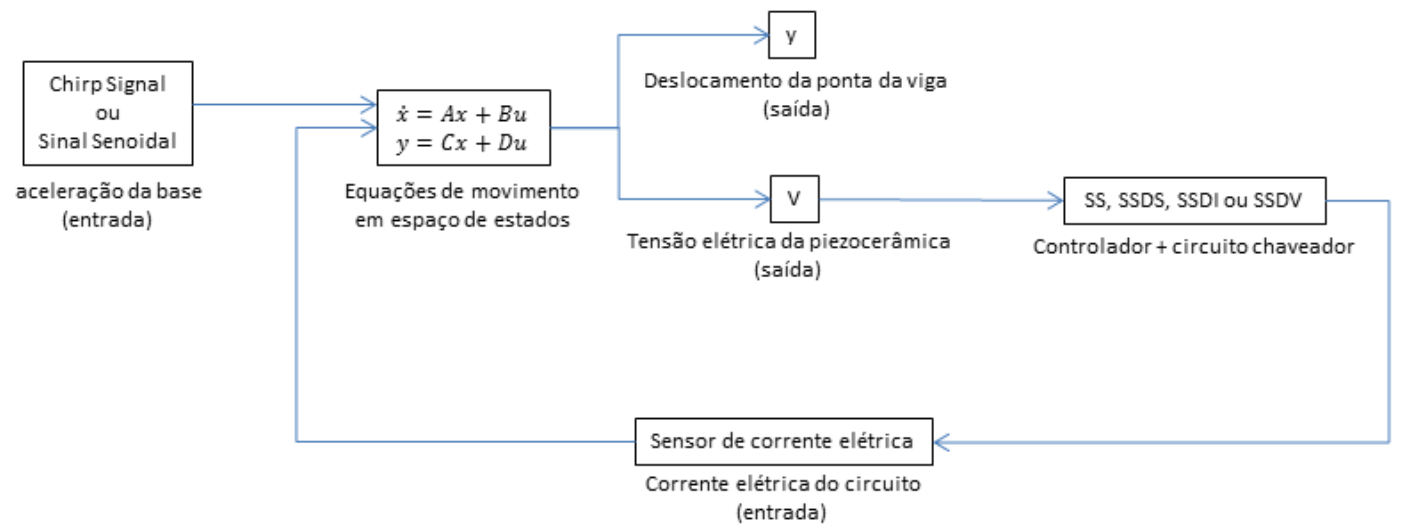

Figura 48 - Fluxograma da modelagem da viga piezelétrica no MATLAB/SIMULINK.

Em Erturk e Inman (2009), uma viga na configuração bimorph é utilizada, onde duas piezocerâmicas PZT-5A polarizadas em sentidos opostos (conectadas em série) é colada a uma subestrutura. As propriedades da viga bimorph e das piezocerâmicas são fornecidas pelos autores, como mostra a seguinte tabela.

Essa viga é conectada em um circuito resistivo-puro para diferentes valores de resistência $(1,6.7,11.8,22,33,47,100,470 \mathrm{k} \Omega)$ e possui uma massa concentrada na ponta de $0.012 \mathrm{~kg}$. A FRF de tensão elétrica é definida como a saída de tensão elétrica por aceleração de base (em termos de acelereção gravitacional $\mathrm{g}=9.81 \mathrm{~m} / \mathrm{s}^{2}$ ).

Para obter FRF's no método numérico, o bloco Chirp Signal foi utilizado como sinal de entrada para fazer uma "varredura" de 0 a $250 \mathrm{~Hz}$. As piezocerâmicas estão ligadas em série, portanto a capacitância equivalente corresponde a metade da capacitância de uma piezocerâmica e o acoplamento equivalente corresponde ao acoplamento de uma piezocerâmica (como foi explicado no final da Seção 5).

Assim, uma comparação pode ser feita entre os resultados apresentados em Erturk e Inman (2009) e os resultados obtidos pela modelagem numérica apresentada neste trabalho. 
Tabela 4 - Dados da viga bimorph apresentada em Erturk e Inman (2009)

\begin{tabular}{cl}
\hline Densidade da piezocerâmica $\left[\mathrm{kg} / \mathrm{m}^{3}\right]$ & 7800 \\
$c_{11}^{E}, c_{22}^{E}[\mathrm{GPa}]$ & 120.3 \\
$c_{12}^{E}[\mathrm{GPa}]$ & 75.2 \\
$c_{13}^{E}, c_{23}^{E}[\mathrm{GPa}]$ & 75.1 \\
$c_{33}^{E}[\mathrm{GPa}]$ & 110.9 \\
$c_{66}^{E}[\mathrm{GPa}]$ & 22.7 \\
$e_{31}^{E}, e_{32}^{E}\left[\mathrm{C} / \mathrm{m}^{2}\right]$ & -5.2 \\
$e_{33}^{E}\left[\mathrm{C} / \mathrm{m}^{2}\right]$ & 15.9 \\
Comprimento da viga $[\mathrm{mm}]$ & 50.8 \\
Largura da viga $[\mathrm{mm}]$ & 31.8 \\
Espessura da subestrutura $[\mathrm{mm}]$ & 0.14 \\
Espessura da piezocerâmica $[\mathrm{mm}]$ & $0.26(\mathrm{cada})$ \\
Módulo de Young da subestrutura $[\mathrm{GPa}]$ & 105 \\
Densidade da subestrutura $\left[\mathrm{kg} / \mathrm{m}^{3}\right]$ & 9000 \\
Massa da ponta $[\mathrm{kg}]$ & 0.012 \\
Constantes de proporcionalidade $\alpha[\mathrm{rad} / \mathrm{s}]$ & 14.65 \\
Constantes de proporcionalidade $\beta[\mathrm{s} / \mathrm{rad}]$ & 0.00001 \\
\hline
\end{tabular}

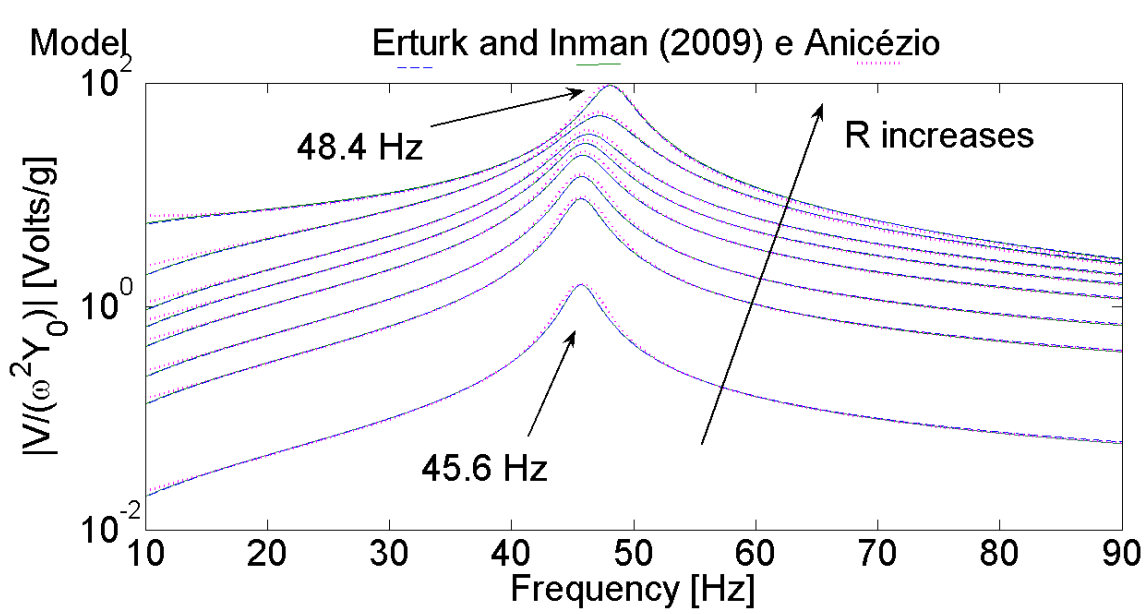

Figura 49 - Comparação entre FRF de tensão elétrica apresentada em Erturk e Inman (2009) e a FRF obtida pela modelagem numérica deste trabalho.

É possível perceber que o modelo numérico desenvolvido consegue prever a resposta de uma viga piezelétrica engastada eletromecanicamente acoplada. Observa-se que a frequência natural de curto circuito é menor do que a frequência natural de circuito aberto. Isso acontece devido ao fato de que o contorno elétrico altera a rigidez do sistema, consequentemente, alterando a frequência natural do sistema (Eq. 2.10).

A partir dessa validação da modelagem do sistema mecânico piezelétrico, é possível testar outros tipos de controladores e analisar suas influências na atenuação de vibração. 


\section{B.4 - Controlador Passivo Resistivo Puro}

Com os dados da viga piezelétrica descrita na Seção 5, o método numérico foi atualizado e a viga modelada numericamente foi ligada a um circuito puramente resistivo para simular diferentes condições de contorno. Já demonstrado na literatura (Erturk e Inman (2008)), resistências de $10^{2} \Omega$ e $10^{6} \Omega$ simulam muito bem as condições de contorno de curto circuito e circuito aberto, respectivamente.

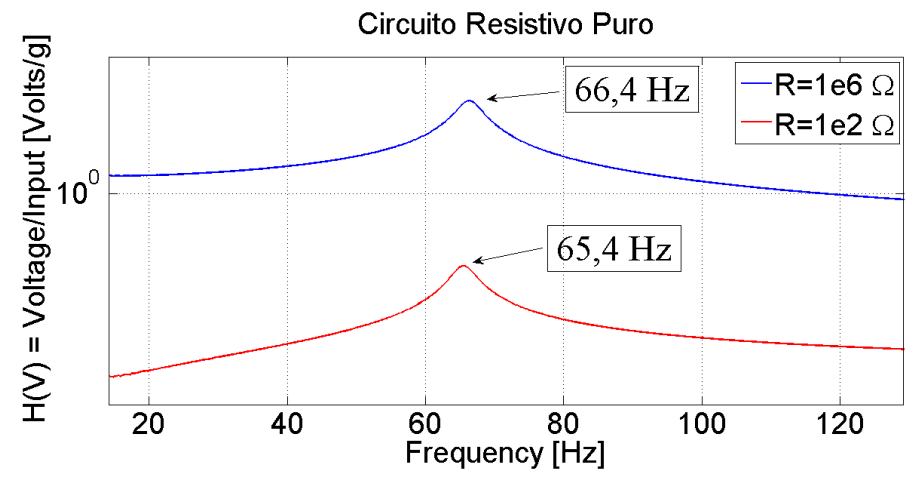

Figura 50 - FRF de uma viga piezelétrica engastada na condição de curto circuito $(R=$ $\left.10^{2} \Omega\right)$ e circuito aberto $\left(R=10^{6} \Omega\right)$.

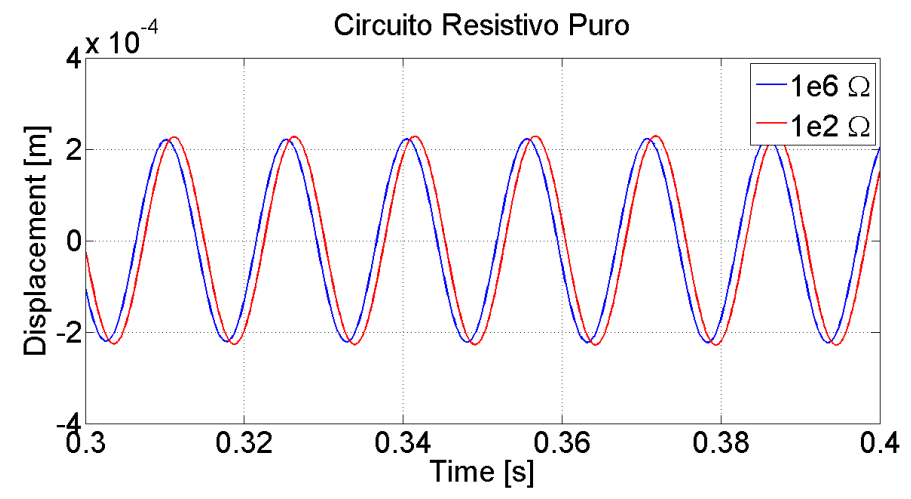

Figura 51 - Resposta de flexão de uma viga piezelétrica engastada em função do tempo na condição de curto circuito $\left(R=10^{2} \Omega\right)$ e circuito aberto $\left(R=10^{6} \Omega\right)$.

Antes das simulações, uma curva de curto circuito foi tirada experimentalmente para determinação dos coeficientes de amortecimento proporcional experimentais (Eq. B.19). Esses fatores são obtidos a partir da FRF de tensão na condição de curto circuito, pois o sistema está desacoplado. Utilizando o método de banda de meia potência, foi possível encontrar as constantes de proporcionalidade analisando o decaimento de dois modos da viga. Para a condição de curto circuito, os valores encontrados experimentalmente foram $\alpha=20.3610$ e $\beta=1.8140 \mathrm{e}-5$.

Assim, a viga foi ligada ao circuito resistivo puro (Fig. 48) nas condições de curto circuito e circuito aberto. A Fig. 50 mostra a FRF de tensão obtida nos dois casos e é 
possível destacar a diferença na frequência de ressonância. A frequência de ressonância do 10 modo em curto circuito é de $65.4 \mathrm{~Hz}$ e em circuito aberto é de $66.4 \mathrm{~Hz}$. Já a Fig. 51 mostra a resposta do deslocamento da ponta da viga no tempo para cada uma das condições de contorno. Nessa abordagem, não é possível verificar a existência de uma resistência ótima (não foram simulados vários valores de resistência), na qual há maior atenuação na vibração e maior potência elétrica gerada (De Marqui Jr et al. (2010)), mas se faz necessária para futuras comparações com outros tipos de controladores.

\section{B.5 - Controlador Semi-passivo SSDS}

O controlador semi-passivo SSDS é formado por um circuito chaveador que altera as condições de contorno do sistema de circuito aberto para curto circuito toda vez que um ponto de máximo ou mínimo é detectado (Seção 2.2.3.1), como mostra a Fig. 52.

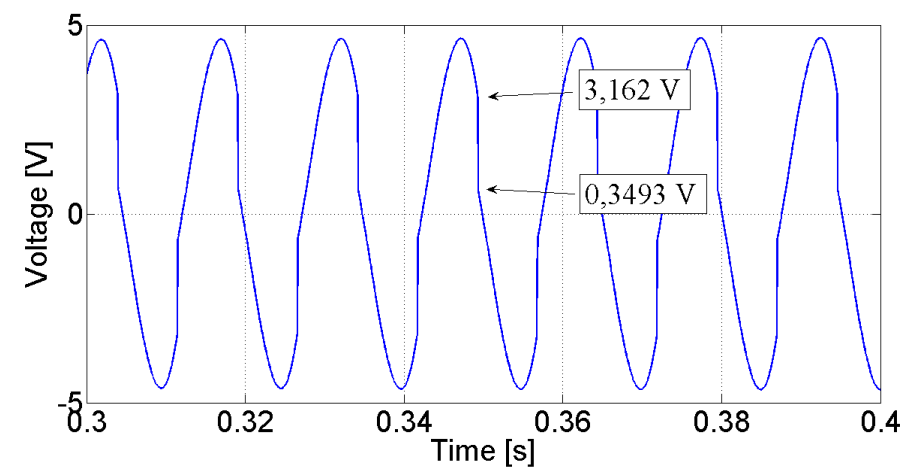

Figura 52 - Tensão elétrica de uma viga piezelétrica engastada em função do tempo no circuito controlador SSDS.

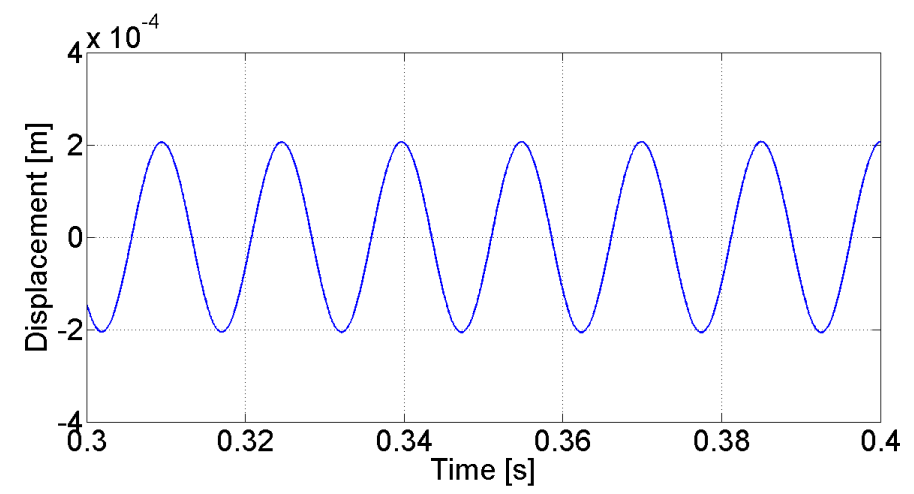

Figura 53 - Deslocamento da ponta da viga piezelétrica engastada em função do tempo no circuito controlador SSDS.

Na teoria, quando o circuito é chaveado, ele descarrega a tensão até que ela seja igual a zero. Nesse momento, o circuito volta a abrir novamente e a condição de circuito aberto 
é reestabelecida.

Nesse caso numérico, percebe-se que a tensão não foi descarregada totalmente, o chaveamento aconteceu quando a tensão era de 1,306 V . Isso aconteceu, pois na simulação foram utilizados valores de diodos compatíveis com a realidade (Seção 5). E na prática, não acontece a situação em que a tensão seja igual a zero para somente depois ocorrer o chaveamento. Pelo contrário, a tensão fica próxima de zero, mas esse valor vai depender do tipo de diodo utilizado e do seu valor de Forward voltage. Observando a Fig. 46, é possível perceber que quando o chaveamento é realizado, dois diodos atuam diretamente no circuito, por isso do valor ser praticamente o dobro do valor de Forward voltage de um diodo. É possível reduzir esse valor residual (1,306 V) se o circuito chaveador possuir uma quantidade menor de diodos atuantes (aqueles que atuam diretamente durante o chaveamento).

Comparando o deslocamento mecânico do controlador SSDS (Fig. 53) com o deslocamento do circuito resistivo puro (Fig. 51), percebe-se que há atenuação na vibração, mas relativamente pouco.

\section{B.6 - Controlador Semi-passivo SSDI}

O controlador semi-passivo SSDI é semelhante ao controlador SSDV, com a diferença que no lugar de um resistor no momento do chaveamento, há um indutor que faz com que a tensão seja invertida, como mostra a Fig. 54. Percebe-se que no momento do chaveamento, a tensão anteriormente positiva passa a ser negativa.

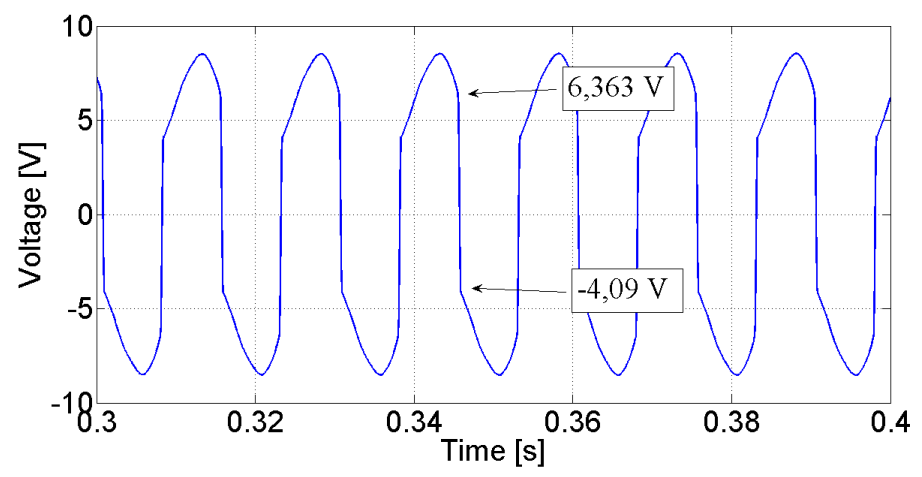

Figura 54 - Tensão elétrica de uma viga piezelétrica engastada em função do tempo no circuito controlador SSDI.

Como no caso anterior, o circuito numérico foi modelado o mais próximo possível da realidade. Assim, percebe-se que a inversão de tensão não foi completa. E isso na prática 


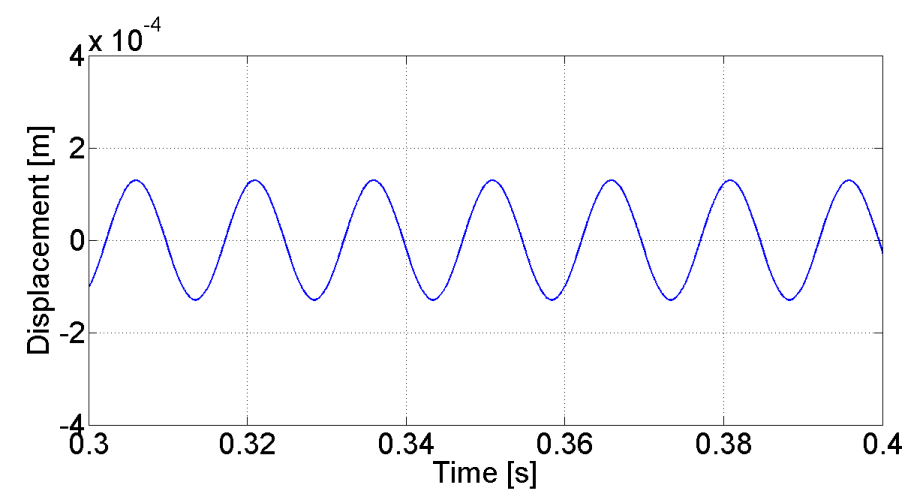

Figura 55 - Deslocamento da ponta da viga piezelétrica engastada em função do tempo no circuito controlador SSDI.

também acontece, pois todo circuito elétrico possui resistências internas e nesse caso, as resistências internas são altas. Assim, o coeficiente de inversão (Eq. B.38) é igual a 0,6428 $(64,28 \%)$.

Comparando o deslocamento no controlador SSDI (Fig. 55) com o deslocamento do controlador SSDS (Fig. 53), é notável o amortecimento na vibração da viga piezelétrica. Isso acontece pois o controlador SSDI maximiza o efeito shunt damping indutivo.

\section{B.7 - Controlador Semi-ativo SSDV}

Já o controlador semi-ativo é utilizado para aumentar o coeficiente de inversão do SSDI, ou seja, ele complementa a inversão afim de que ela se torne completa ou próxima disso.

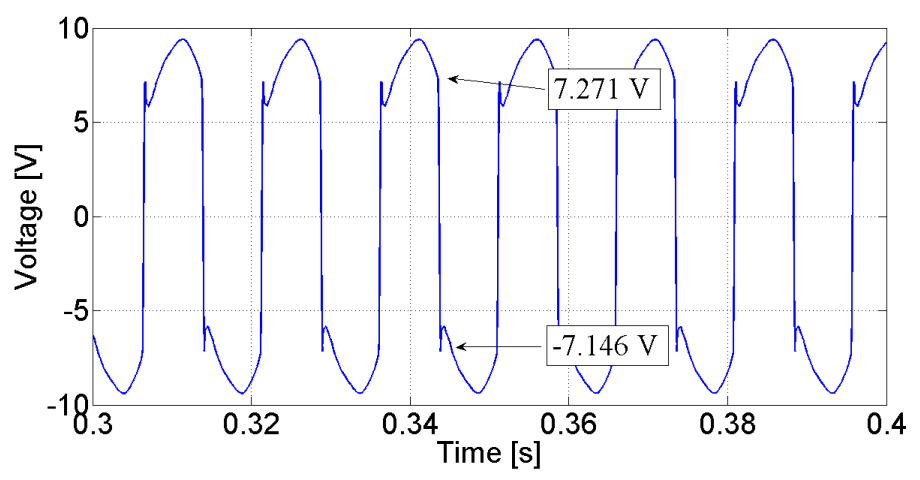

Figura 56 - Tensão elétrica de uma viga piezelétrica engastada em função do tempo no circuito controlador SSDV.

A Fig. 56 representa a simulação do caso SSDV. Nesse caso foi utilizado duas fontes de tensão de $2 \mathrm{~V}$ cada uma. Mas para que o circuito fizesse o chaveamento no tempo correto, foi necessário modificar a resistência do filtro passa baixa para que o chaveador 


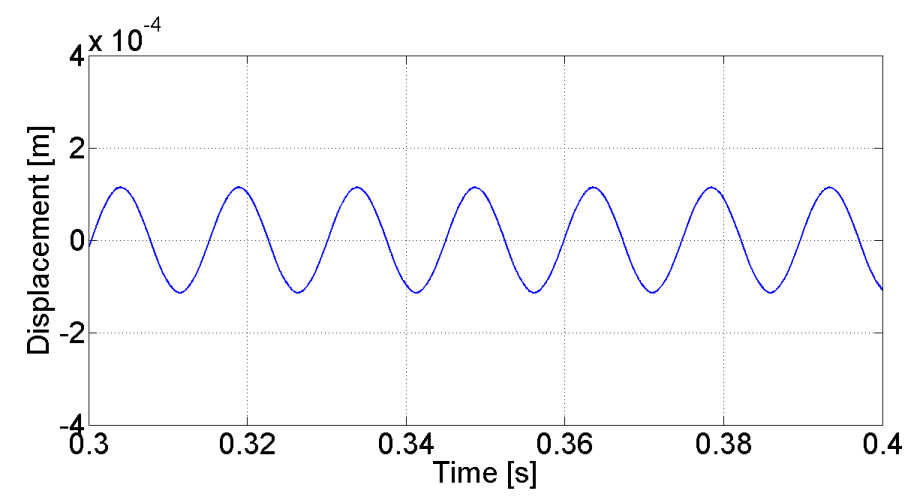

Figura 57 - Deslocamento da ponta da viga piezelétrica engastada em função do tempo no circuito controlador SSDV.

atuasse corretamente. Desta forma, R1 e R6 foram modificados para o valor de $10^{5} \Omega$. Vale ressaltar que o valor dessas duas resistências não altera a resposta do sistema piezelétrico, pois R1 e R6 são responsáveis por ajustar o tempo de subida da curva de tensão do filtro, a qual será analisada pelo comparador para saber o tempo ideal para realizar o chaveamento. Portanto, essas resistências não influenciam o sinal gerado pelo piezelétrico.

Percebe-se que houve uma complementação na inversão da tensão. O coeficiente de inversão que anteriormente (SSDI) era de 0,6428 (64,28\%), agora no caso SSDV passa a ser $0,9828(98,28 \%)$.

Comparando o deslocamento mecânico da viga do controlador SSDV (Fig. 57) com o controlador SSDI (Fig. 55), percebe-se que há um pouco mais de atenuação na vibração.

\section{B.8 - Resultados Experimentais da Viga Piezelétrica Engastada}

Essa seção mostra resultados experimentais de uma viga piezelétrica engastada fixa afim de mostrar que os circuitos até aqui desenvolvidos no Apêndice B funcionam na prática e trazem bons resultados. Por isso, serão mostrados apenas as respostas de tensão elétrica no tempo.

Sabemos que a tensão de curto circuito é muito menor do que a tensão de circuito aberto, como mostra a Fig. 58. A Fig. 58 nos auxilia a visualizar que as tensões elétricas dos controladores são maiores do que a tensão de circuito aberto.

Na Fig. 59, é possível perceber que a tensão piezelétrica não é totalmente descarregada, como já previsto na simulação. Isso acontece, pois o diodo presente no circuito abre o chaveamento antes do momento certo (momento previsto pelo comparador), momento 


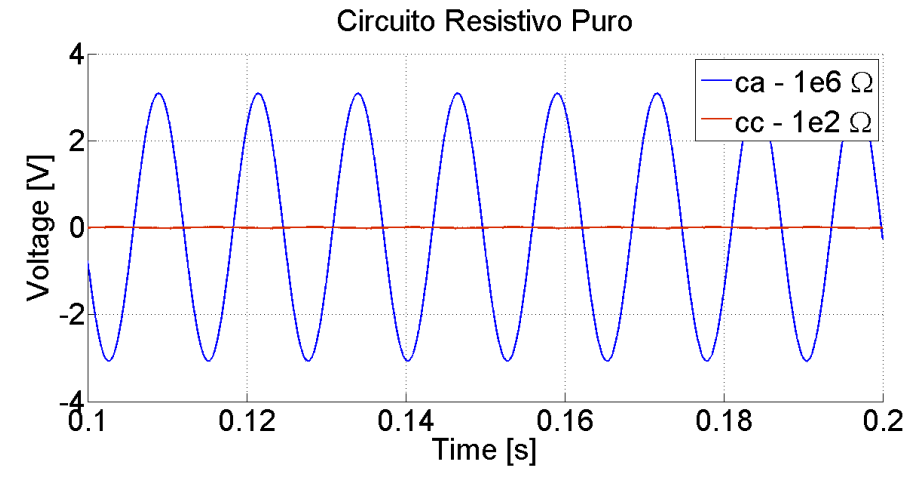

Figura 58 - Comparação entre a tensão elétrica de circuito aberto e curto circuito experimental.

esse quando a tensão atinge o valor de Forward voltage do diodo.

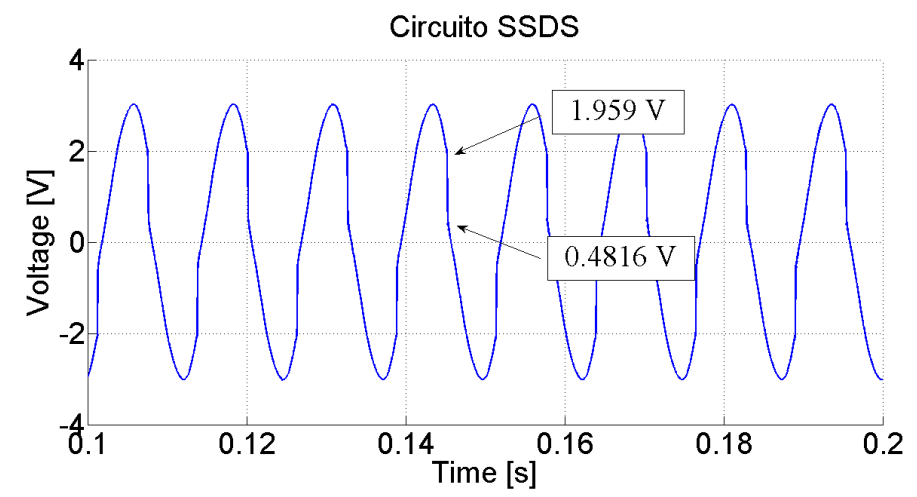

Figura 59 - Tensão elétrica do controlador SSDS experimental.

É possível afirmar que de fato o indutor inverte o sinal elétrico (Fig. 60), mas não de forma completa, pois existem as resistências internas inerentes do circuito.

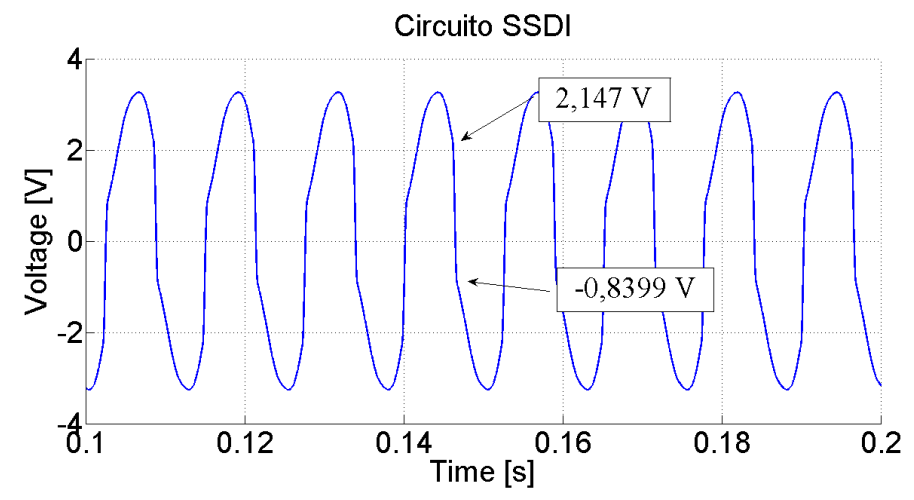

Figura 60 - Tensão elétrica do controlador SSDI experimental.

As curvas acima também permitem observar que o chaveamento não é feito no momento de máximo ou mínimo, pois o circuito chaveador compara o sinal do filtro passabaixa com o sinal de tensão piezelétrico. Quando há uma diferença entre os dois sinais, o chaveador permite a passagem de corrente e então o circuito é chaveado. Portanto, o 
circuito sempre será chaveado com um atraso, pois o comparador precisa de uma diferença de tensão para fazer a comparação.

No controlador semi-passivo SSDI (Fig. 60), observa-se que o coeficiente de inversão foi de $0,3912(39,12 \%)$. No ponto de máximo detectado pelo comparador (com atraso), o indutor inverteu quase que instantaneamente a tensão elétrica, mas a inversão não foi completa.

Nesse caso experimental, as saídas mecânicas não foram medidas, pois o grande interesse era observar e analisar o comportamento do circuito chaveador na resposta do sinal elétrico. 


\section{Apêndice C - Método Alfa-Generalizado}

$\mathrm{O}$

método alfa-generalizado é utilizado para resolver equações diferenciais de segunda ordem,

$$
M a+C v+K d=F
$$

onde $M, C$ e $K$ são massa generalizada, amortecimento generalizado e rigidez generalizada, respectivamente. $a, v$ e $d$ são aceleração generalizada, velocidade generalizada e deloscamento generalizado, respectivamente. $F$ é o vetor de força generalizada.

O método resolve a equação em um passo de tempo discreto $n$, usando

$$
\begin{aligned}
& d_{n+1}=d_{n}+h v_{n}+h^{2}\left(\left(\frac{1}{2}-\beta_{2}\right) a_{n}+\beta_{2} a_{n+1}\right) \\
& v_{n+1}=v_{n}+h\left(\left(1-\gamma_{2}\right) a_{n}+\gamma_{2} a_{n+1}\right) \\
& F\left(t_{n+1-\alpha_{f_{2}}}\right)=M a_{n+1-\alpha_{m_{2}}}+C v_{n+1-\alpha_{f_{2}}}+K d_{n+1-\alpha_{f_{2}}}
\end{aligned}
$$

onde $h$ é o passo de tempo definido como

$$
h=t_{n+1}-t_{n}
$$

$\mathrm{e}$

$$
\begin{aligned}
& d_{n+1-\alpha_{f_{2}}}=\left(1-\alpha_{f_{2}}\right) d_{n+1}+\alpha_{f_{2}} d_{n} \\
& v_{n+1-\alpha_{f_{2}}}=\left(1-\alpha_{f_{2}}\right) v_{n+1}+\alpha_{f_{2}} v_{n} \\
& a_{n+1-\alpha_{m_{2}}}=\left(1-\alpha_{m_{2}}\right) a_{n+1}+\alpha_{m_{2}} a_{n} \\
& t_{n+1-\alpha_{f_{2}}}=\left(1-\alpha_{f_{2}}\right) t_{n+1}+\alpha_{f_{2}} t_{n}
\end{aligned}
$$

Os parâmetros $\alpha_{f_{2}}, \alpha_{m_{2}}, \gamma_{2}$ e $\beta_{2}$ são usados para controlar a amplificação dos modos 
numéricos de alta frequência e são definidos como

$$
\begin{aligned}
& \gamma_{2}=\frac{1}{2}-\alpha_{m_{2}}+\alpha_{f_{2}} \\
& \beta_{2}=\frac{1}{4}\left(1-\alpha_{m_{2}}+\alpha_{f_{2}}\right)^{2} \\
& \alpha_{m_{2}}=\frac{2 \rho_{\infty_{2}}-1}{\rho_{\infty_{2}}+1} \\
& \alpha_{m_{2}}=\frac{\rho_{\infty_{2}}}{\rho_{\infty_{2}}+1}
\end{aligned}
$$




\section{Apêndice D - Dificuldades Encontradas nas Simulações Numéricas}

$\bigvee_{\text {zação desse trabalho. }}^{\text {esse apêndice será mostrado algumas das dificuldades encontradas durante a reali- }}$

Inicialmente, a ideia era mostrar a atenuação de vibração em uma pá utilizando circuito semi-ativo SSDV. Para isso, os circuitos resistivo puro, SSDS, SSDI e SSDV foram testados para uma viga piezelétrica engastada não rotativa, como mostrado no Apêndice 5. Os circuitos elétricos foram modelados no SIMULINK afim de facilitar a posterior utilização no sistema rotativo. Todos os resultados da viga piezelétrica engastada não rotativa tinham tempo de simulação razoável, dependendo do caso, demorava no máximo 3 horas.

Depois de todas as simulações da viga piezelétrica engastada não rotativa, o modelo elétrico já desenvolvido no SIMULINK foi reaproveitado e a modelagem mecânica da viga foi modificada para o caso rotativo.

Com a modificação da modelagem mecânica, o programa em Matlab R2012 pediu uma série de atualizações no programa, afim de que a função Mex -setup pudesse ser utilizada. A função Mex -setup é responsável por chamar a subrotina $\mathrm{C}, C++$ ou Fortran.

Após as configurações do Mex -setup, o programa começou a rodar de fato, mas com tempo de simulação bem grande. No caso mais simples, o resistivo puro, o programa levava cerca de 30 horas para rodar 0,01 segundos com passo de tempo $1 e^{-6}$. Foi necessário utilizar passo de tempo bem pequeno para que o programa convergisse e para que o Matlab não divergisse (constantemente, o Matlab/Simulink apresentava resultados como 0 ou $\mathrm{NaN}$ ).

Para os casos mais complexos (pá ligada aos circuitos SSDS, SSDI e SSDV), o Matlab/Simulink utilizava passo de tempo igual a $1 e^{-8}$. Para o circuito SSDS, o Matlab/Simulink R2012 demorou cerca de 5 dias para rodar 0,1 segundos e para os circuitos SSDI e SSDV, o programa simplesmente divergia no primeiro passo de tempo. 
Então, depois de muitas tentativas e pesquisas sobre um possível erro, os circuitos SSDI e SSDV rodaram em uma versão mais recente, Matlab/Simulink R2014. Porém, o próprio Matlab aplicava o Método Newton-Raphson, ou seja, o programa passava pela análise de convergência duas vezes, uma inerente ao próprio código e outra aplicada pelo próprio Matlab/Simulink. Com isso, o tempo estimado para rodar 0,1 seria de 66 semanas.

Diante desse fato, uma nova estratégia foi adotada e decidiu-se ligar a pá piezelétrica somente aos circuitos semi-passivos SSDS e BSDS, cuja modelagem desses sistemas seria feita somente no Matlab, visando uma economia no tempo de simulação. Os outros circuitos elétricos não foram modelados no Matlab, devido a complexibilidade da modelagem, já que esses circuitos (SSDI e SSDV) utilizam elemento elétrico (indutor) de difícil inserção na modelagem mecânica. 